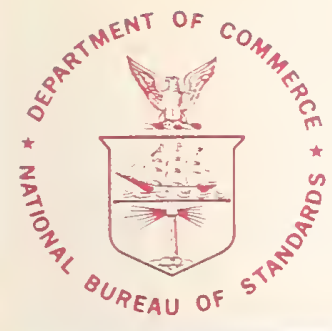

\section{A〕1ュ03087792}

NATL INST OF STANDARDS \& TECH R.I.C

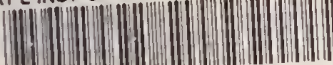

A11103087792

\section{NBS SPECIAL PUBLICATION 441}

ENT OF COMMERCE / National Bureau of Standards

Conterence on Succes/Successful experien 19

\title{
Successful Experiences in Teaching Metric
}

\section{$Q C$ \\ 100 \\ .457 \\ no. 441 \\ 1976 \\ c. 2}

How many centematon in

47.38 klometora

ardere

$47.38 \times 1000 \times 100$

$=4738,000$ centametere. 
The National Bureau of Standards ${ }^{1}$ was established by an act of Congress March 3, 1901. The Bureau's overall goal is to strengthen and advance the Nation's science and technology and facilitate their effective application for public benefit. To this end, the Bureau conducts research and provides: (1) a basis for the Nation's physical measurement system, (2) scientific and technological services for industry and government, (3) a technical basis for equity in trade, and (4) technical services to promote public safety. The Bureau consists of the Institute for Basic Standards, the Institute for Materials Research, the Institute for Applied Technology, the Institute for Computer Sciences and Technology, and the Office for Information Programs.

THE INSTITUTE FOR BASIC STANDARDS provides the central basis within the United States of a complete and consistent system of physical measurement; coordinates that system with measurement systems of other nations; and furnishes essential services leading to accurate and uniform physical measurements throughout the Nation's scientific community, industry, and commerce. The Institute consists of the Office of Measurement Services, the Office of Radiation Measurement and the following Center and divisions:

Applied Mathematics - Electricity - Mechanics - Heat - Optical Physics - Center for Radiation Research: Nuclear Sciences; Applied Radiation - Laboratory Astrophysics ${ }^{2}$ - Cryogenics ${ }^{2}$ - Electromagnetics ${ }^{2}$ - Time and Frequency ${ }^{2}$.

THE INSTITUTE FOR MATERIALS RESEARCH conducts materials research leading to improved methods of measurement, standards, and data on the properties of well-characterized materials needed by industry, commerce, educational institutions, and Government; provides advisory and research services to other Government agencies; and develops, produces, and distributes standard reference materials. The Institute consists of the Office of Standard Reference Materials, the Office of Air and Water Measurement, and the following divisions:

Analytical Chemistry - Polymers - Metallurgy — Inorganic Materials — Reactor Radiation - Physical Chemistry.

THE INSTITUTE FOR APPLIED TECHNOLOGY provides technical services to promote the use of available technology and to facilitate technological innovation in industry and Government:"cooperates with public and private organizations leading to the development of technological standards (including mandatory safety standards), codes and methods of test; and provides technical advice and services to Government agencies upon request. The-Institute consists of the following divisions and Centers:

Standards Application and Analysis - Electronic Technology - Center for Consumer Product Technology: Product Systems Analysis; Product Engineering — Center for Building Technology: Structures, Materials, and Life Safety; Building Environment; Technical Evaluation and Application - Center for Fire Research: Fire Science; Fire Safety Engineering.

THE INSTITUTE FOR COMPUTER SCIENCES AND TECHNOLOGY conducts research and provides technical services designed to aid Government agencies in improving cost effectiveness in the conduct of their programs through the selection, acquisition, and effective utilization of automatic data processing equipment; and serves as the principal focus within the executive branch for the development of Federal standards for automatic data processing equipment, techniques, and computer languages. The Institute consists of the following divisions:

Computer Services - Systens and Software - Computer Systems Engineering — Information Technology.

THE OFFICE FOR INFORMATION PROGRAMS promotes optimum dissemination and accessibility of scientific information generated within NBS and other agencies of the Federal Government: promotes the development of the National Standard Reference Data System and a system of information analysis centers dealing with the broader aspects of the National Measurement System; provides appropriate services to ensure that the NBS staff has optimum accessibility to the scientific information of the world. The Office consists of the following organizational units:

Office of Standard Reference Data - Office of Information Activities - Office of Technical Publications - Library - Office of International Relations - Office of International Standards.

I Headquarters and Laboratories at Gaithersburg. Maryland, unless otherwise noted: mailing address Washington, D.C. 20234.

= Located at Boulder, Colorado 80302. 


\section{Successful Experiences in Teaching Metric}

A Conference in Celebration of the

One Hundredth Anniversary of

the Metric Convention, 1875-1975

Held at the National Bureau of Standards

Gaithersburg, Maryland, May 20-21, 1975

Edited by

Jeffrey V. Odom

Metric Information Office

Institute for Applied Technology

National Bureau of Standards

Washington, D. C. 20234

Sponsored by:

The National Bureau of Standards

The American National Metric Council

The National Education Association

The U.S. Metric Association

The U.S. Office of Education

in cooperation with

The National Council of Teachers of Mathematics

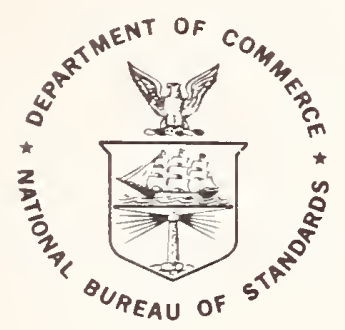

\section{U.S. DEPARTMENT OF COMMERCE, Rogers C. B. Morton, Secretary}

James A. Baker, III, Under Secretary

Dr. Betsy Ancker-Johnson, Assistant Secretary for Science and Technology

NATIONAL BUREAU OF STANDARDS, Ernest Ambler, Acting Director

Issued January 1976 
Library of Congress Catalog Card Number: 76-600001

\section{National Bureau of Standards Special Publication 441}

Nat. Bur. Stand. (U.S.), Spec. Publ. 441, 115 pages (Jan. 1976)

CODEN: XNBSAV 
These proceedings contain the texts of the presentations made at a recent conference on Successful Experiences in Teaching Metric. Specific experiences in introducing the metric system in all areas of educational interest were presented. These ideas will be especially useful to educators just beginning to prepare for their change to the metric system.

Key words: Education, International System of Units, metrication, metric education, metric system, training, Treaty of the Meter 



\section{FOREWORD}

Conference Proceedings, "Successful Experiences in Teaching Metric"

May $20-21,1975$

The United States is in the midst of a major transition. Increasingly, all phases of American society are using the metric system. Education has played, and will continue to play, a key role in insuring that this transition is both smooth and successful. The National Bureau of Standards, through our Metric Information office, has been active in assisting educators and educational agencies to participate in this transition.

The Bureau has been ably assisted in these metric education efforts by the organizations that served as co-sponsors of this meeting. This conference, which was a part of the U.S. celebration of the 100th Anniversary of the Treaty of the Meter, provided an opportunity for more than 300 educators from all areas to share their successful metric education experiences. The publication of these proceedings is intended to further share these ideas with all others who are interested in the field of metric education.
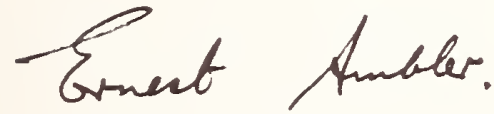

Ernest Ambler Acting Director

National Bureau of Standards 
The United States is just beginning to 'undertake one of the most far-reaching changes to ever occur in the history of our country; a change in our system of weights and measures. Such a change has obvious impact on each of our citizens in varying degrees.

It is widely recognized that education will play an important role in the changeover to metric in the United States. Educators have fortunately recognized the role they have to play and have taken significant steps. in this regard. This Conference was held because it was felt that there have already been many "successful experiences" that should be shared with educators who are now beginning to implement metrication.

Speakers were invited to share their successful experiences in all areas of education, including the classroom and administrative areas. These Proceedings contain the texts of most of the presentations made at the Conference. A few speakers did not make their papers available for publication.

It is hoped that these Proceédings will be of benefit to all educators as they begin to prepare themselves for the important role they will play in assisting our country in this important effort.

Jeffrey $V$. Odom, Chief

Metric Information office 
Abstract . . . . . . . . . . . . . . . . . . . . . . . . . . .

Foreword . . . . . . . . . . . . . . . . . . . . . . . . . . . . . .

Preface

The International System of Units . . . . . . . . . . . . . . . . . . . . . . .

\section{Richard W. Roberts}

Principles and Practices of Teaching the Metric System

in Public Schools . . . . . . . . . . . . . . . . . . . . . . . .

George W. Bright

Metric in General (Elementary) Education . . . . . . . . . . . . . . . . . .

Lou Smith

Metrication and the School Librarian . . . . . . . . . . . . . . . . . . .

Purnell Lawrence

Teaching the Metric System through Television and Other

Audio Visual Means . . . . . . . . . . . . . . . . . . . . . . . . .

Niles F. (Buddy) Calhoun

Metric and Mathematics Education . . . . . . . . . . . . . . . . . . . .

Stuart A. Choate

Experiences in Teaching the Metric System in Science Classes . . . . . . . . . .

Barbara Logan

Metric Gaming . . . . . . . . . . . . . . . . . . . . . . . . . . . .

Cecil R. Trueblood and Michael Szabo

Metric in Preservice Teacher Training . . . . . . . . . . . . . . . . . . . . .

John Lindbeck

Constructing Metric Education Workshops - A Model . . . . . . . . . . . . . .

Phillip T. Larsen

Metric for the Blind . . . . . . . . . . . . . . . . . . . . . . .

Andre Nadash

Metric in Sports and Physical Education . . . . . . . . . . . . . . . . . .

Fred Burgee

Metrication and State Departments of Education . . . . . . . . . . . . . . . . .

Audrey V. Buffington 
Metrication in a Local Education Agency . . . . . . . . . . . . . . . . . . . .

Thomas E. Rowan

Remarks by Senator Claiborne Pell . . . . . . . . . . . . . . . . . . . . .

Successful Experiences in Teaching Metrics in Home Economics . . . . . . . . . . .

Clinita A. Ford

Successful Experiences in Teaching Metric Conference . . . . . . . . . . . . . . .

Eugene M. Schanbacher

A Basis for Successful Teaching of Vocational Metric Education . . . . . . . . .

Richard A. Dieffenderfer

What Can We Learn from the English and Australian Experiences in Metric Education?

Albert B. Chalupsky

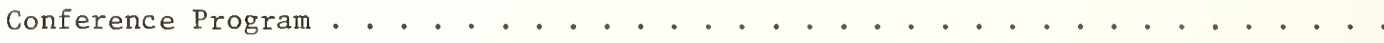

Biographies of Speakers . . . . . . . . . . . . . . . . . . . . . . . . . 


\author{
Richard W. Roberts \\ Director \\ National Bureau of Standards \\ Washington, D.J. 20234
}

If you were music teachers. I'd suggest we sing at least one chorus of "Happy Birthday." Why? Because exactly one hundred years ago today the representatives of 20 nations, including our own, signed the Treaty of the Meter in Paris. The cooperation resulting from that Treaty has produced mary notable results, among them being the development of the International System of Units.

When you look at that name--the International System of Units--a little more closely, its real importance becomes quite apparent. First, it truly is an international system, as the theories and experiments of all scientists provide the foundations upon which the system is built. In addition, all nations are eligible to participate in the Treaty of the Meter and all but five nations are committed to using the International System as their official

measurement system.

Next, it is a system of measurement, structured so that there are simple and logical relationships throughout. For example, the multiples and submultiples of all units are based on powers of 10 , and all carry the same prefix. A thousandth of a meter is a millimeter, a thousandth of an ampere is a milliampere, and so on. And the unit of volume is defined as one cubic meter.

Finally, the System is built upon a series of base units, currently seven in number (for mass, length, time, temperature, electric current, luminous intensity, amount of substance), from which all other units can be derived. There is some confusion over this term "base unit." They are not more basic or fundamental than other units. Rather, they are those units that are considered to have independent dimensional properties and they form a base from which all other units can be expressed mathematically.

Like Rome, the International System was not built in a day. It has a long history of evolution, a process which will continue as new needs arise, as new knowledge is generated.

It was back in 1670 that Fabriel Mouton of France proposed a decimal system of weights and measures. His idea lay dormant, but not forgotten, until the time of the French Revolution over 100 years later. In 1791, the French General Assembly adopted the principle of a system of weights and measures founded entirely on the meter, which was defined as one ten-millionth of the length of the quadrant of the earth's meridian. Area and volume were to be based on the square meter and cubic meter, and mass on the mass of a standard volume of water.

The French proceeded to determine both the arc of the meridian between Dunkerque and Barcelona, and the weight of a known volume of water. On the basis of these measurements, a platinum meter bar and a platinum kilogram were constructed and deposited in the Archives of the Republic in 1799. These standards became the starting point for the development of the SI.

But the creation of a new measurement system did not mean instant acceptance. Confusion and contention existed in France until a law was passed forbidding the use of any but metric weights and measures after January 1, 1840. This action seemed to pave the way for other countries, and by 1880,17 nations, including Spain, Germany, Italy, Austria, Norway, and Greece, had gone metric.

As use of the metric system increased, so did the need for international coordination. The first step in this direction was informal. In 1867, during the world exposition of Paris, a group of scientists formed a Committee of Weights and Measures and of Money to create more uniformity in the world. This initiative stimulated the French government to invite many countries to appoint delegates to an International Commission for the Meter. Twenty-four countries responded and the meetings started in August 1870. The great majority of those present felt that the meter and kilogram, which were in the Paris Archives, should be the reference for rew prototypes. 
In 1872 the Commission met again and confirmed its previous decision to construct new prototypes of the meter and the kilogram. A large number of copies, all made from one single melt of platinum containing 10 percent iridium, were to be made for participating nations. Progress went so well that the French government convened the Diplomatic Conference on the Meter in 1875, to which 20 countries sent government representatives and scientists with authorization to sign agreements. The resulting Meter Convention, or Treaty of the Meter, was officially signed one.hundred years ago. The Convention was ratified by the U.S. Senate, and signed by President Hayes in 1878.

Under the Treaty, an International Bureau of Weights and Measures was created to verify the new prototype standards and to make periodic comparisons of national standards with the prototypes. The Bureau is located near. Paris, is supported financially by contributions from all nations adhering to the Treaty, and is staffed by scientists from many nations. Surprisingly, only two Americans have ever worked at the International Bureau. The first was the famous Albert A. Michelson, and the second is Thomas Witt of NBS, who went over a few years ago to establish a Josephson-junction voltage laboratory.

The operation of the International Bureau is under the supervision of an International Committee for Weights and Measures, a body of 18 delegates, each from a different nation. Dr. Ernest Ambler, Deputy Director of NBS, represents the United States on the Committee. The Committee in turn reports to the General Conference on Weights and Measures, which is composed of delegates from each of the 43 member nations and which meets periodically to vote on matters of substance.

Over the years the General Conference, acting on the recommendations of the International Committee, has expanded and unified the metric system. Some of these actions are:

1948 - addition of the ampere as the unit of electric current, and the candela as the unit of luminous intensity

1954 - adoption of the kelvin as the unit of thermodynamic temperature

1960 - replacement of the meter bar with a wavelength definition based on krypton 86

1960 - adoption of the name "International System of Units" with the abbreviation SI

1967 - adoption of an atomic definition of time

1971 - addition of the mole--the unit of amount of substance--to SI

This evolutionary process has produced a coherent measurement system that is based on the best thought, and the best experimental data, available anywhere in the world. But, as I said before, such a system cannot be adopted for eternity; as science develop $\varepsilon$, so must SI.

Today, all but five nations have officially adopted the International system of Units. Those five nations are Brunei, Burma, Liberia, Yemen, and the United States. And while we are not officially committer, there is no question that this nation is going metric. Many of our largest manufacturing companies--giants such as IBM, Rockwell-International, and General Motors--are changing over. As the large firms convert to metric usage, so must thousands of their smaller suppliers. And as more and more metric products appear in the marketplace, every consumer must become familiar with metric measurements. Many Federal agencies are using metric units, and others are ready to go metric. Bills to guide the metrication process have been introduced in 13 states and enacted in Massachusetts and Minnesota.

A rew weeks ago I testified before Congress in favor of a bill that would commit the nation to a coordinated, voluntary change to SI units. One of the points I stressed was the need for education of all Americans in the use of SI. During the three year metric study conducted by NBS, a survey was taken of public knowledge and attitudes about metric. At that time, the general public knew very little about the metric system. Only 40 percent of the people surveyed could name a single metric unit, and only 20 percent were familiar with the relationship between customary and metric units. 
The survey did show that the more people knew about metric, the more they approved its adoption. For example, 74 percent of those who knew a great deal about metric favored it, versus 14 percent approval by those with little knowledge. This relationship points up the role of public education in a successful conversion program.

A coordinated educational campaign is vital if we are to prepare all of our citizens for the metric America that lies ahead. This fact is recognized in PL 93-380, enacted last year, that states "It is the policy of the United States to prepare students to use the metric system." I know you in the educational community are moving strongly in this area, and I know it's working. Both of my, children have been taught metric at their school here in Maryland, and both of them "think metric" with no trouble at all. The generation of Americans now in school shoujd have no trouble at all as the nation goes metric.

But a much broader educational perspective is needed. All Americans, not just school children, will be affected by metrication. Builders, machinists, salesmen, indeed all consumers, must become familiar with the basics of metric usage. That need poses real challenge for those of you in the educational community. Techniques must be developed for reaching, and teaching, all Americans, not just those in school.

As you probably know, we have a metric information office here at NBS. This small group responds to about 1000 requests for metric information each week, an indication of the broad public interest in metrication. NBS has prepared a variety of informational material, ranging from a snall plastic ruler to a general publication ("What About Metric") to a detailed description of the International System (SP 330). These materials may be of interest to you in your educational activities, and people of our metric office stand ready to help you in any way they can.

The speed with which this nation converts to metric usare, and the smoothness with which the process goes, is largely a function of public understanding and knowledge. And that, of course, presents a special challenge to education. I'm encouraged by your response, I think this meeting will stimulate new and creative approaches to teaching metric, and I'm confident that liter and meter will enter our vocabulary, and our thinking, with very little trouble. 
PRINCIPLES AND PRACTICES OF TEACHING

THE METRIC SYSTEM IN PUBLIC SCHOOLS ${ }^{1}$

\author{
George W. Bright \\ Mathematics Department \\ Emory University \\ At1anta, Georgia 30322
}

At the outset, you should know that all of my involvement in metric education has been with schools and school teachers. I have never worked in industrial or commercial education settings, for my professional interests lie almost exclusively in the area of public school instruction. Working with teachers is an adult education activity, but through these teachers I have also had the chance to watch real students in real classrooms, mostly at the elementary school level. Hopefully, these few facts will help you to understand the context of my philosophy in approaching the problems of teaching the metric system.

The basic tenet of my philosophy is that the metric system must be viewed as only one of infinitely many standard systems of measurement that could have been developed. The concepts of measurement must take precedence over the specialized ideas of metrics. A second tenet is that students must learn to use the units of the metric system as a single measurement system. There seems to be no good reason to attend to conversions between the metric units and the units of any other measurement system. Such exact mathematical relationships are difficult to learn and to remember because they are arbitrary, and such learning does not seem to assist the growth of significant mathematical concepts. However, despite the fact that metric units were originally chosen for reasons of convenience and coherence, they can be used to model elementary number system properties such as place value.

A third tenet is that teachers and teachers of teachers must provide opportunities for their students to begin to think in metric units. Within the next decade an understanding of common metric units will be at least desirable and more likely essential. Providing this understanding and the necessary accompanying skills should be an important goal of mathematics instruction. Use of metric units will help to simplify some measurement concepts and number skills, but this is peripheral to making the metric system accessible.

From the perspective of the mathematics educator, it is also true that the introduction of the metric system into the school curriculum provides an opportunity, never before encountered, to restructure measurement concepts clearly and correctly. The U.S. inherited its measurement system, and it was natural that curriculum developers accepted the pedagogy that grew up around these units. The customary units are so comfortable for most of us that little attention has ever been paid to sorting out the underlying concepts and finding the best ways to teach them. The insertion of the metric system in place of the customary units calls into question all of our assumptions about how students learn to measure. At last, there is welcome impetus to rethink completely the role of measurement in the school curriculum.

In summary, three basic axioms underlie my philosophy for teaching the metric system. First, the metric system must be taught as part of the more general ideas of measurement. Second, conversions should not be included as part of instruction. Rather, the metric system should be exploited as a model for illustrating number system properties and for developing other mathematical concepts. Third, students and their teachers must be helped in learning to think metric. They must learn to use the system as a system and learn to recognize and distinguish among the various units of the system.

There is no one way to accomplish these three goals. But there is one currently neglected aspect of measurement that can help in reaching each of them--estimation. There are many faces to estimation, as shall be explained later; and with judicial use, they can be used to highlight a variety of concepts. Before that discussion, however, there are some definitions that have to be made.

1 Parts of this paper are based on the author's essay on estimation which will appear in the 1976 Yearbook of the National Council of Teachers of Mathematics. 
For convenience of reference, these definitions are listed and explained below:

Measuring is the process of comparing an attribute of an object with whatever unit has been selected as the standard unit for that attribute.

A measurement is a result of measuring and is composed of a number along with a specification of the unit that was used in measuring the attribute.

A measure is also a result of measuring and is merely the number part of a measurement. The unit is understood or is already specified.

Estimating is the process of making a reasonable guess of the measurement (or measure) of an attribute of an object without the aid of measuring tools. A wide variety of procedures may be employed in estimating.

An estimate is the result of estimating and has the form of a measurement or a measure.

The primary distinction to be kept in mind is that measuring and estimating are processes and have many aspects which are unobservable, while measurements, measures, and estimates are products of these processes and are conveyed in either oral or written form. The definitions are stated from the point of view of instruction and teaching. They are somewhat imprecise, but they will serve the purposes of the remainder of the discussion.

Having distinguished measuring and estimating, it is necessary to examine the ways in which they are related. Mathematically, measurement is a correspondence between an object, usually physically present, and a positive real number. Many kinds of characteristics or attributes can be measured; e.g., length, area, volume, temperature, luminous intensity; but in each case there must be an assignment of a number to an object to represent a comparison between a unit and the specified attribute of the object being measured. Measurement for a specified attribute, then, is a function from a set of objects to the set of real numbers. The determination of the specific function for a given attribute depends on the unit that is selected to measure that attribute. Although a simple change of variables will translate the values for one function defined for one unit to the values defined by any comparable unit, the pedagogical consequences of such a translation are not at all simple. Regardless, the primary goal of measurement instruction should be understanding the measure function.

The function is a many-to-one and therefore a mathematically irreversible one, for many objects can and do have the same measure, at least within the tolerances inherent in physical measurement. From the view of the psychology of learning, however, the assignment can be viewed in the reverse way. There is a functional relationship between a measurement and the set of objects which are assigned that measurement. For example, a typical measurement activity is the following:

Measure the length of the table to the nearest centimeter.

The emphasis of this exercise is on the mathematical assignment aspect of the measure function.

If a standard unit such as centimetẹ is to have meaning for students, though, there ought to be opportunities for students to practice using the assignment in the reverse direction. The following activity might accomplish this goal:

Use your measuring tape as a searching device to find something in the room which is 45 centimeters long.

The student is asked to locate an exemplar from the set of objects, each of which is assigned the value 45 by the measure function for length based on the standard unit of one centimeter $(1 \mathrm{~cm})$. One purpose of this activity is to establish a mental picture of the size of a centimeter, or in this case, the size of 45 centimeters. The better the student's mental picture of 45 centimeters, the more efficient will be his search. At least part of his reward for a better mental picture is more rapid completion of the exercise. 
A second purpose of this activity is to help develop meaning for the word, centimeter. If this word has meaning, the student should be able to visualize objects whose attributes are described by measurements using this word. This particular exercise incorporates a safety valve in the form of the instruction 'use your measuring tape'. Even if the student cannot mentally picture the length, 45 centimeters, he can rely on the measuring tape to provide a model which can be physically compared with objects in the room.

The point of all this is that in terms of the cognitive development of children's ideas of measurement and standard units of measure, there seems to be, psychologically, a two-way relationship between an object and the number assigned to that object to represent the measure of some characteristic of that object. It is important in developing useful concepts, that this relationship be presented from both directions. In contrast to the strict mathematical view of measurement in which the relationship is not reversible, the more psychological view should prevail in planning instruction.

There are other important uses of estimation both in teaching measurement concepts and in helping people learn to think metric. For example, estimation activities can provide concrete illustrations of many of the basic mathematical properties of measurement. When restricted to metric units, these activities also can help students develop a mental frame of reference for the relative sizes of the standard units of measure. This latter outcome may be the most crucial for many people, since for many people the importance of mathematics lies in its usefulness in the world. Skill in estimating has much more obvious application than a full understanding of the mathematical structure of measurement.

There are eight basic kinds of estimation. Each of the eight paths in Figure 1 represents one king. It is assumed in each case that the unit has already been selected. There are further subdivisions that could be made of some of these categories, but for the time being these eight will serve well enough. Four (Class A) can be used to illustrate and emphasize the mathematical properties of a measurement function; and four (Class B), to illustrate the reverse relationship between a measurement and objects assigned that measurement. These two basic subclasses, because of their differences, will be discussed separately.

For Class A, the student guesses the measure of a named attribute of a named object which may be physically present or absent. Activities of this kind provide practice in working with the mathematical properties of a measure function. Presumably the student mentally compares the given unit with the named object and determines the appropriate measure. For some kinds of units, however, students may not compare in the expected way. In estimating the area of a rectangular object, for example, some students will estimate the respective linear dimensions and compute an estimate by using the standard area formula. Also, when the named object is present, its position relative to the observer affects the accuracy of the estimate, at least for attributes such as length and area. Accuracy will be greater when the object is viewed straight on than when it is viewed at an angle, either left-right or up-down.

The use of activities illustrating this class of estimation can create a classroom atmosphere somewhat different from that of a traditional classroom. Since students are asked to make reasonable guesses in the form of estimates, the usual right-wrong dichotomy does not apply to their answers. Rather, there is a degree of correctness relative to the discrepancy between the student's estimate and the subsequent measurement of the named attribute.

For Class B, the student either chooses an object from a list of permissible objects or names any object of his choice to which could be assigned a given measure. This kind of activity helps the student mentally picture the size of the specified unit of measurement. Presumably he pictures the measurement in terms of repetitions of the unit and compares this mental picture with objects around him. Some students, however, may picture a succession of objects, assign a measure to each, and compare these numbers with the given measure. Encouragement should be given for making the estimate in the former way rather than the latter, so that the inverse relationship from measurement to objects is highlighted. This kind of activity makes units of measure more accessible to students for use in practical situations. 


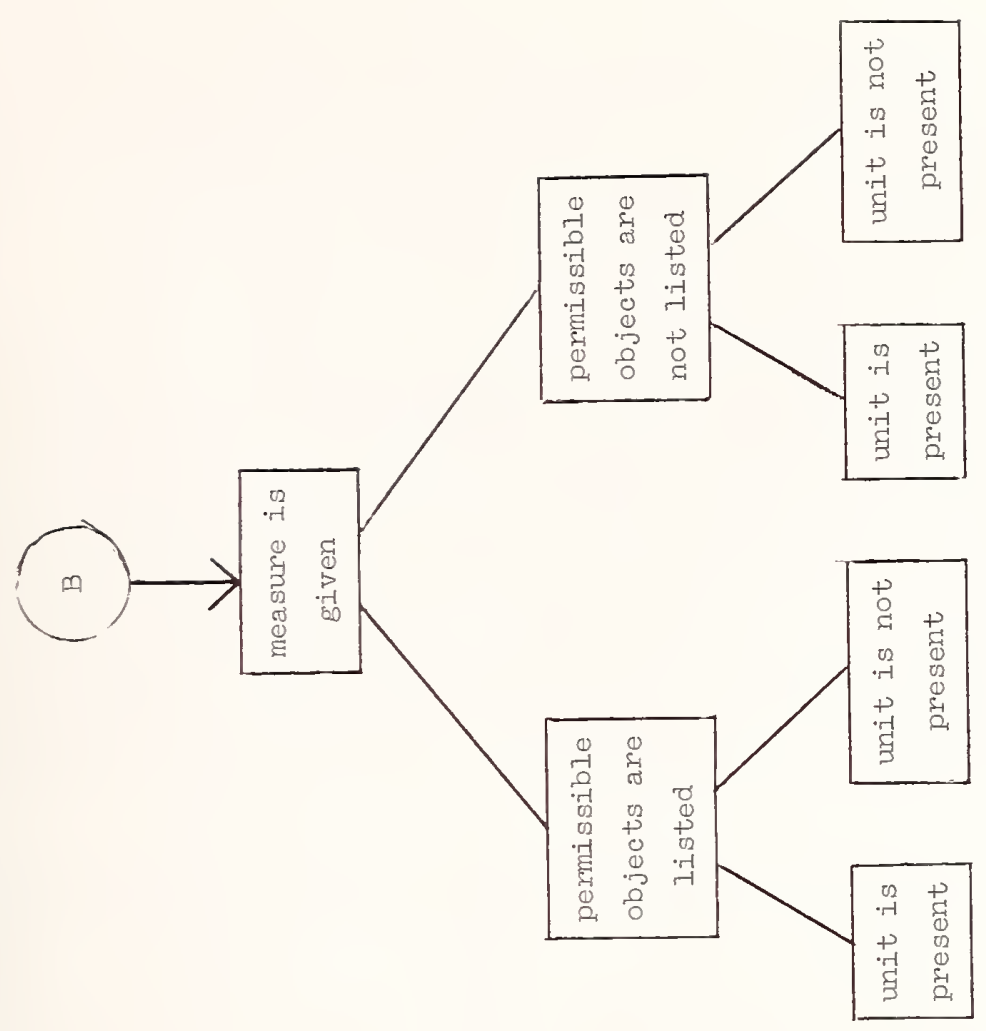

呈

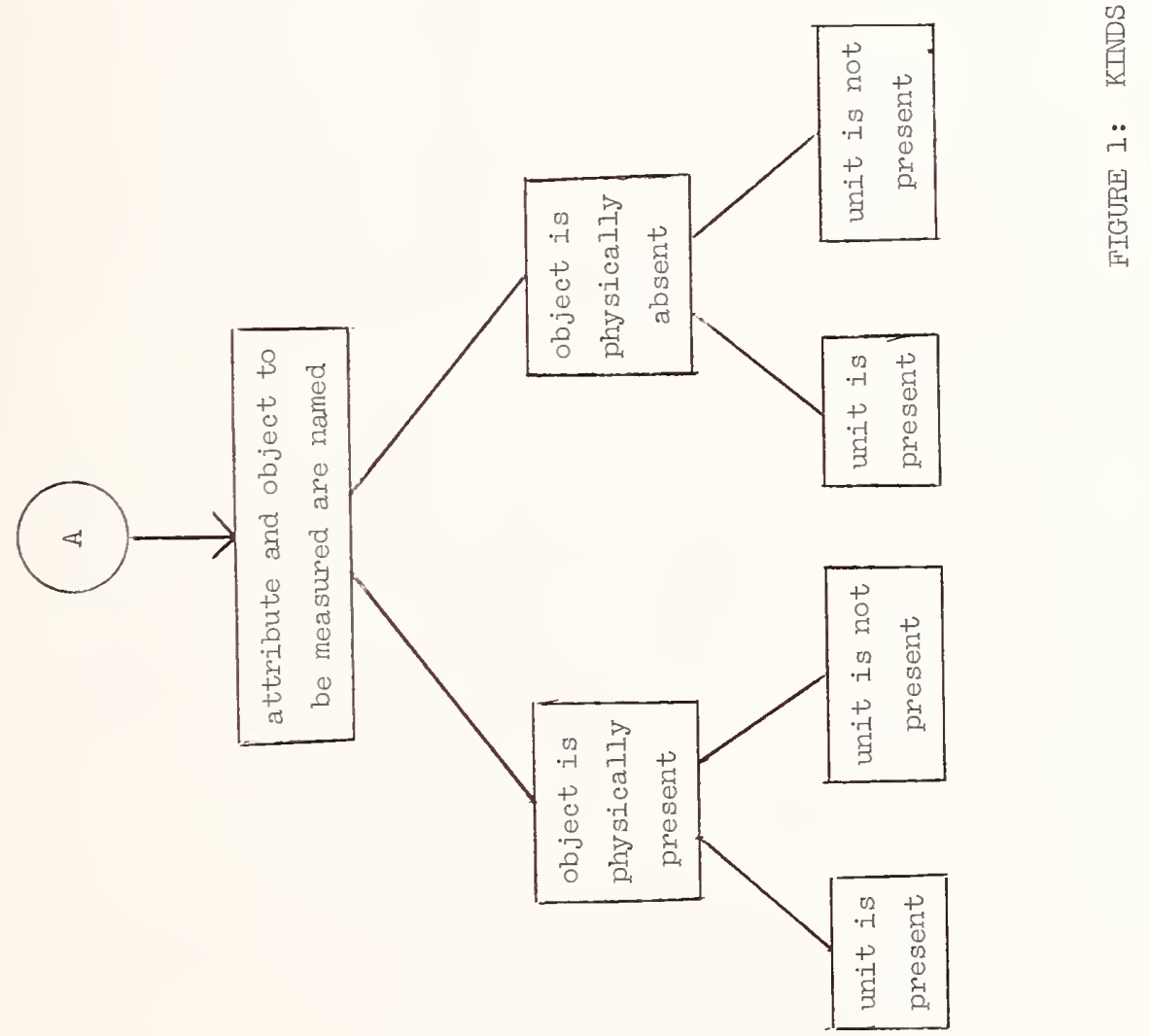


For both subclasses of estimation it seems to be important for students to check their own estimatés rather than relying on an outside authority such as the teacher or an answer key for verification. One goal of estimation activities is to have students develop skills to take into the real world. In order to be truly useful, these skills must be selfcorrecting; students should learn to provide their own checks. Of course, checks do not always take the form of measuring, for such accuracy is not always needed. A sufficient check might be made by comparing the named object with another which has already been measured.

Too, the act of self-checking helps a student distinguish measuring from measurement. The ideas of measurement account primarily for the properties that a measure function should have independent of human error in measuring. An understanding of these properties should be accompanied by an understanding of the kinds of and reasons for discrepancies that occur in collecting real-world measurement data. Having students check their estimates provides an experiential background from which these reasons can be discussed. Concurrently, skills necessary for accurate measuring can be isolated, studied, and improved.

In the context of an entire mathematics curriculum, the development of skill in estimating probably cannot be put into proper perspéctive unless some longitudinal records are kept relating each student's estimates and corresponding measurements. The problem in making such records useful is one of interpreting them in ways that provide information which can be used to improve estimates. One simple procedure is to keep a list of pluses and minuses, plus indicating that the estimate is larger than the corresponding measurement and minus indicating that the estimate is smaller. If a student's records are consistently pluses (or minuses), then he knows, or at least can be told, that he needs to make a conscious effort to adjust his estimates by making them smaller (or larger). Unfortunately, this kind of record gives no hint as to the amount of adjustment needed.

An alternate procedure is to graph the data on perpendicular axes with the measurements represented on the horizontal axis and the estimates on the vertical axis. The graphed points can be compared with the graph of the equation $y=x$. If most of the points lie above the line, then the student is consistently overestimating. If they lie below the line, he is consistently underestimating. He can then decrease or increase his estimates to compensate for his systematic error.

A third procedure is for students to remake the mental image they have of the unit of measure being used. If a student is consistently overestimating, then his mental picture of the unit is probably too small. He might correct this mental picture by having a model of the unit physically present while he makes a few estimates, or he might make a series of measurements without estimatjng to re-establish his measurement environment. Objects thus measured could be used as referents for future estimates which hopefully would be more accurate.

With the preceding discussion as background, it is time to examine estimation activities which appear in current textbooks and to detail ways estimation might be used in teaching measurement in general and the metric system in particular.

1. Without using a ruler, draw a segment which you think is $10 \mathrm{~cm}$ long. Check by measuring.

2. To the nearest centimeter, estimate the width of your hand, the length of your foot, the length of your forearm, and the distance around your head. Check your estimates by measuring.

3. Choose the word that completes the sentence correctly.

A football field is about 1 (meter, hectometer, kilometer) in

length. 
4. Classify each of the following objects into one of five categories:

than $1 \mathrm{~m}^{2}$.

much less than $1 \mathrm{~m}^{2}$; less than $1 \mathrm{~m}^{2}$; exactly $1 \mathrm{~m}^{2}$; more than $1 \mathrm{~m}^{2}$; much more

A bath towel, a stamp, your backyard, a tablecloth.

5. Find three objects with a total mass of $2 \mathrm{~kg}$. Weigh the objects to determine their masses.

6. How much string would be needed to make a tennis net?

Activities like these are useful in getting students to use units of measure in a realworld if not realistic context. Body measurements, too, can provide a frame of reference for making many kinds of estimates, provided one recognizes that, while easily developed, this technique has the disadvantage that as the child grows, so do the reference objects. The child must be aware that over an extended period, re-measuring of his body is necessary, and corresponding adjustments must be made in his procedures for deriving estimates.

External referents such as the width of a door are invariant in size but are also often difficult to carry around. Relying solely on external referents may consequently cause some inconvenience to students. A combination of body measurements and external models probably provides the best way of identifying a set of reference objects.

At the same time that students are measuring objects in and around the classroom, they should measure objects in their homes so that the home environment is also relatable to the standard measurement units that are being used. In this way the transfer of estimation skills from the classroom to the real world can be facilitated. If explicit help is not provided, transfer may not occur at all.

In spite of the variety of estimation exercises found in existing textbooks, the impression that one gets from examining such books is, first, that estimation is not considered to be an important topic, and second, that there is neither a very good understanding of nor appreciation for the extent and proper sequencing of activities necessary to develop estimation skills. As early as the 1959 yearbook of the National Council of Teachers of Mathematics, Payne and Seber suggested broad guidelines for teaching estimation.

The practical value of being able to estimate the size of physical objects is recognized by almost all people... The teacher should realize that this kind of estimation is difficult and somewhat cumbersome to teach. There are several reasons for this. It is time consuming; it may be difficult to apply a measuring instrument to the quantity; and a certain degree of mathematical maturity seems desirable, if not necessary. But this does not mean that we should ignore this useful aspect of estimation. It is even more reason for giving concentrated and systematic study of this topic. ${ }^{2}$

In spite of this statement made more than 15 years ago, essentially all textbooks have ignored systematic development even of minimal estimation skills. The few activities that are included are scattered more or less indiscriminately. Often they are segregated in brief sections headed "Explore," "Investigate," or "Extra for Fun" and thus become attachments to, but not part of, the mainstream of concept development. Unfortunately, such superficial treatment of estimation is often accompanied by a similarly superficial treatment of measurement. This double dose of inadequate instruction leaves a quite distorted view of measurement which for most students is never corrected. Such deficiencies form the status quo that many mathematics educators are trying to overcome during the change to the metric system.

2 Payne, Joseph N., and Seber, Robert C. "Measurement and Approximation." In The Growth of Mathematical Ideas, Grades K-12, Twenty-fourth Yearbook of the National Council of Teachers of Mathematics. Washington, D.C.: National Council of Teachers of Mathematics, 1959. 
One way to convince textbook authors to make some desirable changes is to show how mathematical concepts can be modeled in the metric system. Grouping by tens, important for understanding place value, is reinforced by measurement with metric units. Multiples and submultiples of principle units are determined by grouping by tens or by subdividing into tenths. Use of the metric system, therefore, is likely to enhance a child's understanding of numeration.

The metric system can also be used in developing decimal notation. Length measurements such as 3 meters, 7 decimeters, 4 centimeters might first be translated to a measurement in terms of the smallest unit; i.e., $374 \mathrm{~cm}$. The next most logical translation is in terms of the principle unit; i.e., $3.74 \mathrm{~m}$. The decimal point in this notation can be thought of merely as a bookkeeping device with the positions of the digits relative to the decimal point indicating the unit of measure that should be attached to each. This interpretation leads to several correct readings of the measurement. For example, $3.74 \mathrm{~m}$ could be read as 3 meters, 7 decimeters, 4 centimeters; as 3 meters, 74 centimeters; or as 374 centimeters. For young children, the interpretation of $3.74 \mathrm{~m}$ as 3 meters, 74 centimeters is probably the easiest to understand. After all, children understand "three point seven four dollars" (\$3.74) as 3 dollars 74 cents, and the analogy between the metric units and monetary units should be emphasized whenever feasible.

After decimal notation is comfortable for students, mathematical ideas underlying the notation can be developed. The relationships among metric units of measure can be used to illustrate relationships among place values and to provide a physical embodiment of the ideas inherent in decimal notation. That a centimeter is one-hundredth of a meter is easily grasped and that the notation for 1 centimeter is $0.01 \mathrm{~m}$ is reasonable, since in the notation for money one cent is written $\$ 0.01$.

The metric system also affords some exposure to the structure of language. The use of prefixes in naming units of measurement provides an opportunity to examine a systematic procedure for developing a set of logically related words. This procedure, in turn, sets the context in which other sets of words which are related to each other might be evaluated.

Finally, the metric system provides an opportunity to structure an example of substitution of variables. Definitions of units can be used in place of their respective names, with the resulting patterns reinforcing the concepts of decimal notation. For example, a centimeter is one-tenth of one-tenth of a meter; and a millimeter is one-tenth of one-tenth of one-tenth of a meter.

One of the problems teachers face in implementing the metric system in classrooms is deciding whether to use supplementary curriculum materials and, in the case of a positive decision, deciding which of the myriad available materials to use. It has proven helpful to teachers to provide a means of gathering objective data about the booklets and programs which are commercially available. These data can be gathered by randomly sampling 8 or 10 pages from each student booklet and categorizing the instruction with respect to each of the following items:

1. Most appropriate grade level:

$$
\begin{aligned}
& k-3 \\
& 4-6 \\
& 7-8 \\
& 9-12
\end{aligned}
$$

2. Amount of teaching required:

none

some

much

very much

3. Amount of student activity:

none

some

much

very much 
4. Kinds of measuring tools

5. Amount of class time required:

6. Amount of conversion to customary units:

7. Use of symbolism:

8. Use of measurement concepts: none

ruler or tape

balance

volume containers

other

5 minutes

10 minutes

20 minutes

more than 20 minutes

none

some

much

correct

mostly correct

sloppy

correct

mostly correct

sloppy

Once goals and objectives for instruction on the metric system have been established, the materials that best match these goals can be selected by analyzing the data for these eight (plus any other relevant) categories. For example, if it had been decided that metric instruction should be supplementary, activity-oriented, anti-conversion, and require a minimum of special materials, then a program which rated low in category 2 , high in category 3 , low in category 5 , and low in category 6 , which required few special materials, and which was at the appropriate grade level, would be selected. A procedure such as this for evaluating materials probably will allow school districts to meet their goals better than if materials were merely judged appropriate or inappropriate.

Beyond the problem of selecting materials, teachers will also face the problem of educating parents of students. In order to understand the changes that will be encountered in everyday life, adults need coping skills somewhat different than those needed by children. Only a few critical pieces of information would seem to be important to adults:

a meter is a little more than a yard;

a centimeter is a little less than one-half inch;

a kilometer is about two-thirds of a mile;

a liter, which is another name for a cubic decimeter, is a little more than a quart;

a kilogram is a little more than two pounds.

This information provides the base for adults that is needed for most everyday uses of the metric system. It can be provided simply and directly along with typical, reinforcing examples of situations which likely will be encountered. There is no need to provide detail about the metric system as a system; that kind of information just won't be of much value for adults. Certainly, explaining the metric system via tables of units and equivalents would mask the information that will be of practical importance.

When the metric system is introduced to adults, however, enough must be said so that parents know how the information they have learned fits into the system that their children will learn. Differences between the pedagogical approaches used for adults and those used for their children should be made explicit. In particular, the undesirability of teaching conversions to children needs to be explained. The existence of systematic relationships among units should be made known to parents, though the specific details of these 
relationships are not important. Instruction of children is more likely to be effective if general reinforcement of the instruction occurs at home. In short, parents must not be left out in the cold during the changeover to the metric system. The change will affect them directly, and the educational community should help them lower the dissonance that they feel.

It should be noted in passing that the change to the metric system is not, as some would have you believe, like the change to the new math of the $1960^{\circ} \mathrm{s}$. The use of the metric units of measure in place of customary units is a change that will affect every adult in the U.S. The change has not been imposed by a small group of people; rather, it is a change necessary to bring this country in line with the measurement system that has been accepted by essentially every other cnuntry in the world. The change to the metric system cannot be ignored. Adults simply must face up to the fact that they will have to learn at least minimal information about a new system of measurement.

The change to the metric system is most likely to be viewed like the new math when a teacher moves too quickly to the abstract properties of the system. For example, too early use of symbols for units of measure can have the tendency of reducing the metric system to a set of information to be memorized rather than used. Students should become very comfortable with metric units and the relationships among these units before symbols are used to stand for the names of these units. Games often fall into the trap of too early symbolism and abstraction. Few commercial games involve actual measurement of objects other than, perhaps, length measurement for objects which are less than 20 centimeters long. Probably the reason for this is that abstract properties and/or length units are much easier to package and sell in a box than open-ended activities requiring the student to go out and measure. Homemade games can be developed for specific classrooms at little or no expense which will teach measurement skills far better than most of these commercial games. At least during the early stages of learning to measure, such homemade games are to be preferred.

At some later time, as follow-up to measurement activities, abstract exercises can and, of course, should be used, though in moderation. For example:

(1) For each pair of measurements, circle the smaller:

(a) 6 meters, 6,000 centimeters

(b) 4.25 kilograms, 425 grams

(c) 8 square meters, $\quad 800,000$ square centimeters

(2) List the following in increasing order:

7 meters, 45 decimeters, 0.06 meters, 82 millimeters

(3) Make a pattern that will fold into a box without a top with a volume of 24 cubic centimeters. How many patterns can you make?

(4) Draw a rectangle with a perimeter of 26 centimeters and an area of 24 square centimeters.

These activities provide students an opportunity to practice measuring and estimating, to understand abstract relationships among units, and to learn metric symbols.

Mathematics educators are beginning to develop a new sense of awareness of the role of measurement in the mathematics curriculum. For the most part, this new understanding seems to have been triggered by the raising of consciousness about the imminent change to the metric system. Some basic questions force themselves on us; e.g., Do we teach mass or weight?; but these questions quickly lead to more subtle ones; e.g., At what grade level should we begin to use decimal notation for recording measurements? These in turn point the way to concerns important to the entire structure of the mathematics curriculum; e.g., How important is the traditional work with fractions? That a seemingly simple change of measurement systems can have such a profound effect on the mathematics curriculum would justify the claims that mathematics is a highly interrelated discipline and that measurement is a critical part of mathematics. The challenge to mathematics education now is to solve the problems of the metric changeover systematically so that the result is better mathematics instruction for the youth of today and tomorrow. 


\title{
METRIC IN GENERAL (ELEMENTARY) EDUCATION
}

\author{
Lou Smith, Mathematics Specialist \\ Cresthaven Elementary School \\ White Oak, Maryland 20910
}

Good morning! I have been asked to share with you information concerning a project implementing the teaching of metric measurement in elementary school. I regret that

irrs. Guido, principal of the specific school involved, could not be with you this morning.

Cresthaven is an elementary school that serves an upper-middle class community in Silver Spring, Maryland. It has a student population of about 375. This year the community has entered into a project of initiating the metric system as the primary measurement language of the elementary school children. Our anticipation is that by the end of the school year 1975-76, we will have a totally metric school.

The first phase of the program which is in effect now will make it possible for the kindergarten through third levels of the school to become acquainted with and use the metric system. Rather than considering this a switch to metric or a phasing in of the metric system, we are looking at it as a total approach of small group instruction, exploration and discovery with manipulatives, stressing development of the language, the use of estimation and the checking of estimates by measuring.

Kindergarten level children use non-standard units of measure exclusively, but we use such units throughout the primary grades to develop the skills and understanding of measurement techniques so that the children can work fairly accurately and have the readiness to really understand the us, of metric units. During this non-standardized phasé, children measure with parts of the body such as hand-spans and foot-lengths; with such objects as apples, books, pencils, pieces of string, strips of adding machine tape--anything that a child selects as an appropriate unit of measure. As a result of the work with such units of measure, communication between classrooms and much discussion within classrooms we help develop the concept of the need for a standard system of measure. Then we move into the use of the meter as a standard international unit of measure.

When the young children are ready for the use of the meter measure, we stress the use of the meter and centimeter but we do introduce the decimeter so that children can see the "tenness" of the system, that it is based on powers of ten.

Third graders weigh and record using grams and kilograms and measure capacity using liters and milliliters. In the 1975-76 school year, the program will be extended through sixth grade.

We have found that, as someone mentioned earlier this morning, children really do take to metric; they like it, they are enthusiastic about it, they don't have the hangups of already knowing the customary system and they are thrilled with measurement!

We have used the Montgomery County list of Pre-Algebra Objectives as a guide for the teaching of measurement skills. However, we have surely gone beyond the minimal requirements because of the interest of all involved in the project, plus that of the media. We were hurled into the project and have done more measurement sooner, probably, than an average primary team would have done because of visitors wanting to see metric classes, do a TV program, interview children or something along that line.

We have appreciated the attention of the media and the general interest of the public but it has caused a few changes in the timing of our plans. We are, at the same time, naturally concerned with the usual things; the reactions of the children, demands of curriculum guides and nonmetric standardized test results, plus parent and community expectations.

We are concerned, of course, with accountability but we have a creative staff with a special interest in metrics. This brings me to the subject of the development of the total project. As you know, Montgomery County provides a lot of inservice training for teachers and, as a result of a metric workshop taught by a math teacher specialist in the summer of 
1973, a corp of teachers at Cresthaven developed a special interest in the subject. They did some differentiated staffing within the school so some of them could help other staff members. As a result of that beginning, the staff and $I$, assisted by the leadership of the P.T.A., the math department, and the Area Director for Instruction, wrote a proposal for a local school project. The project was selected as one to be funded by the County School System.

During the first semester, a workshop for teaching metric measurement was provided at Cresthaven for Area teachers. At the end of the workshop session, all members of the local school staff, including principal, aides and regular substitutes, had received training in metrics. We felt at that point that we were ready to involve children and the local community.

At this time, we have worked with children, have held a series of three well-attended workshops for interested adults in the community, have evaluated commercial and teacher-made materials and have a resource room open to county teachers, parents and other interested parties. Any information concerning our activities and what we have learned in the process of implementing the project is available there. We have found that by stressing the measurement activities that ordinarily occur in a classroom, teachers have mostly developed their own activities at the primary levels. One of the most popular areas of activity has been cooking. Children have always cooked in the classrooms and we found that the metric cooking was of special interest to them. Copies of all the metric recipes went home. This, in turn, generated extra interest at home and requests for information and measuring devices. We have two sets of slides we would like to show you: one is cooking within a classroom and one is a demonstration of the use of some of the metric measuring instruments. I am going to turn this section over to Mrs. Lori Clements, teacher at Cresthaven, who will narrate the slides and then answer questions you have.

\author{
Lori Clements \\ Teacher - Local Project Director \\ Cresthaven Elementary School \\ White Oak, Maryland 20910
}

As Lou has mentioned, one of our main objectives has been to get the children active in the metric system. We have found that one of the things they enjoy doing most is producing a consumable product--in other words we can eat it--and that's what they like. In the first slide you are going to see, they are getting ready for a party, which is to be complete with cookies, punch and placemats all prepared metrically--one of the children reads aloud while the others follow along. All the ingredients are listed in milliliters and grams and the directions are all metric--the cookies are baked at $270{ }^{\circ} \mathrm{C}$. With the help of the metric aide this group is adding and combining ingredients for peanut butter cookies. We found that children did not hesitate at all when they were asked to measure a number of grams of flour or a number of milliliters of the other ingredients--they are not yet that familiar with the standard system and had no problem at all.

This is the metric lab which Lou mentioned before--all of our materials, which we have been able to purchase through our special funding, are kept in this lab. Teachers use it mainly to bring in small groups. Our half-time aide staffs it and she helps the small groups. These students are using the balance scale--which is not new, probably, to any classroom or to any school--but they are using it with gram weights--they are estimating the weight of familiar and sometimes unfamiliar objects and checking their estimate by measuring them on the balance scale.

This was by far the most popular piece of equipment. Those of you who are not familiar with it--and you can't see all of it here--it is a trundle wheel, and it is used to measure distances on a flat surface. The bottom reads "start" here, and they line that up with the beginning point of the distance they want to measure and then they walk forward with it. As they pace the distance off, it clicks off every meter. And all year long we have been hearing clicking through our halls, because the kids have been fascinated with it. So I would suggest that if you could only purchase a few pieces of equipment, tivis is one the kids really enjoy. 
Here they are stretching up to see who is the tallest in the room. When they found out some of them were $120 \mathrm{~cm}$, that really sounded tall.

Here they are weighing themselves in kilograms and the boys were asked to compare their weight to that of an average football player of 100 kilograms.

Here they are reading a thermometer. They had no trouble reading the thermometer in Celsius but it seemed a lot cooler until they got used to it. With our energy conservation, the metric room was often below $20{ }^{\circ} \mathrm{C}-$-which sounded a bit chilly.

This is familiar balance scale, which is used for computation in many schools now--but here the student is using ten gram weights to compute rather than just the plastic cylinder itself. 
Purnell Lawrence, Librarian

Bunker Hill Elementary School

4613 Eastern Avenue, NE.

Washington, D.C. 20018

Two hundred years ago Paul Revere sounded the alarm: "The British are coming!" and set in motion a confrontation which resulted in a new nation - a non-metric nation. In recent years a new cry has been heard throught the land: "Metric is coming!!" The twentiethcentury American, like the Minutemen of the past, rose up to defend those things held dear. Some even declared: "We'd rather fight than switch!"

There had been rumors of a Metric Invasion for many years, but we had been able to hold out against the meter, liter and gram for generations by simply ignoring them. However, some bits of metrication had been adopted in some areas. Librarians have included in their collections $35 \mathrm{~mm}$ filmstrips, $16 \mathrm{~mm}$ films, $8 \mathrm{~mm}$ loops and books measured by the centimeter for a number of years. With the warning, "Metric is coming," and later "Think Metric," librarians entered the metric world. It was soon evident that in order to "Think Metric" it was necessary to "Do Metric."

In the District of Columbia public schools, city-wide and regional workshops offered training sessions for local educational personnel. Special courses and self-teaching activities were used by some. Librarians were ready to team up with Math and Science Resource Teachers. Soon they were shelving books by the meter, drinking by the liter and losing weight by the kilogram. This librarian has had the advantage of working in a building where a metric-minded Math Lab Resource Teacher conducted a subtle, but penetrating training program. Daily Celstus temperature measurements were made and posted. Bulletin boards carried metric puzzles, problems and information. Staff members made tea by the liter and sweetened it by the gram.

After this initial training, librarians began to prepare for the metric invasion. Realizing that the foot, quart and pound were under heavy attack and would soon be defeated, they launched a massive search for materials to help teachers, students and their parents make the transition to meter, liter and gram. Books, newspaper articles, articles in professional journals, and even comic strips were part of these earliest collections. The National Bureau of Standards publications, as well as those of the National Council of Teachers of Mathematics, the American National Metric Council and those distributed by the Education Departments of various business organizations, were a part of the core collection. Films, filmstrips, tapes and recordings were also included. A kit of measuring devices was assembled.

As materials became more plentiful it was necessary to look more critically at their content. Again, this librarian was at a great advantage by being a member of a team whose responsibility it was to assemble a bibliography of metric materials suitable for use by teachers, students and parents. There were many opportunities to preview and discuss materials and to learn to determine their metric accuracy with the assistance of experts. During the period of transition it will be necessary to search for materials for the user who will learn the metric system as his first measurement language, as well as the user who will need materials to help him change from the customary to the new language.

Librarians joined early in the massive educational task. Armed with an initial collection, some "know-how" of meter, litter, gram and Celsius, the librarian was ready to launch an attack of her own. Three alarms were sounded: "Metric is Coming, Change!", "Think Metric!", "Go Metric!" Librarians advanced with a wide range of metric experiences designed to get people thinking metric. These experiences were offered to teachers, pupils and parents.

Some Librarians have:

1. Provided opportunities for teachers to receive training in the effective and skillful use of materials in the metri-kit. 
2. Set up Metric Learning Stations for teachers and students.

3. Provided bibliographies for teachers, students and parents.

4. Assisted in the selection and acquisition of metric materials.

5. Teamed with curriculum specialists as they developed materials needed for curriculum development. software.

6. Conducted a "View-In" for teachers, students and parents using all available

7. Assisted in the organization of "Metric Day" in a building.

8. Provided exhibits of metric materials.

These learning experiences won over most reluctants and set them on the metric way. However, if there should be one last hold-out who won't give a centimeter, I recommend some sure-fire metric magic:

\section{Serve a "Metric Tea"} he eats.

Provide measuring devices and require the diner to weigh and measure food before

Display metric materials collection.

2. Conduct a "Metric Weigh and Measure-In"

Provide scales and tape measures.

Provide a My Metric Measurements card to record findings.

Provide devices for measuring other common objects.

Award prizes.

Show filmstrips.

\section{Organize a "Metric Labeling Collection Contest"}

Provide prize for each item bearing metric measurement symbols.

Display materials containing metric measurements with the caption, "Metric is

Here."

The metrication of America will be a long and slow process. The enormous educational tasks will require materials and experiences to meet the needs of every man, woman and child in this country. Librarians will be expected to select from the influx of materials that which is accurate and suitable for the education of those within our schools and the re-education of those who have left our schools. Librarians will continue to provide experiences in the skillful use of materials. When the final mandate: "Go Metric!" is sounded, librarians will be among the leaders in the attack. 


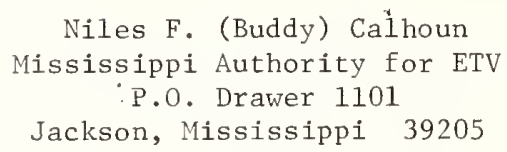

In 1972, the Mississippi Authority for Educational Television decided to develop a series on the metric system. Our Mathematics Advisory Committee had determined that the metric system was a topic that would be of great importance to education in the next few years. We also found that there was support for metric education by the NEA and NCTM but only a few definite guiding facts.

Two facts were most important in helping us determine that we would actually do a series:

(1) The U.S. was going metric, slowly but surely!

(2) No one would or could predict the exact outcome of metric conversion and how it would affect education.

Therefore, we felt that to be relevant and useful our series should be motivational and informative. It would be a series that would be transitional rather than pure sí--yet it would lead to a pure SI. It would have two major objectives:

(1) It should motivate the viewer to want to know more about the metric system and to actually become involved in using metric measures.

(2) It should teach some facts which a student could easily grasp and relate to his real world.

With these thoughts in mind, the Mississippi Authority for Educational Television has produced fifteen, 20-minute lessons on the metric system. These lessons are now available for use in our state and other states in the nation. In fact, several states in the nation are now currently using this series. (See appendix Item A)

How did we go about developing our series? What is really important in audio visuals as far as teaching the metric system is concerned? Well, there are many different answers to these questions but one of the ways we found some of the answers was by making a survey. Frankly, we found from the people surveyed that most adults felt that children should learn the metric system but maybe they (the adults) shouldn't have to be exposed to it. Even though most adults felt that the children should be the primary learners of the metric system, they did concede that they would view information about the metric system on television if it were presented. We of course realized that the child in school is more inclined to view television rather than the adult and we designed our lessons to be as motivational as possible for the $5 \mathrm{th}, 6 \mathrm{th}, 7 \mathrm{th}$, and $8 \mathrm{th}$ graders in our schools. (We did design the series so that it would have appeal for the general adult population, also, since we must reach teachers as well as students).

Music is a great motivator and it appeals to practically all people, as does the medium of television. So, we chose to present some of our facts in musical form. one of the facts that we wanted to get across was that the metric system uses preiixes, so we did this musically.

Although we present in many ways the fact that the metric system is a decimal system-that it is based on tens--a musical form to present this fact using puppets has a particular appeal for the younger student. This form of reinforcement of the fact that the metric system is a decimal system was used because of the great appeal of not only the music but of technique. So, technique is very important in our thinking about how to get across metric ideas. The fact is that many techniques will work and we used many different techniques to get across the same information. 
To help the viewer establish physical relationships to metric units, we chose to show linear units in relation to human body parts or to other common objects. We feel that this helps the viewer develop a built-in relationship that will let him estimate when he uses metric units. Estimation, as most of the other speakers have mentioned here today, is of great importance, we feel, in learning to use the metric system. Along these lines, one of our segments "Man and Meter," used drawings to help get across the relationship between a grown man and certain of the linear metric units.

We use the term weight with its ganerally used meaning throughout the first part of this series. This was done for the adults' and teachers' benefit since we felt that we might encounter the stigma that new math has developed in the minds of many adults. I think that we as educators made a mistake when we projected the idea to parents that they wouldn't know what new math was all about so they should just leave the teaching to us, and forget about it! This sort of thing we cannot let happen with the metric system. We must have the parents involved and behind us all the way! Through television, and especially open broadcast instructional television, as is our case, the parent can and sometimes does follow along at home by viewing the lessons which the child views in school. We should use all media forms available for parent awareness. (See appendix B)

Animation as a technique helped us to get across metric symbols without even having to say a word. The movement, along with sound effects, is very important in relating the fact that kilogram, for instance, is represented by "kg."

Also, as you will see in some of our segments, we relate pounds and kilograms in an easy to convert way. We wanted to make the transition from the use of pounds to kilograms as simple as possible for adults. Teachers felt that the only way we could do this was to give some reference point that they could fall back on. So, we give them a simple sort of crutch to help them convert. I know "convert" is a dirty word and dirty work and we don't want to teach conversion! But, usually to convert in a simple manner from pounds to kilograms we show that the number of kilograms is a little less than half the number of pounds.

We also use commercials as satirical ways of presenting the metric system. We found some of the more familiar commercials, with metric units replacing the customary units, to be most effective with adults and children.

Frankly, it appeared to us that the change to measurement of temperature in degrees Celsius should be an edsy one to accept. We, therefore, felt that only a little information could go a long way in this area. But we again used several different techniques to get across the information. For example, we used an animated scale with a little sing-song type of background narration and a take-off then on Mission: Impossible to get across certain basic facts.

Certain of o:m segments included activities that would be easy to reproduce and would hopefuily motivate the viewers to reproduce them. A segment which is a take-off on Sesame Street physically demonstrates that a liter is a little more than a quart. It also prepares a student to accept the "re" spelling of "meter" and "liter." Throughout our programs we used the "er" spellings. However, when we began to produce this program, we did not overlook the fact that the "re" spelling could possibly be used in future textbooks adopted in Mississippi. However, all the books that are adopted currently use the "er" spellings for "meter" and "liter."

Our television lessons do reinforce each other. Each little segment generally is repeated in a different way throughout the series, but we do still think that it's very important that the teacher follow-up each lecsen. The telelessons were never designed to stand alone. The only way that one can really learn measurement or a measuring system, we feel, is to do some measurement activities. The television can motivate you to do these things and it can give you ideas on how to do them, but it's the actual experience with measurement activities that really helps a child develop that intuitive feeling for measuring. And, we feel that only through practice will a child ever be able to successfully use the metric system.

To go along with these ideas, we designed some extra material. We do supply free of charge to all the schonls in Mississippi who request them, a Metric Kit. This Metric Kit 
includes a teacher's manual which tells about each of the lessons. It includes a set of Master Sheets which the teacher can duplicate or use as transparency masters to help get across some of the new ideas or reinforce those taught on the program. It also includes a set of 135 activity cards that can be used to individualize the study or can be used as group type activities. It includes a set of thirty 30 -centimeter rulers, a set of $1.5-$ meter tape measures and a small classroom Celsius thermometer. This material we feel will help the students and the teacher follow up the telelessons in the most positive way.

Why did we go to this trouble and expense? Because measurement, I repeat again, is learned by practice and we wanted to assure that the student would have materials to work with.

Were we or are we successful in our efforts? We have done several things to check to see how successful our learning system is. One of the studies involved Clinton, Mississippi Junior High School students in the 6 th grade and 8 th grade. Here are some of the facts that we discovered:

(1) Three of the sixth grade classes (all average and above average students) had our standard 20 question pre-test and the same 20 question post-test. This group scored an average of 5.3 questions correct on the pre-test. After viewing the first five lessons in the series, they scored an average of 14.0 on the post-test--an average gain of 8.7 questions. These lessons, I should point out, were shown within a four day period so adequate follow-up was really not possible.

(2) The eighth grade group, including the entire scope from the very lowest achieving student to the very top notch ones, had these scores: An average of 6.8 questions on the pre-test and an average of 14.3 questions on the post-test--an average gain of 7.5 questions.

(3) The best individual performance was by a girl who scored 0 on the pre-test and 18 on the post-test. This is probably because one of our choices always was for each of the 20 questions an "I don't know" answer; and she probably felt that she did not know anything about metrics on the pre-test. Yet her post-test score indicated a pretty good gain--maybe self-confidence as well as in metric knowledge. The worst individual performance was by a remedial student who scored 13 on the pre-test and 9 on the post-test, for a gain of -4 questions. And, we don't know what we did to that poor student but we probably either mixed him up or the student was a good guesser on the pre-test and not-so-good a guesser on the post-test.

Talking briefly about general audiovisuals use for metric education, let me mention the fact that the Five-State Consortium on Metric Education has prepared several forms for different media for the use of all the states in the country. Information about the FiveState Consortium may be obtained by writing Dr. Robert Jones, Director, Mathematics Division, N.C. Department of Public Instruction, Raleigh, North Carolina (Appendix C). Mississippi has, for instance, helped to prepare some cartoons and a slide presentation, based on National Bureau of Standards materials, which will be available to all the states. Other materials that have been developed include some slides which we use for getting across icleas for adults--teachers and parents. They're very simple, very effective, and if you intend to produce a slide set on your own I would suggest that you follow these rules. (1) Do keep your slide presentation very positive. (2) Keep it very simple. (3) Give only the basic information that's necessary for the group to whom you are speaking. (4) P1ease try to create as positive an atmosphere/attitude as possible in your presentation. This amounts to just being enthusiastic about what you're doing in most cases.

In our working with students on follow-up activities for our series we use some slides and other visuals, especially to help teach the process of estimation. An example of one of these is a cartooned man which appears to be approximately two meters tall and a baby which appears in relationship to the man to be approximately one-half of a meter tall. If you want to get across this form of relationship visually you must use something that can be simply but easily related to by the viewer. We assumed that the viewer could relate the 
height of a tall, full grown man to his approximate height in meters. Some things cannot be assumed, however. A child or an adult for that matter has to reach a certain level of abstract reasoning, has to reach a certain level of visual maturity, in order to be able to understand and relate to visuals. To show a child who has never seen a real whale a picture of a whale on IV, where it looks about the size of an ordinary catfish, and then try to have that child imagine what the whale is really like may be a difficult task! In developing/ designing any sort of visual aid you must keep in mind one real perspective, the relationship of your viewer to what he is viewing. The degree of perception necessary to determine and to establish certain metric relationships visually is very important.

There are many good, commercially-prepared audiovisual materials available now: films, filmstrips, slide-tape presentations, tape cassette programs, workbooks, all sorts of materials! Again the visual part of these is most important. If you can work from the physical exercise and the visual presentations to your pencil and paper type exercise, then we think you'11 be more successful in your teaching of metrics.

Metrics is really more than just math or science, it's life, it's drama, it's comedy, it's culture, it's (or will be) a part of all the things that we have going for us as human beings. Therefore, the metric system has to become so much a part of us that we can function with it without paying any special extra attention to it. We've tried to incorporate this idea into our television by building in some real viewer involvement--both covert and overt.

If I have to leave you with some ideas of what we must do in orker to get metric across to our students, whether we use audiovisual aids or any sort of aid, then here are the things that I would list:

(1) Think Metric

(2) Think Student

(3) Think Metric

(4) Prepare

(5) Think $* * * *$ !

(6) Avoid Overkill (This is something that I think is very important.)

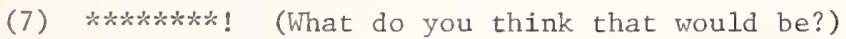

(8) Be Innovative! (This is an overworked word but one that seems to mean that you can do anything you want to, but actually it means to be involved, be enthusiastic.)

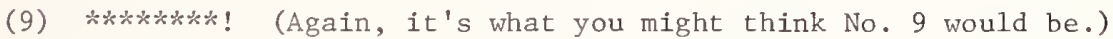

(10) Get All Involved (This could be interpreted in two ways--get yourself all involved--and get everybody involved in metrics.)

(11) Think: Why Metric:

(12) This item on through infinity would be--you guessed it, "THINK METRIC."

And, if you get tired of talking about the metric system, you can do as we do in our teleseries--sing about it! 
A. The series, The Metric System produced by the Mississippi Authority for Educational Television is distributed nationally by Great Plains National Instructional Television Library, Box 80669, Lincoln, Nebraska 68501; and is viewed on educational stations in the following states (some of these are state-wide networks and others represent a single station); Ohio, Louisiana, North Carolina, Wisconsin, West Virginia, Michigan, South Carolina, California, Kansas, Mississippi, New Mexico, New York, Missouri, Minnesota, Illinois, Virginia, Alabama, and Pennsylvania.

B. From: MICROWAVES, August, 1973, P. 16. Concerning the metrication of Britain: "In school, a majority of pupils between 10 and 16 now understand metric terms, it is claimed... According to the information received, a publicity campaign to educate and advise the public is still needed."

C. The 5-State Metric Consortium on metric education is a project funded by Title V section 505 of the ESEA of 1964 with North Carolina as the administrating state. The five states involved in the project are: California, Delaware, Minnesota, Mississippi, and North Carolina. Dr. Robert Jones is administrator of the project. The project calls for the development of model plans for the metric education of students, teachers, parents and the seneral population as well as other target groups. 


\author{
Stuart A. Choate \\ 2000 E. Hammond Lake Drive \\ Bloomfield, Michigan 48013
}

There is no doubt that the U.S. is going metric, Perhaps we are not moving as rapidly as some wish, but we are moving. It is certain that this change is not the smooth transition we would desire. In fact, the switch can be likened to the herky-jerky movement created by the young learner who attempts to coordinate the clutch and gas pedals of a stick-shift car.

As a member of the mathematics education community, I realize that the change to the metric system was not conceived by mathematics educators nor supported in the sense that it is a "necessity" for the teaching of mathematics. It was business and industry that urged the change, and rightly so. The economic implications are clear. It should also be clear that the mathematics education community supports the rationale of business and industry and we think we should go metric. We receive some bonuses as a result: (1) a measurement system that "makes sense" in terms of the interrelatedness of units, (2) an easier system to teach, and (3) a system in common with other sciences on which we can focus our instruction.

The result of the historical events has been that the mathematics community is playing the role of "reactor" to the current events. This may not be the desired role, but history has shown this to be common. While a multitude of bills have been introduced in Congress over the years, the recommendation of mathematics educator organizations regarding metric did not reach fruition. Over 30 years ago it was urged that the metric system pe adopted. (In other areas, the "new math" for instance, statements by educator groups were not readily responded to positively either. Publishers took ten years to change; the basic cause was economic.) It is not desired that we establish a national curriculum on metric education or in any other area, whether it be new math, algebra, social studies, or ser education. The role of mathematics education organizations should be to present guidelines for sound mathematical and pedagogical practice.

The views stated here are those of the writer, particularly the statements made thus far. Even though what follows is not an official view, the approaches to metric education are generally those of the mathematics education community.

As an involved member of the National Council of Teachers of Mathematics and working mainly in a consultative role, my recent experience has been with teachers in the field. The focus here will be to describe ny operation when an administrator cries, "Help! What do we do about metric?" The fear of being overwhelmed by a "new" system of measures might be complicated by one or more factors. Such factors are the decrees by supervisors at the local or state level saying, "We will be metric in two years," or that, "Assessment tests will contain metric this next school year."

The approach used is an attempt to relax the teachers and put the changeover into perspective. Initially, the writer attempts to show that the metric system is not difficult. Fewer facts and relationships than one might imagine are necessary for both children and adults to be operative metrically.

\title{
Teacher Inservice
}

While teacher groups in the field are generally not as sophisticated as this gathering, it is important in the initial meeting with teachers to create in them a disposition for going metric. It is this initial meeting which will be described in some detail.

As an aid to placing the metric changeover into perspective, reference is made to a newspaper article and cartoon which appeared in the Washington Post on January 9 , 1975. article focused on the legislative progress, reactions from business and industrial people, and comment relative to the Australian experience with metric. The article is well done, but the accompanying cartoon creates serious negative effects for the uninitiated which 
cannot be overcome by the article. While several situations are portrayed in the cartoon, one example is given here. A speed limit sign showing $50 \mathrm{mph}$ is crossed off and replaced by a metric sign showing " $80.450 \mathrm{KM} / \mathrm{HR}$." The error in symbolism was not a serious objection. However, no highway department exists that will post the sign suggested. The sign will likely read "80 km/hr." It is our obligation to help eliminate, via advisement, the fearcreating effects of well intentioned people.

Another aid in maintaining perspective is a warning that the excess of materials in the marketplace may give a distorted view of what is important and what is needed. The teaching of metric can begin with a minimum amount of equipment as suggested here:

\section{Necessary}

- metersticks

- rulers, 15 and $30 \mathrm{~cm}$

- cubic decimeter container (that will hold water)

- balance scales/weights

- mixed size containers

$\ell, 1 / 2$ ८, $250 \mathrm{ml}$

- square centimeter grids

(paper and acetate)

- Celsius thermometers
Nice to Have

bathroom scales

$50 \mathrm{~m}$ tape

flexible $1 \mathrm{~m}$ tapes

trundle wheel

The purchase of packaged sets of materials could easily result in undesirable materials, thus an unwise use of money. An example is a meterstick which attempts to focus on the notion of decimeter by painting alternate decimeters a solid color which covers the graduation marks. Students cannot easily use such an instrument to measure an object which is $15 \mathrm{~cm}$ long. It is this writer's opinion that such purchases are unwise, and that individual items should be requisitioned. The same company does, however, produce many quality items for use in teaching metric. It is to be pointed out that the teaching of metric can be begun on a "shoestring," which should be of some comfort to the budget officers of school districts.

Another effort made in working with teàchers is to present guidelines for teaching metric. Basically, the change to metric provides an opportunity to rethink the teaching of measurement. The central issue is measurement, and metric is that standard system we will all eventually use. If the teaching of measurement is poorly done, knowing all about the metric system will not produce the desired result.

Some major guides for teaching measurement follow:

(1) Choose a unit of measure and use it to measure many objects. The major notions are that unit selection is arbitrary, that measurement is an iterative process, that standardized units are desirable, and that the unit selected for measuring should be appropriate for the object being measured.

(2) The estimation process is a vital outcome of measurement experiences. Or it could be stated that estimation is the key to good measurement. (This topic was discussed extremely well by Dr. George Bright in his presentation.)

(3) Multiples or subdivisions of the basic units are used when appropriate. There are two aspects. First, they should not be forced by introducing them at too early a stage in the youngster's learning of measurement. Second, it is not necessary nor advisable to use or teach all of the possible multiples or subdivisions for the sake of completeness. Using those which are convenient makes the goals of measurement realistic. Proficiency in the use of a limited number of units is preferred to an acquaintance with many units. This point needs to be strongly emphasized. It might be recognized that there is a difference between SI as a system and 
the needs of students as well as sound educational practice in mathematics.

4. The nature of the measuring process is approximate. After one is comfortable with statements such as, "It is about 2 meters long," or "It is 2 meters and a little more," the student has some motivation for attacking the issue of fractional parts and the meaning of decimals.

5. The final idea is that measurement is an active process. Students learn to measure by measuring. They do not learn as passive spectators. Hands-on activities are the key,

At this point another warning should be raised. Student activity should be carried out with the "real" units. Scaled down versions that sometimes appear in textbooks do not provide students with a model of the unit and can easily lead to undesirable results. Evaluation of student progress in measurement may, by virtue of the process, require new techniques. The act of measurement requires more than reading where the endpoint of a segment aligns with the graduations on a ruler. Paper and pencil techniques are necessarily restrictive to smaller units. Measuring with a meterstick as well as units of mass and capacity are not possible in such a situation. Evaluation must be designed so that students can be observed in the "act of measuring."

Some guides for teaching metric:

1. Create an environment in which "thinking metric" is paramount. Selection of a unit and using it to measure and estimate in many situations will encourage, if not insure, thinking metrically.

2. The second point is that there are not very many units that one must learn; only eight units. (An alternative is three basic units and three prefixes.)

The result of teaching the complete system for the sake of completeness is pointed out in a "Peanuts" cartoon. Peppermint Patty is reacting to questions such as, "How many barrels in a hogshead?" etc. After some of these questions she gave up in exasperation saying, "It's zero time!" The indication was that she would just as soon forget it, take a grade of zero and get on to another topic.

The units which students and adults need to know are those with which they come in daily contact. They are:

Length
kilometer
meter
centimeter
millimeter

Weight (Mass) $\quad$ Capacity (Volume)

kilogram gram

liter

milliliter

Some teachers find the decimeter to be useful. If so, it might be added to the set of units.

It is recommended that dekameter or hectometer not be used because first, they. are not useful enough for everyday situations and second, it is not particularly instructive to compare the "complete" metric system with our numeration system. The mathematical payoff does not exist.

3. Parallel systems, metric and American, should be used when teaching measurement. However, the metric system should be the major system and introduced first when standardized units are necessary. Other than the obvious point that metric units are easier to learn, the metric system will be the primary system and deserves the majority of the emphasis. 
The fact that must be reckoned with is that for some period of time, American units will be used. Those American units our students will find in the marketplace will need emphasis. The remaining units will have historical interest. Also, we will have to face the fact that junior and senior high school students, like adults, will not be able to change overnight. Some careful plans will have to be laid, similar to the attempts to ease the minds of many elementary school teachers, which will emphasize the perspective one needs when changing the basic structure of our system of measures. (It is recognized that guidelines for teaching metric in middle school/junior high are currenly the weakest of any level. An effort is being made to make a contribution in that area.)

4. The act of converting between the metric and American system is passe. For those whose occupation requires it, conversion tables should and likely will be provided. The remainder of the population should be "thinking" metric, not converting.

While appearing to be a contradiction, the following must be recognized as a reality of the metric changeover. Since youth and adults will already have acquired the use of one system, some "gross" conversions are appropriate for them to maintain perspective and it may contribute to their attempts to go metric.

\title{
Gross Conversions
}

\author{
1 l is about 1 quart \\ $1 \mathrm{~kg}$ is about 2 pounds \\ $1 \mathrm{~m}$ is about 1 yard \\ $1 \mathrm{~km}$ is a little more than $1 / 2 \mathrm{mile}$
}

The cartoon, "Peanuts," again illustrates the point. Peppermint Patty is telling Franklin that they are going to learn the metric system and that someday it probably will be official. She proceeds to read conversions outloud, "One inch is 2.54 centimeters, one foot is 0.3048 meters, ...." and so it goes. Franklin replies, "I'11 never measure anything again as long as I live!" Many people are like Franklin.

If converting were emphasized, mathematics educators would be faced with the prospect of trying to teach two systems of measurement. It would certainly be difficult to have high expectations for two systems when the current system is not, on the whole, learned well. Converting between the metric and American systems would not increase the prospects of learning measurement.

5. As suggested previously, changing to the metric system will present the opportunity to rethink the teaching of measurement and to do the kind of job mathematics educators have intended.

6. The metric system will have some impact on the elementary school curriculum, but the effect will not be as drastic as projected by some. It certainly will not, as suggested in a Sears, Roebuck and Co. publication, shorten the elementary mathematics program by $11 / 2$ to 2 years. The change will likely be some realignment of the decimal-fraction content.

It is obvious that metric and decimals are related. Decimals can be nicely derived from fractions, since tenths imply equal size pieces. The mathematical sequence might be the following:

(a) Fraction concepts: unit, equal-size pieces, naming, symbolizing.

(b) Decimal Concepts: based on multiples of ten, equal-size pieces related to fractions that are tenths, hundredths, etc.

(c) Decimal operations: related to whole number operations.

(d) Fraction operations: conceptual development of algorithms and practice. 
Work with fractions is basic to rational numbers, real numbers, and algebraic development. Eliminating fraction work as some individuals have suggested would hinder the student's development and readiness for further mathematical endeavor. It is likely that the order of introduction will change as suggested and that fraction operations may be delayed until the sixth grade.

Summary

The initial session with teachers described above has accomplished two major goals as attested by the inservice participants. First, the metric system has been seen from a perspective that views the changeover as not being as complicated or radical as thought. There are fewer details than expected--not as many units, and conversions are out. Second, measurement is still the focus and metric is the standard system that will be used. With this, teachers have given a sigh of relief.

Subsequent sessions with teachers focus on the following aspects: (1) Orientation and acquaintance wi,th the metric system itself. Teachers work with ideas and materials similar to those of their students. Emphasis is placed on estimation, use of units appropriate to the measurement situation, the interrelatedness of the various aspects of the metric system, and on correct usage of language and symbols. (2) Activities appropriate to various grade levels and the appropriate sequencing of metric content and activities.

\section{Activities of Organizations}

The National Council of Teachers of Mathematics and a number of its affiliates have been engaged in the metric venture. While particular inclass experiences or teacher training efforts aside from conference and workshop presentations cannot be cited because the organizations do not deal with classrooms, there are several activities which have had impact. Through its journals and supplementary publications both philosophical and practical ideas and activities have been given exposure to more than 80,000 subscribers. Specific issues and columns in the journals have focused on teaching ideas at all levels.

The NCTM Metric Implementation Committee has contributed articles and workshops. Currently this committee is focusing on several specific areas. First, a "competency goal" list for students has been prepared and is going through the proper steps to gain NCTM approval. It will list in three parts the competencies that students might be expected to attain. This list contains "shall be able to's" for the end of grades 3, 6, and 9.

Another endeavor is to prepare a set of guidelines on metric education for use by teacher-education institutions as they prepare mathematics teachers. It has been indicated that few such institutions are emphasizing metric education.

A third effort is to prepare a guide for materials selection by teachers and administrators. It was suggested earlier what kinds of materials are necessary, nice to have, etc. This guide is to be more definitive and point out some of the pitfalls one might encounter if care is not taken.

An effort will focus on teaching metric at the middle school/junior high level. A major difficulty centers about the fact that students have had exposure to measurement as well as the American and metric systems. It is because students come to this level with differing exposures and capabilities that a single recommendation is difficult, if not impossible to propose. Hence, a document with many suggestions and the flexibility to make local adjustments is necessary. This is no mean task.

Finally, a parent/community education pamphlet is in preparation. This is a guide for a school and/or district as they seek to take metric education to the general public. The NCTM recognizes that the community is vital in the acceptance of metric and the public will determine how smoothly the transition is made.

The parent/community pamphlet discusses the importance of perspective, again, and the advisability of operating on a "need to know" basis. The questions are: How can we help the community see metric in perspective? and What is it that the community needs to know to be "operative" in a metric society? This pamphlet attempts to answer these questions. One 
view is that numerous contacts in a variety of ways is a better approach for the public than attempting to present the "whole story" in one or two sessions. (We made the mistake of trying to educate parents about the "new math" by telling them all there was to know about principles, bases, etc. They choked on the rapid-fire feeding of information. An effort is being made not to repeat the error.)

Included in the pamphlet, in addition to general statements about a multiple approach to community education, are some specific examples of how it might be carried out. One possibility outlined is a parents' night. In general, there is a brief historical look at metric, why the changeover to metric, an audiovisual presentation of the necessary notions of metric and where one might find them in use, a discussion of what adults will need to know as they go to the supermarket. (Shopping can be done if one realizes $1 \mathrm{~kg} i \mathrm{~s}$ about 2 pounds. Except for meat, most purchases are made by looking at relative sizes of containers rather than the specific capacity or mass. Produce can be weighed, the scale read, and the price computed without "knowing" metric. Comparison of prices will be easier in the decimal form. If one knows that the price is divided by the measure, then this act can be performed without complete knowledge of the metric system or any other system for that matter. (This writer would not be satisfied if the knowledge of adults were as limited as suggested here. The point is that adults can be operative and that their "whole world" does not have to change immediately. Certainly, one would desire the adult community to have a much greater understanding of the measurement system.)

A refreshment period is recommended with suggestions for decorations that are metric in nature. This includes placemats, cups, cookies, etc. The final phase of the parent night is an open house in the mathematics area where once again several 'suggestions for activities and organization are presented.

other metric events are described such as a metric fair, metric olympics, and a community metric day.

The other major section of the pamphlet centers about the media and communication to parents. Outlined are ways to present a monthly (or more often if possible) newsletter which would describe current student activity, some important metric notion, and a parent activity. Alternatives to a school newsletter is the local newspaper where, depending on local conditions, student and teacher articles can appear. If a regular column appears in the newspaper, a broader coverage is gained for metric. Finally, suggestions appear for encouraging the local radio and TV stations to promote metric with the guidance of mathematics educators.

Members of NCTM and its affiliates have produced some programs which are worth mentioning. Through an NCTM teacher-center grant the Montana Council purchased and outfitted a highway travel trailer. This trailer is manned by Montana nembers and they put on displays and workshops throughout their state. In Edmonton, Alberta, Canada, a locally produced handbook on teaching metric is in use. This booklet is of extremely high quality and is an asset to their endeavor. The Alberta Council has a "metric trunk" which they send to cistricts on request. Contained are materials and an inservice program so local people can produce workshops. The :ichigan Council has several such trunks but provide the manpower to travel about the state giving workshops.

The Michigan Council's trunks consist of a Metric borkshop Kit which are inexpensive models and instruments and a monograph to assist teachers in learning the metric system. The monograph contains activity cards for use by elementary children. Three metric trunks have been prepared for utilization in metric workshops.

A workshop is designed to fit the specific needs of a particular district. It can vary from a 1 1/2 hour presentation to provide awareness of the metric system and an introduction of the monograph to a full day inservice session that would provide elementary teachers an opportunity to explore the metric system more thoroughly.

An important aspect of this workshop is that the knowledge and materials can be adapted for immediate and inexpensive use in an elementary classroom. The materials in each trunk inservice 24-36 teachers and would cost about $\$ 120$ if a district wished to purchase similar materials for use by their teachers. Any school system will be able to 
immediately use all linear activity cards and almost all area activity cards without any commercially-purchased equipment.

\section{Conclusion}

The focus is supposed to be "successful experiences in teaching metric." While this discussion did not deal with in-class' experiences with children, there will no doubt be some at this conference. Due to my current involvement, the major focus has been on teacher inservice education. It is at this point that successful classroom experiences begin. No exemplar lessons or booklets produced will insure appropriate classroom activity. The major requirements are that teachers feel comfortable with the metric system, that they have the broad view of measurement and how metric fits into the picture, and that teachers understand their role in the overall effort to make America metric. It is to this end that this writer's effort has been made. Successful experiences for and with teachers provide a high probability of successful experiences for children. 


\author{
Barbara Logan \\ University of Delaware \\ 131 Prestbury Circle, Apt. H \\ Newark, Delaware 19713
}

We are continually reminded that the teaching of the past decade has not been appropriate for the world we live in and that it will be less suitable for the future. In the area of science education we have seen sweeping curriculum reform and our presence here today indicates that we are aware of the coming reform in the area of measurement.

Others in this conference have touched upon the need to prepare for metric, opportunities for funding, the use of media in teaching metric and the like. I would like to share some activities used in teaching the metric system in science classes that I and others have found successful.

In working with science teachers in workshop settings for the past four years, I have encouraged them to adopt five rules in teaching the metric system.

RULE 1

Your primary effort should be devoted to helping students to THINK METRIC.

Thinking metric means visualizing relative size in metric units, co the teacher's primary responsibility is to provide the learner direct, purposeful experiences with the units of the metric system.

In 1968, a study conducted in Nevada showed that science teachers taught the metric system chiefly through discussion and lecture techniques. I In all the literature on metric instruction pouring off the press in the past five years the consensus seems to be that active measuring on the part of the students is vital to establishing the concept of the metric units. This brings us to -

RULE 2

Use the guess and measure technique or in more acceptable terminology: Design dual activities of estimation and verification.

This activity should call upon the student to estimate a measurement then to check his estimate by measuring. If you are asked to estimate the height of a room in meters, you may make a preliminary estimation of 10 feet. Then you may reason that this is a little more than 3 yards and finally report the height of the room as "about 3 meters." This is NOT the way to teach today's students to estimate. We want to give them experiences leading to instinctive estimation in metric units. And so -

RULE 3

Avoid conversion back and forth between metric and U.S. customary units.

For many years our foreign language teachers have taught students to be bi-1ingual; there is no reason why they can't learn to operate dual measurement. For sometime there will be a need to have knowledge of both systems. However, the attempt to interweave the two systems by tedious study and complicated conversion factors is discouraging and senseless.

RULE 4

Be consistent! Use metric units in all everyday situations not just when you're studying a unit on metric measures.

Physics teachers, who have traditionally touched on the metric system, and then, have ignored it to teach acceleration due to gravity as 32 feet per second squared and air pressure at sea level as 15 pounds per square inch will have to make some adjustments. It 
won't do for the rest of us to announce: "Today, we're going to have a test on the metric system so everyone sit at least 6 feet from your neighbor."2

We can subtly attune our students to metric by requiring $2 \mathrm{~cm}$ margins on reports submitted instead of the usual 1 in., or we can begin to specify paper size as approximately 22 by $28 \mathrm{~cm}$ rather than $8-1 / 2$ by 11 in. In biology and health classes, we can designate vital statistics of organisms in metric units.

RULE 5

Give them what they need when they need it!

Science teachers have tolerated the need to spend time teaching the metric system because of the poor background of their students in this area. For many students measurement has been nothing more than memorizing tables, equivalencies, and key formulas which they apply with no conceptual knowledge of how they function.

No student should be subjected to the entire metric system at once, but at whatever grade level you teach, some concept of measurement should be taught and the students should learn that concept in metric units.

Without a doubt, the student entering science classes at the junior high and senior high school levels, six to ten years from now will be better prepared in metric measurement skills than they are today. In the meantime, science teachers must design activities that will reinforce and in many cases establish the concepts so that the student will be able to use this tool efficiently.

These activities should guide the learner to abstract generalizations from actual measuring experiences. Rather than presenting a host of formulas for the student to memorize, let him derive what he believes to be an adequate rule after he has measured several things similar in nature.

Through the activity the teacher "sets the stage" and then directs pupils in the exploration of new ideas, performing experiments and stating generalizations.

Let us consider a few activities that have been successful for others, bearing in mind that grade level is not as important as the level of sophistication the student shows in the areas of metric measurement. When considering activities for students in the upper grades (junior and senior high school) we must remember that for the most part they have had little exposure to metric or at best a negative experience with it. They need experiences which are non-threatening and at which they can be successful.

In the areas of linear measurement, primary learners (whether age 6, 16, 26 or 60) must be led through a series of activities involving non-standardized units (ribbons, string, etc.) to the discovery of the need for some standardized unit. Once they have learned the terms meter and centimeter various projects may be used to reinforce the concept of the units and the skill in using the tools. Skill in using the tool includes selecting the proper tool for the task at hand, e.g., using a meterstick or trundle wheel to measure the length of the hallway instead of using a $30 \mathrm{~cm}$ rule.

\section{ACTIVITY 1}

\section{HEIGHT CHART}

Middle school science programs usually include a section on the human body growth and development. A class project might include measuring everyone's height in centimeters or meters. Students who are more than 100 centimeters tall will allow the opportunity of recording height as decimal parts of meters, e.g., Jane: $1.51 \mathrm{~m}$. If this activity is done in the fall and a class record is kept, it can be repeated several times during the year to compare growth rates. 
Students may be grouped into pairs to measure body parts. Charts depicting arm length, head size, etc., can be constructed or graphs showing the relationship of height and arm length or age and head size might prove interesting.

In the upper grades or high school individual charts can be prepared (Fig. 1). 3 Notice the column ESTIMATE. The student is asked to estimate each measurement before verifying it. He may begin to associate various estimated lengths with body parts.

\title{
Body Facts: How Well Do You Know Yourself?
}

\author{
Materials: meterstick, metric tape measure. \\ Directions: Find the following body measurements in centimeters. (Make an estimate \\ first, then check your estimation.)
}

1. Your height

2. The length of your foot

3. The width of your finger

4. The width of your hand

5. The distance around your waist

6. The distance around your wrist

7. The distance around your neck

8. The distance around your chest

9. Your head size

\begin{tabular}{|c|c|}
\hline Estimate & Actual \\
\hline & \\
\hline & \\
\hline & \\
\hline & \\
\hline & \\
\hline & \\
\hline & \\
\hline & \\
\hline & \\
\hline
\end{tabular}

FIGURE I

\section{ACTIVITY 3}

PET MEASUREMENTS

Measurement of pet.

Measuring their pets, (height of dog and cat or length of pet snake) can add interest to additional experiences in measurement for elementary science students. Secondary science students should be required to keep records of laboratory animals (mice, guinea pigs, rabbits, frogs, snakes, gerbils) including length, height, weight, food intake, etc., in metric units. 


\section{PLANT MEASUREMENTS}

At the upper elementary level extensive practice in using the measuring instruments and recording the data is needed. Plant studies provide opportunities for measuring roots, leaves, shoots, amount of water given. Records of this data can then be used for graphing experiences. Simple testing devices can then be prepared to check progress (Fig. 2). ${ }^{4}$

\section{ACTIVITY 5}

\section{LEAF COLLECTIONS AND METRIC}

In the fall it is easy to collect a variety of leaves and use these in science classes for hundreds of activities. When pupils collect leaves have them "fix" them by covering them with clear contact paper to keep them from wilting or drying out too quickly.

In addition to the classification activities that can be conducted relative to color, veining, edges, and source, we can also ask the student to classify by size. Because it is difficult to judge which leaf is "largest" due to variations in length and width, an area study can be introduced. (Fig. 3). 5
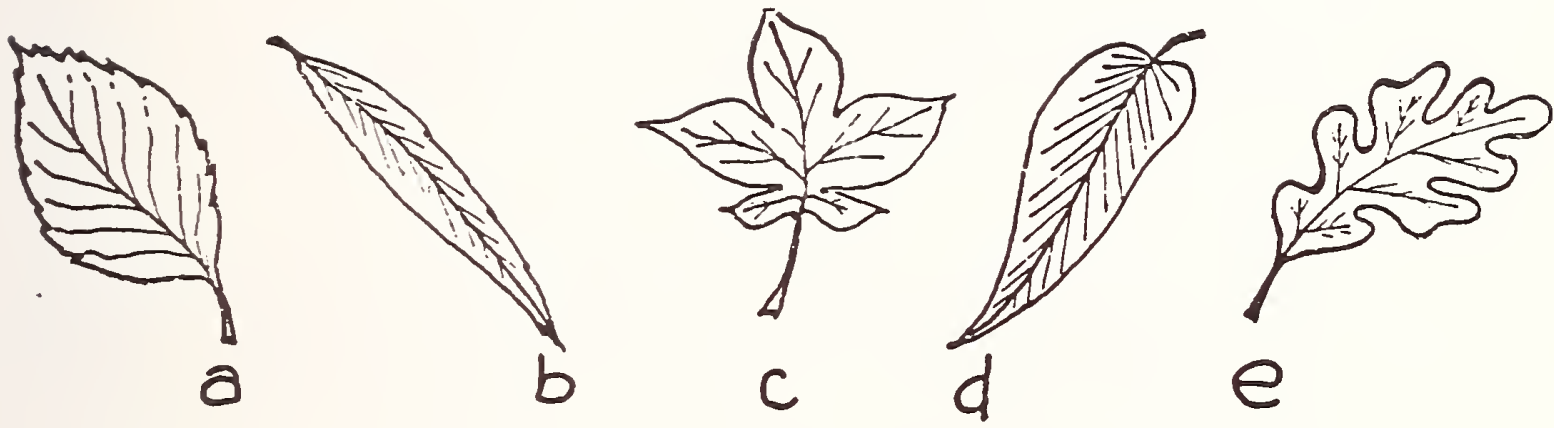

Materials needed: 5 leaves, differing in size or shape

Directions: Label or name the leaves. Estimate how many square centimeters in each leaf. Make a table to record your guesses and measures:

\begin{tabular}{|c|c|c|}
\hline Leaf & Estimate & Measure \\
\hline $\mathrm{a}$ & - $\mathrm{cm} 2$ & $\mathrm{~cm} 2$ \\
$\mathrm{~b}$ & $\mathrm{~cm} 2$ & $\mathrm{~cm} 2$ \\
$\mathrm{c}$ & $\mathrm{cm} 2$ & $\mathrm{~cm} 2$ \\
$\mathrm{~d}$ & $\mathrm{~cm} 2$ & - \\
$\mathrm{e}$ & $\mathrm{cm}^{2}$ & \\
\hline
\end{tabular}

Now measure the leaves. You may wish to use centimeter grids or paper. Complete the table. Make a display for the class to show the area of each leaf.

\section{FIGURE 3}

To determine the area of the leaf:

1. Pupils place leaf on square centimeter graph paper and trace its outline. 

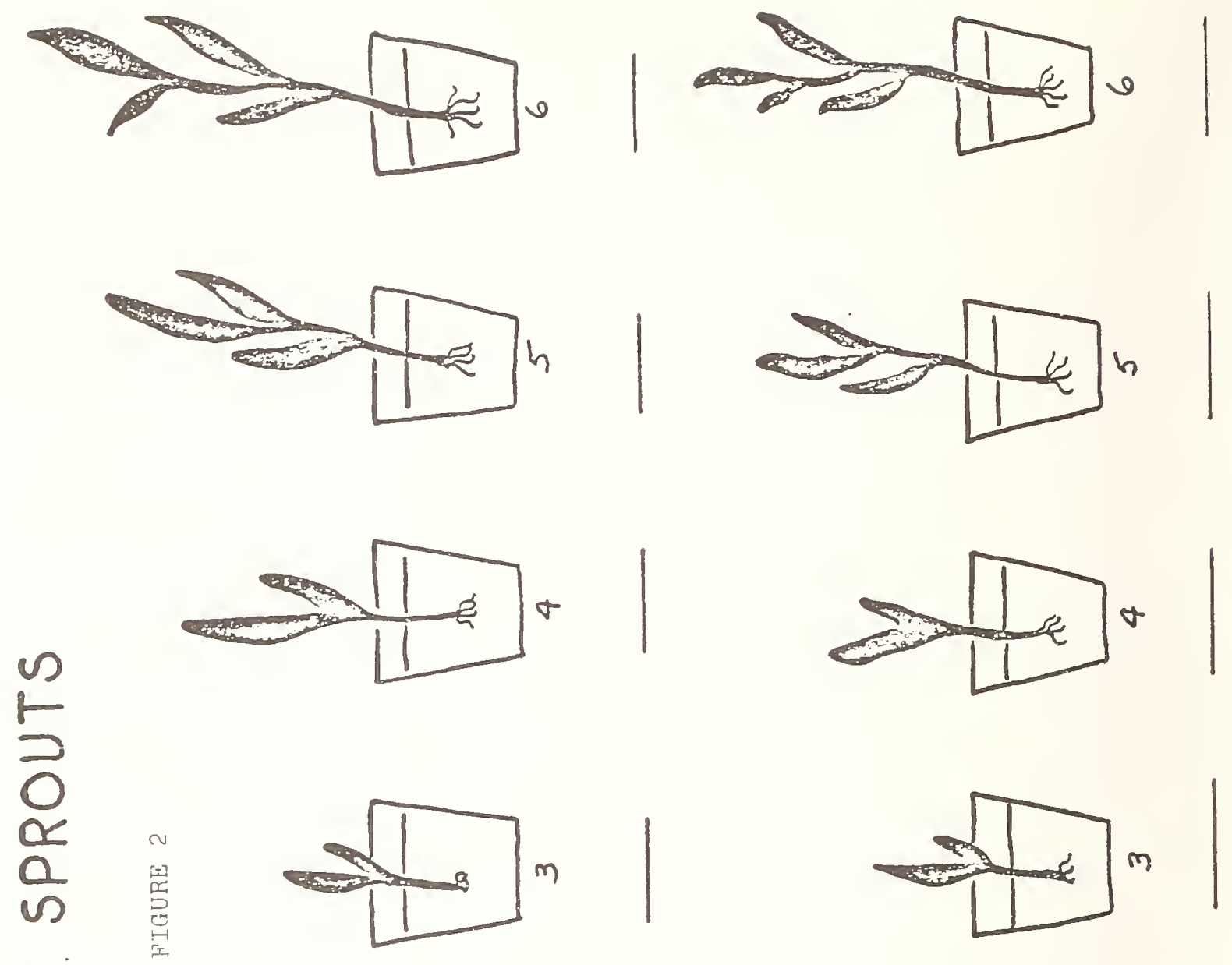

$\frac{5}{2}$
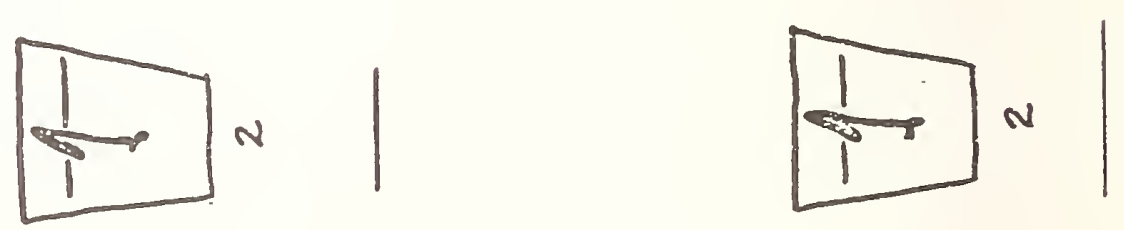

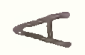

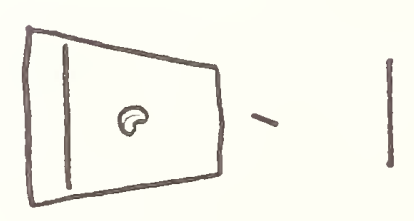

$\infty$

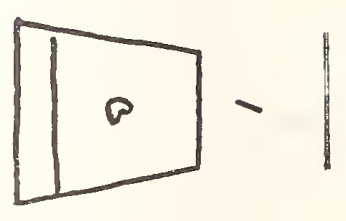

us

$\frac{1}{0}$

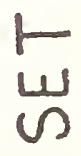

$\frac{1}{0}$ 
2. Estimate the number of blocks it covers.

3. Count the approximate number of squares.

4. Repeat this activity with a leaf that the pupil estimates to be about the same size.

If this activity is repeated by using objects with regular sides, the students can be led to discover the formula of length $\mathrm{x}$ width to determine the area of a regular surface. Increasingly more difficult (abstract) problems can be designed by asking the students to solve problems involving carpeting or tiling of floors, making floor plans, reading blueprints, planning gardens, etc.

Perimeter studies can also be done by covering the outline of the leaf with a piece of string and then measuring the length of the string used to determine the perimeter of the leaf.

\section{ACTIVITY 6}

\section{SCAVENGER HUNT}

A fun culminating activity for the study of linear measurement involves a Scavenger Hunt. In one method of conducting this activity, the teacher measures a number of objects in the room or within a designated area and records these measurements on a checklist for the students or on three by five cards. Measurements must be recorded in the proper units and it should be indicated if they are other than a length or width. For example, if you measure the circumference of a door knob, it should be indicated that this measurement is a circumference.

The students, equipped with meterstick, metric rule and string or metric measuring tape, are asked to find the object measured within the designated area. If they locate an object that measures the same as indicated on the card or checklist, but is not the actual object keyed, they are given credit after proving that the object they found does indeed measure the same. It is good to have an award for the individual or team that finds all the items.

Variations on procedure can include additional practice for the students. Divide the class into groups or teams. Assign the teams to various areas to do the initial measuring and preparation of scavenger hunt cards. Teams would then exchange cards and try to identify the objects keyed by the other teams.

\section{ACTIVITY 7}

\section{HOPSCOTCH: A CRUTCH}

Students will need much practice in converting from one unit to another within the metric system, from meters to centimeters, etc. In problem situations where students have difficulty in correct placement of the decimal point, this Hopscotch may be of help. (Figure 4)

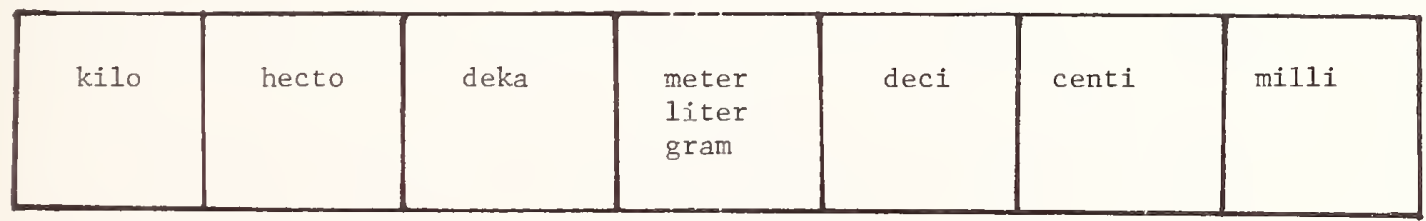

FIGURE 4

Procedure:

a. Locate the original unit on one of the squares. 
b. Count the squares to the new unit.

c. Move the original unit's decimal point as many places as blocks in the same left or right direction.

Example:' $5.5 \mathrm{~m}=$ $\mathrm{mm}$

a. Place finger on the block marked meter.

b. Move to the block marked millimeter, counting the blocks as you move.

c. The decimal point is moved three spaces to the right just as your finger moved three blocks to the right when going from meter to millimeter on the chart.

$$
\text { Example: } 5.5 \mathrm{~m}=\underline{5500.0} \mathrm{~mm}
$$

Admittedly this is a crutch, but for the junior or senior chemistry/physics student finding transition difficult, it helps to reduce a great deal of frustration.

Since there is no distinction in the metric system between dry and wet volume, these measures are much easier to teach in metric. All measures regarding volume emanate from the basic liter.

\section{ACTIVITY 8}

\section{BOX UPON BOX}

In order to develop the concept of volume, the teacher will need to have boxes of different shapes and varying size. ${ }^{6}$ The students can fill the box with cubic centimeter blocks and then count the blocks to find the approximate number it will hold. Many boxes should be tested and arranged in order according to the number of blocks that can be contained.

Pupils might next estimate the number of cubes needed to fill a given container, and discuss ways of finding how many it will take without actually filling the container with cubes. This leads to the rule of multiplying length $\mathrm{x}$ width $\mathrm{x}$ height to establish volume.

Many experiences of this type are needed before the pupils are completely familiar with the concept of volume. As the student progresses, the liter may be introduced as a unit of measure for larger containers.

\section{ACTIVITY 9}

$$
\text { WHAT'S A LITER? }
$$

Display a clear plastic cubic liter container which is graduated in $100 \mathrm{ml}$ divisions. Have various other graduated containers available. These should vary in capacity from $100 \mathrm{ml}$ to 1 \& and should be filled with colored water.

Ask the students to estimate which one of the containers of colored water could be emptied into the plastic cube, filling it without spilling over. Test the one they select and note the number of milliliters it contained.

Starting again with the empty cubic liter container, fill it to various levels, comparing the gradations on the plastic cube to those on the graduated cylinder.

If the activity is done again, using the centimeter cubes, the teacher can help the student relate the cubic centimeter notation to milliliter notation. 


\section{EVERYDAY CONTAINERS}

Additional estimating exercises may be provided through the use of household objects of varying capacity, e.g., teaspoon, coffee can, milk carton, juice cans, olive jars, tea cup, fruit jars, vases, etc., and a set of calibrated measuring beakers. ${ }^{7}$

Students can measure amount of water each container can hold by using the measuring beakers. To find the liquid volume of the smaller containers, it may be easier for the students to first fill the container with water, then determine its volume by pouring its contents into the appropriate graduated cylinder.

After sufficient practice to allow students to be able to eyeball various volumes they may be challenged to pairs of bottles having different shapes. The pairs should be comprised of bottles of somewhat different volumes but not so different that it is obvious which is larger. A sample record kept by the students may read as in Figure $5 .{ }^{8}$

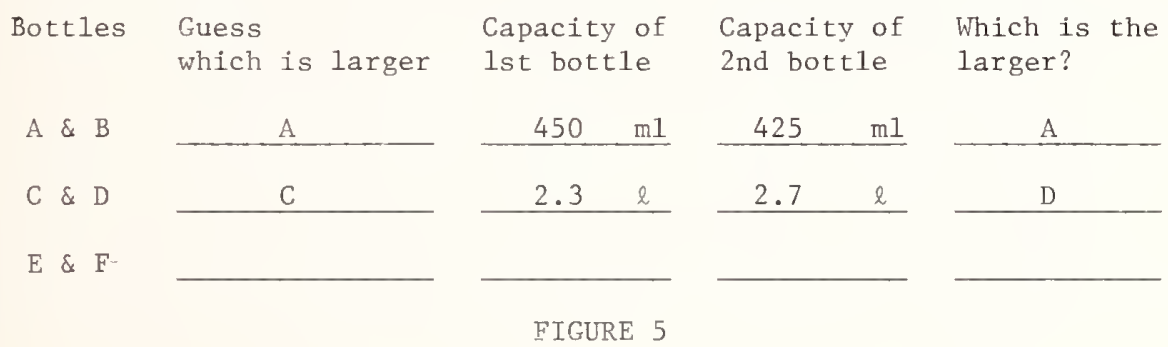

A variation or additional activity might involve competition as follows. Select ten or twelve items from your collection of containers and identify each by letter or number. Have the students estimate the capacity of each in milliliters or liters.

Divide the class into groups or teams and have each team check the volume of each container. Team points may be gained by whoever estimated closest to the actual volume. The team with the most points wins and an appropriate award is given. In one instance, the award was $100 \mathrm{ml}$ of cola for each member of the winning team.

\section{ACTIVITY 11}

\section{SHAPES AND VOLUMES}

Piaget did a great deal of work with young children on building the concept that solids with equal volumes can have completely different shapes. It is interesting to note that many of our students at the junior and senior high school level have yet to verify this fact for themselves.

In most physical science programs we can find examples of suggested labs involving the methods for measuring the volume of small, irregular shaped solids. Before doing the activities suggested in your text, you might provide a bit of a Piagetian experience.

Prepare 10 or 12 objects in various sizes and shapes with clay and identify each by letter or name. Any item heavy enough to float and not be damaged by water can be used, but the use of clay provides the opportunity to demonstrate a very important principle.

Several methods might be used in determining the solid volume of an object. The student might first place the object in a container and then fill the container to the top with water. The object being measured should then be removed from the container and the container filled to capacity using a graduated cylinder. The total amount of water needed to fill the container with the object removed is recorded and is the solid volume of the object. (Figure 6) 


\section{How to Lose Pounds Without Dieting}

\section{Materials: bathroom scale (metric)}

Directions: Estimate your mass. Find your mass on the metric scale. Put your name on the chart and color up to your mass. Then find nine friends, measure their masses, and record them on the chart.

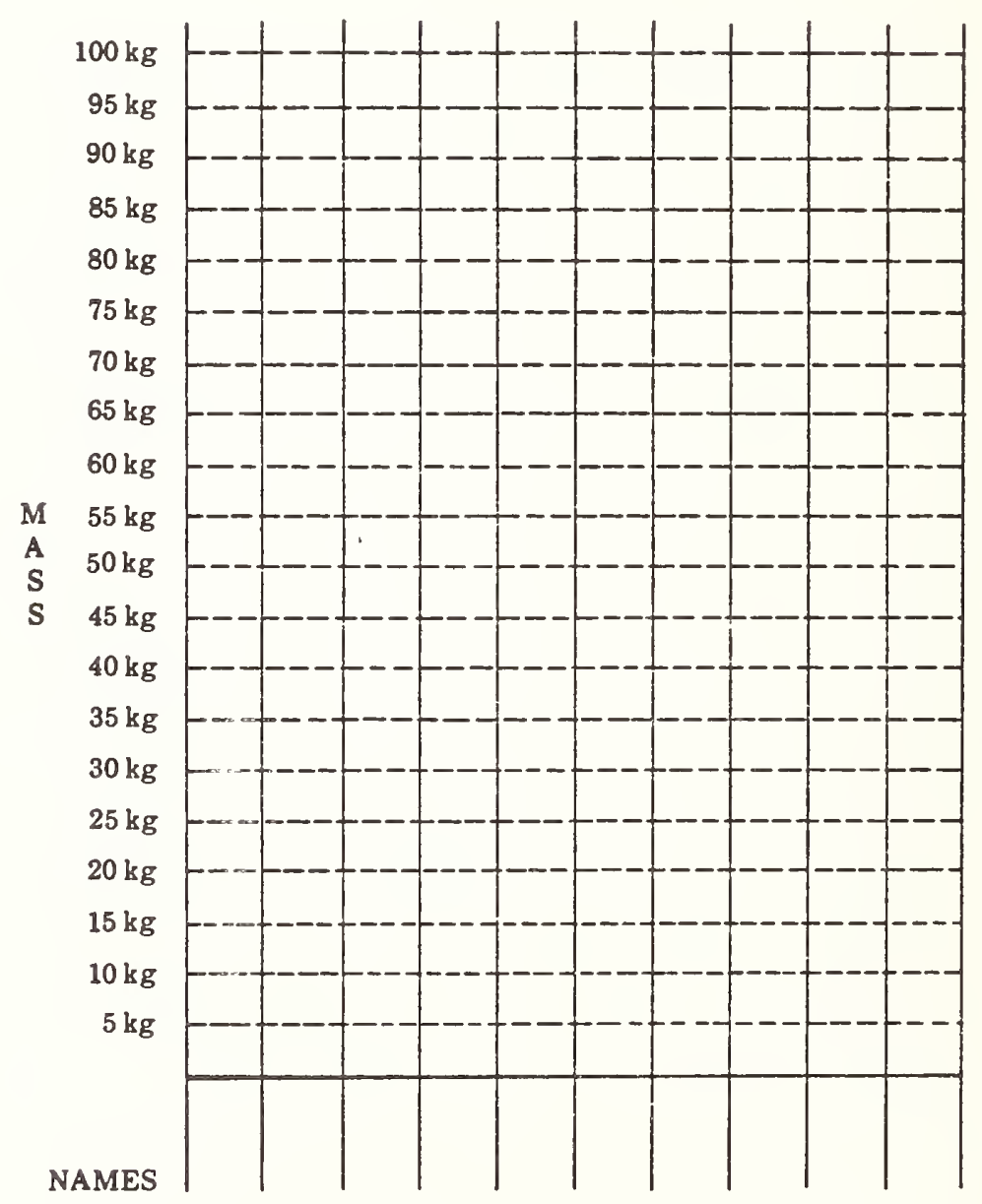

FIGURE 7 


\section{How Much Are You Worth?}

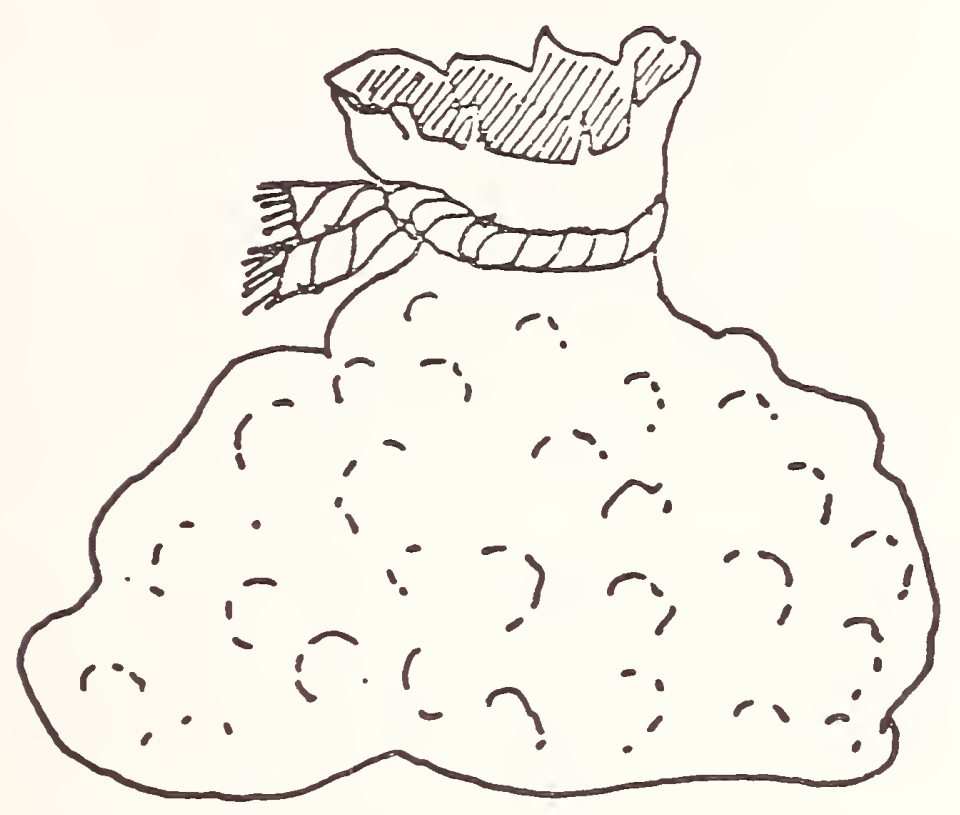

If you had a bag full of pennies which weighed the same as you, how much would they be worth: What equipment would you need to find this out? Tell what you would do to find out. Do it.

FIGURE 8

One of the neatest things about the International system of Measurement is the relationship: one cubic centimeter of water = one milliliter = one gram. The simplest activity to impress this on the mind of students, young and old, is found in Physical Science: Ideas and Investigations in. Science by Dolmatz and Wong. In the activity, the student is instructed to weigh a dry graduated cylinder and record its weight, fill the cylinder to 100 milliliter mark and weigh it again. They are then asked to determine the weight of the water, a simple subtraction exercise. By a series of questions they are led through the mathematical steps needed to determine the weight of a cubic centimeter of water.

The student is then given a small plastic cube-shaped contairer which is exactly one cubic centimeter. He follows the same procedure of weighing and recording the empty and full container and then determining the weight of the water in the small container. He is then asked the question: "How much water do you think is in the container?" His answer will be one cubic centimeter.

When this activity was done with a group of adults, their reaction was, "Oh, how neat." For some chemistry students this simple activity was a real help in understanding the basis of specific gravity concepts. 


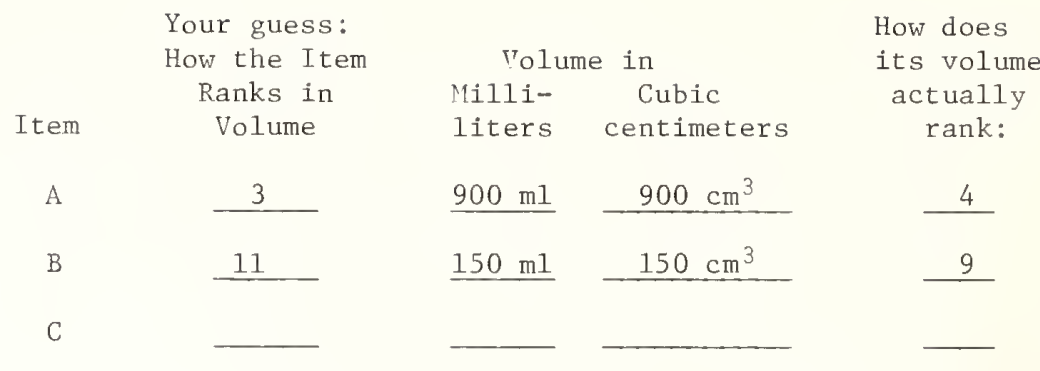

FIGURE 6

However, solids are more appropriately measured in cubic units. Since liquid volume of one cubic centimeter is one milliliter, it follows that the solid volume of the clay object is recorded then in cubic centimeters.

In another method the students use an overflow can and directly measure the solid volume of the object in terms of the amount of water displaced. This then should be recorded in terms of cubic centimeters. In the upper levels this activity, coupled with one to be mentioned later, lead into a study of specific gravity.

If the teacher has used clay in the activity described above, he might roll a chunk of clay into a ball. Ask the students to find its volume. Then, taking the same ball of clay and in clear view of the students, flatten the ball into a pancake shape, making it clear that you have neither used any additional clay nor have you removed any clay. Ask the student to decide if the solid volume of the new shape is less than, equal to or greater than the solid volume of the ball. This should be repeated until all the students realize that changing the shape of a piece of clay does not change its volume.

In designing activities dealing with mass or weight the same basic procedures can be used. Provide sufficient experiences for the student to weigh various objects so that he might gain a feel for the gram and kilogram.

Once the student has developed a certain amount of skill in using the balance and in estimating mass, provide containers filled or partially filled with differing materials. Ask the students to order the containers ( $\mathrm{l}$ use old film cans or pill bottles) by weight. Their estimates can then be verified using a balance.

Don't overlook the obvious. Have the students weigh themselves on a bathroom scales calibrated in metric. (Figure 7) 
Not all activities suit all classes nor all students. Nor do you have to spend a great deal of time and energy designing original activities. Many have been prepared and a little time spent browsing through the various sources on the market will supply you with sufficient ideas for nearly every level of sophistication that you will meet in your classes. At the end of this article, I have included a limited bibliography of sources we have found most useful.

If we design non-threatening activities through which our students can have some successful encounters with metric notation we may hear our students re-echo the words of the student in the limerick:

There once was a student named Peter Who asked, "Why use meter and liter" But when he found out

He let out a shout

"Cause meter and liter are neater!" 
1 Murphy, Mary Oellerich, and Polzin, Maxine A. "A Descriptive Analysis of the Teaching of the Metric System in the Secondary Schools." Science Education. Vol. 53. No. 1, February 1969. p. 89-94.

2 Henry, Boyd. Teaching the Metric System. Chicago: Weber Costello, 1974. p. 8.

3 Delaware State Department of Public Instruction. Introduction to Metric Measurement. Dover, Delaware: Department of Public Instruction, 1974. p. 17.

4 Logan, Barbara. A Manual for Substitute Science Teachers. Dover, Delaware: Del Mod System, 1973.

5 Delaware State Department of Public Instruction. op. cit. p. 29.

6 Boyd, Henry. op. cit. p. 28-32.

7 Ibid. p. 21.

8 Ibid. p. 22. 
Cecil R. Trueblood and Michael Szabo

The Pennsylvania State University

148 Chambers Building

University Park, Pennsylvania 16802

INTRODUCTION

Traditional learning activities in which students play games and "have fun" have been viewed with some skepticism by educators because learning has been viewed as a serious rather than frivolous endeavor. Consequently the use of educational games to some teachers connotes students just "enjoying themselves" without attending to any specific purpose or educational objective.

Academic or learning games were first developed by educators in an attempt to associate "enjoying learning" with achieving specific cognitive or skill objectives in a manner that would reconcile these seemingly incompatible outcomes. Added interest in gaming has resulted from the contribution of gaming instruction to the attainment of value clarification (affective) objectives. Learning games as used in the context of this presentation may be defined as a small group activity structure in which players use or acquire a body of knowledge, skills, and attitudes as resources as they compete/cooperate with other players under specified conditions, rules, and procedures.

We have recognized the applicability of educational gaming to the cognitive, psychomotor and affective domains inherent in learning the metric system of weights and measures. Through metric games students can learn the structure of the metric system and acquire basic measurement skills in a rich and stimulating environment. Therefore, the purposes of this presentation are to describe:
1) the advantages of using metric games;
2) guidelines educators can use to design metric games; and
3) ways in which such games can be used by proponents of metric education.

\section{ADVANTAGES OF METRIC LEARNING GAMES}

Numerous advantages to educational games have been cited in professional literature. The four advantages with high potential for metric learning games are that they can:
1) facilitate cognitive learning;
2) enhance skill development;
3) act as 'a source of motivation, and
4) affect other variables in the educational environment which have considerable impact on learning the metric system.

The impact of games upon cognitive learning has been documented by Boocock and Schild (1968) and Edwards, DeVries, and Snyder (1972). The latter have shown a significant increase on several dimensions of mathematics achievement in seventh grade mathematics classes.

Boocock and Schild (1968) have indicated that learning games substantially improve those skills which are simulated by or incorporated into games. This factor is quite pertinent to metric gaming since basic measurement and estimation skills are central to acquiring competence with the metric measurement system. Indeed, the authors have found that teaching of the basic measurement skills (i.e. the nature of any linear area or volume unit) is a necessary readiness factor to learning any system of measurement.

According to Boocock and Schild (1968), the clearest advantage of learning games is their ability to mntivate students to want to learn. Metric learning games seem to be 
intrinsically motivating for a number of reasons. First, game participants are required to negotiate the games's rules, debate about the correctness of answers and in general interact with one another while they engage in a decision-making process. In short, they must become actively involved in using the game's metric content to become effective players.

Second, as pointed out by Gordon (1972), gaming provides students with the opportunity to exert control and influence over their social environment. That is, their actions switch from being passive consumers of knowledge to active decision-makers and information processors. Game participants thus gain a feeling of being a cause of events in a metric game. In addition, metric games provide teachers with a chance to have participants experience some feeling of success while using the metric system. This positive feeling or attitude comes from being able to effectively compete in a metric game and to exert some control over the game's outcome. In general, this positive orientation and motivation is transferable to other metric measurement activities and helps the student to build selfconfidence in his ability to use the metric measurement system.

Finally, metric games affect other learning-related variables that impact upon the total learning environment. It is readily apparent that learning games promote social interaction among a game's participants. As teachers already know, students do learn from interacting with their peers as well as the teacher. In the case of metric learning games, this interaction would seem to enhance the learning of the game's content, related measurement skills, and general gaming strategies. DeVries and Edwards (1973) have verified a significant peer tutoring effect when students were encouraged to compete with each other on a team basis. Thus it is highly likely that metric learning games played on a team basis will encourage team members to help peers learn the metric measurement system.

It has been observed that the correct use of feedback will positively influence student's academic growth. Allen (1969) showed that games can result in a significant increase in the amount of positive reinforcement in the classroom. Educational games have also been shown to result in less perceived difficulty and greater student satisfaction with class activities. (DeVries \& Edwards, 1973). There is no reason to suspect that these general positive outcomes would differ for metric learning games.

As Gordon (1972) explains, learning games provide the teacher control over various feedback options. It increases the teacher's capability of altering the frequency, immediacy and sources of feedback normally encountered in the typical classroom situation of 30 students to one teacher. This capability stems from the natural reduction in numbers of persons competing for rewards, the student's immediate access to correct answers, and the opportunity to observe the strategies and counter strategies employed by other players. This implies that after making a move in a metric learning game, a participant immediately learns about the correctness of his response and the influence it has upon other players.

A final note on metric learning games is that they can help overcome resistance to change and aid in the development of a sense of relevance concerning what is learned and how it will apply to future situations. These two advantages are particularly important and related to the adult attitude toward the metrication of the United States.

\section{GUIDELINES FOR DESIGNING METRIC GAMES}

A set of general guidelines were developed (Szabo \& Trueblood, 1975) to enable educators to design, produce and evaluate metric learning games for specific classroom applications. They have since been refined by using inservice and preservice teachers attending university courses, workshops and federally-funded inservice programs. Elementary and secondary teachers have used the guidelines to produce and evaluate metric games and related activities that fit into their metrication curricula. These guidelines are discussed in general terms below to focus upon their basic purpose and function.

Establish Specific Outcomes. Carefully choose instructional objectives from the cognitive, affective and psychomotor domains that involve at least two content areas. example, one could choose the common science and mathematics processes of observing, measuring and classifying. This approach which integrates content areas reinforces the philosophy that metric measurement is an integral part of our way of life and is not isolated to one content area such as mathematics. This integrated approach will conserve 
instructional time and promote transfer of metric measurement skills from one subject area to the other. It is also helpful to organize these objectives around a common theme because common themes are suggestive of other games and can be used to relate metric games to other on-going classroom activities.

Write Simple Rules and Procedures. Rules and procedures are crucial to making a game self-instructional and student directed. It is essential to keep the rules simple and straightforward so that play moves quickly from one player to the next and to promote maximum involvement in the game. Include in the rules and procedures how the game begins, how a player obtains feedback concerning his answers or decisions, and what scoring procedure will be used. The rules and procedures are crucial because they determine which player strategies will work and fail, the kinds of decision making that will be encouraged and what resources the players are permitted to use.

Use Simple Materials. Most metric games can be constructed by using simple, inexpensive materials consisting of some combination of the following: a playing board or surface, the pieces or tokens out of which the game is built, the decision devices such as dice or spinners and the task determiners such as card decks or written instructions on the playing surface. Task determiners communicate whether there is to be individual winner or 1oser, and/or collective team effort. They also establish how the pieces or tokens are to be used to gain points or to trap an opponent's pieces or tokens during the game. Figure 1 shows a typical game board used extensively by the authors.

Provide Immediate Feedback. Immediate knowledge of results is one of the key features of an instructional game which provides motivational and instructional impact. In most cases feedback can be built into a game by using one of the following: an answer deck, a student leader whose level of competence will allow him or her to make reliable judgments, or the back of task cards used to direct the player's activity.

Build in Some Suspense. Experience has shown that games enjoyed by the players contain some element of risk or chance. This can be incorporated into games by using random decision devices such as dice or spinners or by placing instructions on the game board that arbitrarily change a player's status in the competition. Card decks that administer reward or penalty points also help create some suspense. These suspense-creating features which help keep the difference between the players' scores at a minimum apparently help make the game a "fun game."

Have Students Record Diagnostic Information. Supplying each student with a score is an important feature of each game. The score sheets help the teacher to judge when the game should be altered to make it more challenging, to decide which players should compete with each other, to select student leaders and to decide when to terminate the game. The score sheets also supply players with a record that shows individual scores across each round of the game and serves to motivate them to improve. This feature can be built into most games by using numbered task cards, by having the student leader place cards yielding right answers and cards yielding wrong answers in different piles, or by having the student leader record the results of each player on a class record sheet. A sample score sheet is included in Figure 2.

Create the Game to Allow Variation. Games that allow the teacher to quickly create a variation through minor rule or material modifications have the most potential for success. This is true for two reasons. First, it keeps the game from becoming stale because the players know all the answers and decision points. Second, the teacher or players can modify the game without a large time investment.

Evaluate the Game. Try the game with a small pilot group of students. Use the firstround score sheets as a pretest. Keep the succeeding score sheet in the correct order. By comparing the first with the last-round score sheets for specific students, a decision about the achievement of the stated instructional objective can be reached. Filing the score sheet according to the various game's instructional objectives will provide a longitudinal record of a student's progress as well as diagnostic information for future instruction. Finally ask the players if they enjoyed the game by using self-report forms such as a faces inventory or a short questionnaire. 


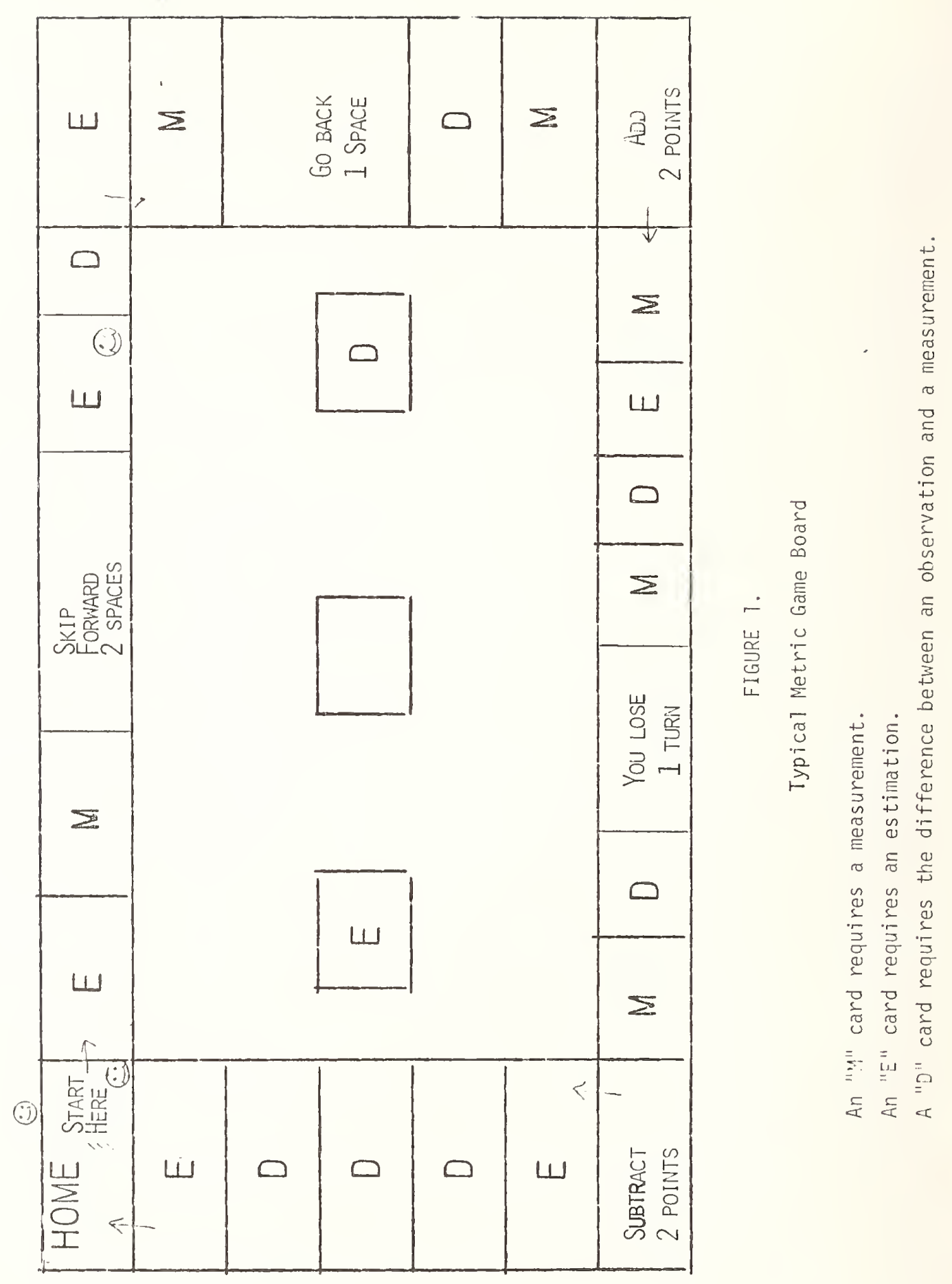




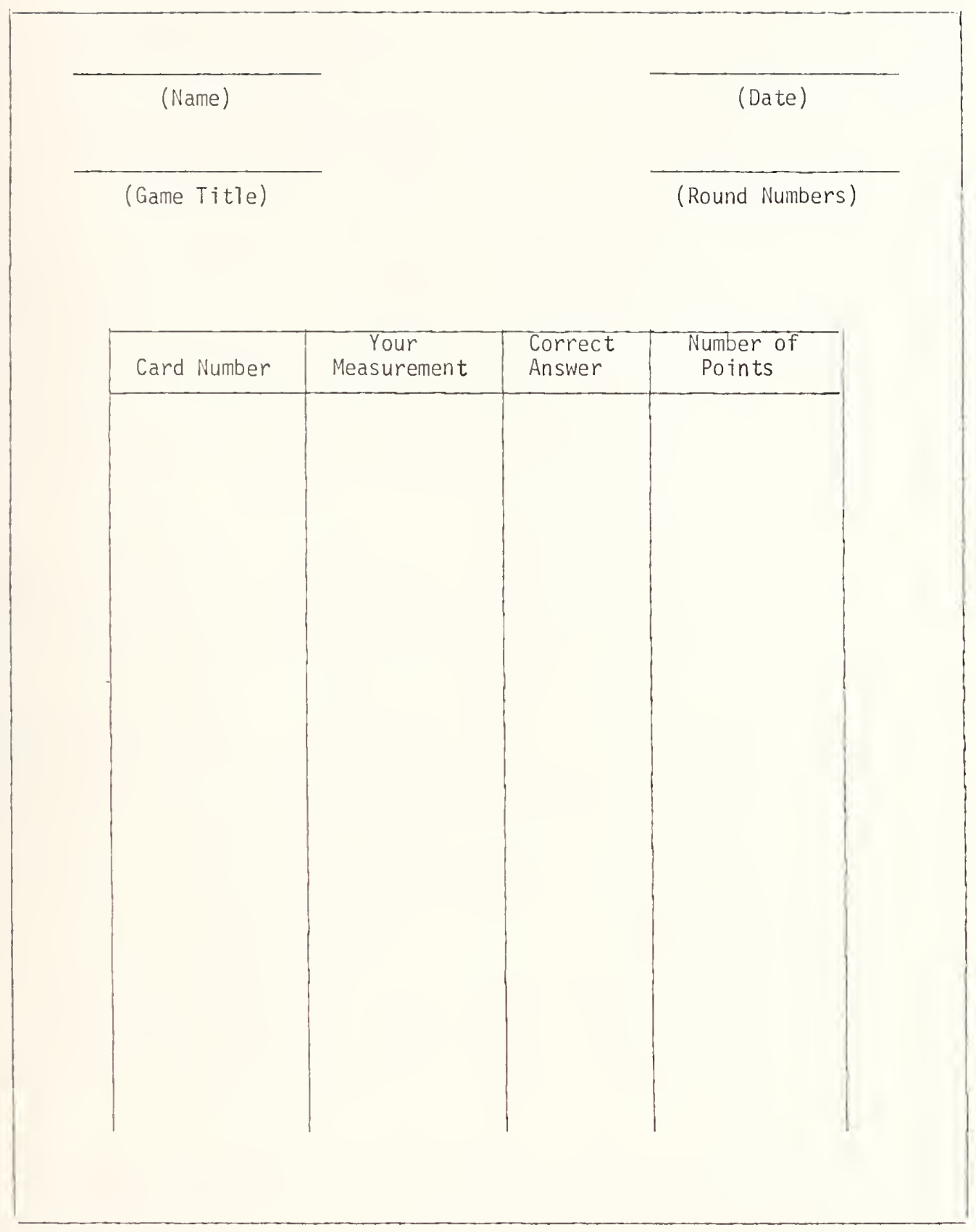

FIGURE 2.

Student Record Sheet for Metric Game 
Potential uses for metric games are limited only by the imagination of the instructor. Four ways in which they have been successfully used include teaching, diagnosis, evaluation, and teacher training.

Teaching. Used in a teaching role, metric games can effectively teach students in a variety of areas simultaneously. Basic measurement and estimation ski11s can be learned and practiced through games. Cognitive knowledge of the metric system (e.g., units, prefixes), the interrelationship of the parts of the metric system, and the application of the metric system to the acquisition of new knowledge through problem-solving can also be taught. Social change and positive attitudes for adopting the metric system with minimal social disruption can be stressed using the same learning game.

Diagnosis. The concept of teacher as diagnostician can be applied through numerous testing and evaluating environments, including gaming. A diagnostic approach to teaching begins with a diagnosis of learning needs whereas nondiagnostic teaching typically begins with some form of norm-referenced instruction. Metric games can be used to identify either those areas of inadequate knowledge and skills for a class of students, for smaller subsets of the class, or for individuals. Although the latter cases require more teacher time, an effective records keeping and materials distribution system can greatly reduce the time and work involved. For example, to be used in the diagnostic process, a procedure for recording student performance during the first several times students play a particular metric learning game should be designed. Obviously the procedure should vary depending upon the type information desired.

As an example, if the teacher wanted to know whether students knew the meaning of the prefixes used with each metric measurement unit, the teacher could simply provide each player with a record sheet. These forms when collected at the end of the two gaming periods would tell the teacher which prefixes the students know and do not know. Thus the forms from each student can be used to decide which prefixes should be encountered most often in succeeding rounds of the game by the game participants.

On the other hand, if a teacher were interested in a student's ability' to measure and record an object's length correct to the nearest centimeter, the teacher could compare the results reported by a student on a score sheet with his or her pre-established criterion. The results from several gaming periods would then show how many other times that particular game or a modified version might be used to help students who consistently scored below criterion.

Evaluation. Metric games can 'serve as evaluation instruments to assess learning outcomes which are expected to result from direct instruction, other learning games, or other teaching techniques. As an evaluation device, games can complement or replace traditional paper and pencil tests which measure a highly verbal and limited portion of a learner's knowledge. That is, they permit the direct evaluation of actual measurement and estimation skills and enable the teacher to observe given dimensions of related social/ affective behaviors in a somewhat controlled environment. The visual reality and performance aspects of such testing may help to ameliorate the academic differences between racial, cultural, and social classes which are highly bound up in verbal testing (Semler and Iscoe, 1963; Securro and Wa11s, 1971).

Teacher Training. Teacher training is traditionally viewed as inservice or preservice. The former involves practicing and experienced teachers with quite specific educational interests and styles. Metric games are quite useful with these teachers in that the games are easy to conceptualize, design, and field test. The results are usually so encouraging that the teacher is quickly convinced of their value.

Beginning preservice teachers usually have not yet focused their interest and attention on one classroom or school unit and thus need training at a somewhat more diffuse and abstract level. For them, metric games can be used as a mode1 for mini-curriculum development, an alternative to the type of classroom experience so pervasive of recent experiences of the university student, and an introduction to a variety of learning structures including small groups and individual student attention. 
Both inservice and preservice teachers have developed and used metric games as one component of their professional development. As one example of the former, interdisciplinary metric games for use in various grades with elementary and secondary students.

Students in elementary matheriatics education courses at The Pennsylvania State University regularly develop metric learning games and acquire a good deal of information about the metric system in the process.

The authors' experience in the use of metric games also included curriculum specialists in school districts who hold major responsibility for implementation of a metric curriculum. Among other considerations, these persons were concerned with the best efforts with a cautious eye to spiralling budgets. The appeal afforded by metric gaming to curriculum specialists resided in the fact that teachers can develop appropriate games at minimal cost (even when extra compensation for curriculum development efforts are counted) to the school district. Furthermore, the materials developed seemed more likely to be tailored to the unique needs of the particular school districts. In comparison the costs of commercially made instructional games and metric curriculum materials are presently quite high and corresponding quality, in the authors' opinion is highly variable with a tendency on the poor side.

An attempt to provide the above information to school administrators resulted in presentations of workshops on "Gaming and Metric Education" at the State leve1 (Pennsylvania Association for Supervision and Curriculum Development, November 1974) and the National level (National Association for Supervision and Curriculum Development, March 1975). These sessions were extremely well attended and numerous requests for added information have been received.

A final note on the usefulness of metric games: The authors concluded early in the game that their efforts to train individual teachers would be severely limited by the sheer number and geographical dispersion of those to be trained. Thus, the concept of leadership training workshops for metric education was developed. The essence of this idea is that leadership teams from schools, districts, or intermediate units would be trained to in turn conduct metric education workshops with school personnel at the local level. Needless to say, the development of metric games plays a large and successful role in these leadership workshops.

At present, the authors have developed a comprehensive plan for metrication of public schools on a statewide basis through leadership training workshops. The plan is being adapted to meet the needs of an Intermediate Unit (serving 17 school districts) and one large and one moderate size school district in Pennsylvania. 


\section{REFERENCES}

Allen, L. E. EQUATIONS: A GAME OF CREATIVE MATHEMATICS. New Haven: WFF N' PROOF, 1969 .

Boocock, Sarane S. and Schild, E. 0. SIMULATION GAMES IN LEARNING. Beverly Hills, SAGE Publications, Inc., 1968.

DeVries, D. L. and Edwards, K. J. LEARNING CAMES AND STUDENT TEAMS: THEIR EFFECTS ON CLASSROOM PROCESS. American Educational Research Journal. 10 (4), Fal1 1973, 307-318.

Edwards, K. J., DeVries, D. L., and Snycier, J. P. GAMES AND TEAMS: A WINNING COMBINATION. Simulation and Games. 2, 1971, 425-454.

Gordon, Alice K. GAMES FOR GROWTH: EDUCATIONAL GAMES IN THE CLASSROOM. Chicago: Science Research Associates, 1972.

Houser, Larry L. (Ed.) METRIC SYSTEM INSTRUCTION: AN INTERDISCIPLINARY APPROACH. Westminster, Mo., Carroll County Board of Education, 1974.

Securro, S., Jr. and Walls, R. T. CONCEPT ATTAINMENT OF CULTURALLY ADVANTAGED AND DISADVANTAGED CHILDREN USING ARTIFICIAL AND LIFELIKE STIMULUS TASKS. Journa1 of Educational Psychology. $62,1971,531-538$.

Semler, I. J. and Iscoe, I. COMPARATIVE AND DEVELOPMENTAL STUDY OF THE LEARNING ABILITIES OF NEGRO AND WHITE CHILDREN UNDER FOUR CONDITIONS. Journal of Educational Psychology. $\quad$ 54, 1963, 38-44

Trueblood, Cecil R. and Szabo, Michael. PROCEDURES FOR DESIGNING YOUR OWN METRIC GAMES FOR PUPIL INVOLVEMENT. In Higgins (Ed.) A Metric Handbook for Teachers. Reston, Va.: National Council of Teachers of Mathematics, 1975. 


\section{METRIC IN PRESERVICE TEACHER TRAINING}

Dr. John Lindbeck, Director

Center for Metric Education and Studies

Western Michigan University

Kalamazoo, Michigan

49001

I am going to talk to you this afternoon on preservice education programs. There is so much one can say about this, that what I am going to do is take the liberty of'simply describing what we did in the Industrial Education Department at Western Michigan University to establish a preservice program in metric education. In talking to industrial trainers, training and development people, retail and office personnel who are in charge of training programs, one factor emerges: to treat metrication costs and activities as routine business expenses. You have heard that many times. If you subscribe to the Metric Reporter, you have heard these words spoken and you have seen them written many, many times. This is so important to training and development programs in industry; it is equally important to training education preservice or inservice in public education.

It is a mistake to suggest to your administrators that in order to accomplish metric change in your institution, you have to set up an elaborate organization and get special funding. While it would be nice to have money to operate a little more freely, it is important to just take metrication in the stride of a normal, routine, inservice program that you have to offer in any school in the country.

Very specifically, I want to talk to the points in figure 1 as they relate to getting a group of fifteen faculty members who know nothing about metric, and welding this group into a team that can accomplish metric change most efficiently and at the least possible cost. This is the task for everyone associated with preservice programs. By preservice I mean the "pipeline" student. We are concerned with the student who is enrolled at Western Michigan University in the Industrial Education Department right now who is going to graduate as an industrial arts or vocational education teacher, or go into industry as training and development personnel. Preservice involves these persons.

One of our first tasks was to appoint a metric coordinating committee. A coordinator should be a person in the department who is committed and interested in metrication. He had read about this, he had perhaps attended a few seminars, he vas keenly concerned with what should be the approaches and what were some of the problems or issues relative to metrics as it pertains to industrial education teachers.

1. APPOIIT METPIC CMDPIMINTING CNMITTEE

2. TRAIN FACILTY

3. DEVELDP METPIC PLMI

4. PLAM STIMEST MnIILF.

5. PLAN TECHNICAL LAP, ACTTVITTES

6. EVMLINTE ADD MONIFY

7. UPDATE FACIILTY 
To train the faculty was the next step. One of the first things this committee did was to train itself, and they did this through our Center--six of the faculty members underwent a metric seminar training program that lasted about 30 hours. They are a very well trained group. We were fortunate in being able to handle it that way. Not all schools can and it is unfortunate, but there are other options that we can talk about. But the faculty has to be trained also, and you have to decide exactly how you are going to achieve this. Are you going to take 30 minutes from each of your faculty meetings and lock everybody in to an introduction to SI and then begin looking at some of the particular concerns as they relate to drafting laboratories, graphic arts, wood technology, metal technology, etc.? There are many ways of achieving this also. But one has to give some serious thought to providing faculty with the necessary training to do a job.

Concomitantly, this committee is developing a metric plan for the entire department. Exactly how are you going to achieve this? What kind of a time line are you concerned about? You are also concerned about costs--how you can phase costs in and out--remembering my first statement, "Treat these as normal business expenses insofar as possible." Many other issues surface as a committee begins looking at specifically what the training needs for the department are.

Planning a student module is also important. It was decided that the best way to effect metrication, insofar as the student was concerned, was to get a self-teaching program for the students. And, fortunately, a U.S.O.E. project going on at Western, produced such a program., It was "Going Metric for Students." It is a self-learning program and it takes about a half' hour. We had that option, or there are several commercial booklets available which can give a student a pretty good introduction to SI. We were after a simple overview and then locking them into the units they would be most likely to need in an industrial education program. We decided on Going Metric for Students package with some modifications-we wanted to update it with some other materials. We tried it out on some pilot groups and it worked well. When a student has gone through this module, he takes the self-administered test, turns it in to any one of a group of faculty who issues him a little card as a certificate of completion. There was some discussion about giving college credit, but we decided against it.

Planning technical activities was the next phase. I show you an example as Figure 2. We are looking at a means of providing initial metric learning experiences in, for example, a drafting program. The students take three courses and they can take more beyond that if they are going to specialize in certain phases of technology. In a first course we give them an initial laboratory experience which takes from two to four hours. I say from two to four hours--it depends on what labs they are in. Woodworking lab requires a little less than metalworking or the drafting lab so there is a variance there. These are initial experiences in using measuring tools, becoming familiar with the units that are used in that particular course, and looking at product and engineering standards. That is one thing we haven't really talked about at all here today because most people in the room are not concerned about product and engineering standards. We in industrial education are because we have to worry about replacement sizes for lumber, for metal tubing, barstock, screwthreads, rivets, pressures for welding tanks, etc. Until these standards are developed and approved, we can only make intelligent guesses as to what these are. These are some of the things that we have to be concerned about.

Next there is the matter of evaluating and modifying as the program commences and you get feedback from students. You can make adjustments--you can make changes. For example, this is one thing that has already occurred: We had allocated far too much time to helping students learn to read a micrometer and a vernier caliper. We were considering perhaps an hour--you can do it in 15 minutes. Understand, all these students know how to read a customary inch micrometer and vernier. So we are not teaching them how to use a vernier caliper or a micrometer. Instead, we are showing them that there are different numbers on the tool, so they are going to read it differently. It didn't take as much time as we thought; we modified the program accordingly.

A final important point is updating our faculty. Let me give you an example. There was a workshop in power and energy--auto méchanics, if you will, and small engines--last summer that was heavily oriented towards matters of metrication as it relates to that whole discipline. One of our persons, the person in charge of the power/auto area, went there. 
We contributed to his expenses. We try to support'people however possible, because it is important that you do constantly update thenl and keep them apprised of changes. As new products in engineering standards come out, for example, we get notification of this through the ANSI Reporter or the Metric Reporter; you immediately write for copies of these and you make sure standards get disseminated. Everybody who is interested or has to know something about these should look at them.

Now, let me refer you to one of these programs in a technical area (See figure 2), This is partial--it goes on for another page--but I think this is sufficient to give you an idea how we structured this. Our concern is merely to set up a series of introductory learning experiences. This happens to be in the drafting $1 \mathrm{ab}$. You can see, "Given the metric dravings, students will be able to identify and record metric linear dimensions in millimeters, etc. Define and identify the characteristics of the following measurement units as they apply to drafting." These are the four units, length measurement units, of course, that will be used in drafting. You want them to be aware of these--and you say, "What's the kilometer doing in there?" They do mapping also and so they have to know that one. And in some sensitive machining operations they are dealing with micrometers of surface finish, so that is an important one too.

Then there is the matter of converting metric dimensions to inch dimensions and so on. You will note that there are three other references to converting. We recognize that in industrial education programs you have to convert. Because we have dual dimension drawings which we are using in industry, and whenever you have dual dimension drawings, a conversion issue is at stake and we have to have people understand what this means. We have them understand it and achieve some skill in it by making them do it. This is what I am concerned about as I speak about conversion.

I will maintain that the idea of having dual readout micrometers or other instruments is not a bad idea. I don't see a great deal of harm in this--there are pros and cons certainly. They don't cost any more, they can be used either in customary inch readouts, or they can be used in metric. (I don't want to get philosophical regarding this. I am trying to be as pragmatic as possible.) If for a teacher in a given situation it makes more sense for that person to buy dual readout tools, do it. If you are going to achieve something with it, do it. Don't be concerned that, "I wonder if I am going to ruin the psyche of this little child when ten years from now they are still going to be using that inch ruler as a crutch and not be reading the metric scale on it." I don't really think it is that serious. If you wish to work in straight metrics, purchase appropriate tools.

The last point is that with these particular kinds of skills and knowledge forming activities we try to make sure that students have a basic knowledge of the units which are used, metric units used in that particular program. We also want them to have an understanding and appreciation and a certain amount of skill in the measuring instruments, the tools, the machines that are used in that program. In the metal working program, these are: the machinist's rule, $150 \mathrm{~mm}$ rule, generally; vernier; micrometer; lathes--we have an allmetric lathe and we have converted a milling machine with special dials. We want students to understand the operation of each of these and actually practice with them by doing some things. We have some simple exercises in one program. In another program it is actually building a metric product in wood. We want them, furthermore, to understand the elements of product and engineering standards which I mentioned to you just briefly. That is very important to them. So these three components are reflected in every technical activity for a particular area.

I was very impressed and very pleased to get the report of Dr. Chalupski's project dealing with inservice education in Australia and England. I hope he talks briefly about the recommendations he makes in the back of the manual which relate to what are some of the concerns that Americans should have as they embark upon inservice and preservice educational programs. We can learn something from the Australians and from the English who are going through this. It is important that we all recognize that there is no one way of achieving preservice programming. There are so many ways of having this come about. I am asking (I) that you look to that first statement I made, and that is to try to treat these as normal business expenses and activities insofar as possible, and (2) that you very early get into a planning session, get some kind of strategy or planning group organized at your institution. We at Western Michigan University have planned for it; when the crunch comes, we are ready. We have looked at options; we have even tried some things out. These are the hallmarks of successful preservice metric programs. 


\section{A. Drafting}

The purpose of this educational experience is to assure performance of the following tasks by drafting students.

1. Given a metric drawing, they will be able to:

a. Identify and record metric linear dimensions in millimeters utilizing standard dimensioning practices.

b. Define and identify the characteristics of the following metric measurement units as they apply to drafting:

$$
\begin{aligned}
& \text { 1. } \mathrm{km}=\text { kilometer } \\
& \text { 2. } \mathrm{m}=\text { meter } \\
& \text { 3. } \mathrm{mm}=\text { millimeter } \\
& \text { 4. } \mu \mathrm{m}=\text { micrometer }
\end{aligned}
$$

c. Convert metric dimensions to inch dimensions using the conversion table found on a drawing.

2. Given a list of dimensions identified by inch or millimeter symbols, they will identify the unit of measurement and:

a. Convert inches to millimeters (multiply inch dimension by 25.4 ) and round to the proper number of decimal places in the dimension figure for equivalent accuracy.

b. Convert millimeters to inches (divide millimeter dimension by 25.4 or multiply by 0.03937 ) and indicate the proper number of decimal places for equivalent tolerance.

c. Convert inches to millimeters or millimeters to inches to appropriate decimal specifications by reading from a conversion table.

3. Given a list of standard abbreviations and symbols, they will be able to define and explain the application of each.

4. Given proper tools and a workpiece, they will display the skills required to:

a. Measure identified parts with a metric rule to an accuracy of $0.5 \mathrm{~mm}$.

b. Measure identified parts with a metric micrometer to an accuracy of $0.02 \mathrm{~mm}$. 


\author{
Phillip T. Larsen \\ Center for Metric Education and Studies \\ Western Michigan University \\ Kalamazoo, Michigan 49001
}

During the past two years, requests for inservice workshops in metric education have increased at a rapid rate. This seems to indicate a growing awareness and need for training in metric education on all. levels. However, many of the school personnel making these requests lack adequate background in the area of metrics to know what kind of training is needed for their staffs. Recently a local school superintendent called to request a workshop in metrics. After raising several questions about his staff and the type of workshop he wanted, he interrupted me saying, "Don't make this so complicated. All I want is a standard presentation in metrics." A short time later I found out that the school district was trying to fill-in a time slot on an inservice day and the superintendent, who recently attended a conference, had heard the charge for schools to prepare for the conversion to the metric system. This experience along with several others pointed out the need for a plan to help school administrators formulate a structure for metric education inservice workshops.

If the colleges and universities are to be of service to the schools in providing metric education, then the needs of each school and/or school district should be determined. What is needed, is a set of guidelines that will enable those responsible for constructing metric workshops to plan according to the specific needs of the schools. One way to achieve this end is to raise certain questions about the background and goals of both the schools and the community. When a request for a metric presentation or workshop is made by a school dis-trict, an attempt should be made to obtain as much background information, by the workshop planners, as possible. A form used with the school personnel requesting a metric workshop is shown in Appendix A.

Why do you want a metric education workshop? Very often this question determines whether the training staff should even consider any further involvement in the planning and conducting of a workshop. Too often those requesting the training want their staffs to become involved in metrics for the wrong reasons. To tell early elementary school teachers that they will have to know all about SI metrics, practices, prefixes and units in order to teach their children, is a wrong reason. The major emphasis for children of this age group should be on the development of the concept of measurement with a focus on the development of the child and how he learns.

Once the reason for conducting a metric workshop has been established and appears worthy of support, then the objectives of the workshop should be listed. In other words, what do the participants hope to get out of the workshop? These objectives can be identified by either the requesting school or by the training staff but in any case these objectives must be stated clearly and the entire workshop is then built on this foundation. The type of workshop is usually dictated by the objectives. The three most common types of workshops, Awareness, Orientation and Implementation, may have some similarities in structure and content, but the overall goals of the three types of workshops are quite different.

\title{
Planning a Metric Workshop
}

Although information may not be obtained from all of the questions on the Metric Inservice Workshop form, an attempt is made to secure as much background data as possible about the schools, students, teachers and community. Some background information has proven helpful to the trainers for both planning and conducting the three types of workshops. 
In order to plan an effective workshop, the following information concerning the workshop participants is necessary: the function or type of participants, teachers, administrators or instructional specialists; the extent of background of the participants in metrics; the number of participants expected to attend; and the reasons or incentives for the participants to attend the workshop.

Poor timing of a workshop may lead to built-in failure for the workshop. A five-hour session after the school day, the day before Christmas vacation or an all day Saturday session for teachers may induce a high level of animosity into the workshop, thereby resulting in failure for the workshop. Another possible built-in failure may result from the administration requesting the workshop for the teachers. The administration of a city school system recently requested an all day orientation workshop to be conducted on a Saturday. Fifteen minutes into the workshop, it was quite obvious to the workshop training staff that these teachers had no interest in metrics, children, education or anything else for that matter. They were openly hostile and more rebellious than the children who sit in the classroom and defy you to teach them something. In talking to the assistant superintendent it was learned that the teachers had already attended a number of Saturday sessions and that the administration was penalizing the staff for going out on strike earlier in the year. In essence the teachers were compelled to attend and they were going to be trained in metrics whether they liked it or not.

Sometimes limitation or restrictions are imposed upon the structure of the workshop. Often these limitations are uncontrollable and no one can be faulted for this. However, these limitations can be dealt with in such a way as to minimize any adverse effects on the outcome of the workshop. The location, types of facilities and length of the workshop are examples of these. The size, structure and types of room to be used for the workshop may make the difference between success and failure. Activities may require flat tables, sinks, electrical outlets, chalkboards and/or projection screens. If none of these are available, the variety of activities to be conducted in the workshop will be severely limited.

Most requests for metric workshops include a desire to have hands-on experiences. A variety of visual aids and demonstration activities will also encourage a greater degree of involvement on the part of the participants. For teacher workshops, too much talking or lecturing seems to inhibit the progress of the workshop. As the structure of the workshop develops, determination of the content to be covered must be made. Some of the content areas that are included in many of the metric workshops are: the status of metrics; SI metrics: the concept of measurement; specific measurement concepts such as mass, weight, length, volume, and temperature.

The type of collected data discussed in the foregoing is useful in planning any of the three general types of metric workshops. An example of collected data for each of the three types of workshops is shown in Appendix B.

\section{Orientation and Implementation Workshops}

In an Orientation or Implementation Workshop participants begin thinking about how metrics will affect the school's curriculum, classroom structure and teaching methodology. Therefore information about the curriculum programs, textbooks and classroom activities will enable the workshop planners to develop a structure that will integrate a metric education program into the existing curriculum. As much as possible the workshop design should employ teaching strategies consistent with the philosophy of the school district's curriculum. This will not only facilitate integration of the metric program into the curriculum but in most cases reduce the anxiety of many teachers who feel they will be forced to add another program to an already overburdened curriculum. Teachers are also apprehensive about having to change their teaching styles or entire curriculum to reflect a dominance of the metric system.

An implementation workshop requires more extensive planning than other types of workshops. Information concerning the background of the teachers will increase the chances of the metric education program being implemented into the classroom. First, community and student data is needed by the workshop planning staff to insure an integration of metrics into the curriculum in order to achieve the goals and objectives of the school. A second very important reason for collecting this background information is to utilize some of the 
natural resources and talents available locally. Traditionally most areas of education have overlooked the resources closest to them.

What kind of structure should the metric curriculum have? Should it be an add-on? Should it be integrated into the existing program? Should this be a unit in the mathematics program? These questions must be answered by the school's personnel, usually in conjunction with the workshop staff. The needs of the school district are the next major consideration in determining whether the school will adopt a commercially prepared metric program, a portion of one, or construct both the materials and program in metrics. Unfortunately much of the materials and programs available in metrics leave something to be desired; consequently, many school districts are developing their own metric programs.

The background of students, teachers and community have now been compiled. Parameters for the workshop have been established and the basic structure decided. What is now needed is a plan for implementation into the classroom. This plan is determined by whether the workshop function is to train trainers of teachers in metrics or to prepare teachers to teach metrics in their classrooms. Although there is some overlap in the training of the two groups, the major emphasis for each group is somewhat different. Appendix $C$ and Appendix D provide examples of some possible characteristics and activities of each of the two types of workshops.

The workshop for teachers should provide them with an opportunity to engage in a variety of hands-on activities. Many of these activities should be the same as those used with the children in the classroom. Practice in developing metric units including the writing of course and lesson objectives, lesson plans, and methods of evaluating student progress can reduce the anxiety exhibited by many teachers who are being exposed to metrics for the first time. The identification of the measurements concepts and metric units to be taught in conjunction with certain areas of the curriculum, and at specific grade levels, is an essential activity in a teacher workshop. By the conclusion of this workshop each teacher should have developed a unit that could soon be implemented into his or her classroom. Also the teachers will have accumulated a number of ideas, materials, activities and listings of available resources for direct use in the classroom or for development of other metric units.

The workshop for trainers should include most of the teacher workshop activities as well as training in: how to conduct a workshop; SI metrics; the rationale for going metric; methods for evaluating metric materials; construction of metric activities; and techniques for evaluating the usefulness and effectiveness of the classroom metric activities.

There appear to be certain elements that are common to successful workshops. Hands-on activities, discussions of the relationship of the experiences to child development, demonstration of various teaching strategies and an emphasis on the development of the concepts of measurement are several of the more pertinent common elements of successful metric workshops.

When planning any of the three types of workshop it is worthwhile to determine what kinds of follow-up will be needed. If possible, long-range plans should be established to insure continuity and efficiency in developing a comprehensive training program in metrics that will facilitate the implementation of the metric program into the school's curriculum. Sometimes teachers have had a bad experience in a metric workshop or training program and this would tend to inhibit implementation to a greater degree than no prior training. If a metric workshop is worth doing, then it is worth doing well. 
Date Received

Contact Person

Telephone

Address

Type of Activity
Date of Activity

Agency

Address

Time Leve1

Area

Staff

METRIC INSERVICE WORKSHOP

Reason for Workshop:

Objectives of Workshop:

Type of Workshop: Awareness-Orientation-Implementation-

What Group of Participants? Teachers-Administrators-Sec Sci Teach-Sec Math Teach- E1 Instru Spec.-Mid Sch Teach-

Number of Participants:

Length of Workshop:

Participant Incentives: Inservice Day-College Credit-Paid Rate-Union Supported- Cred Sal Guide-

Time of Workshop: Day, Day and Hours

Request Initiated by: Teachers-Administration-Union-

Workshop Structure: Activities-Hands on Experiences-Discussion-Talk-Film-FilmstripsTransparencies-

Content Emphasis: Awareness-Status Metrics-Concept Measurement-SI Metrics-Mass-WeightLength-Volume-Temperature-SI Practices-Adv Physics Concepts-

Location and Facilities: Desks-Flat Tables-Water Outlets-Electrical Out lets-Projection Screen-Moveable Chairs-Chalkboard-

Status of Participants: No Metrics-Aware Metrics-Some Train Metrics-Teach Metrics-Update Metrics-

Textbooks or Curriculum Programs:

Educational Philosophy: Traditiona1-Open Classroom-Demonstration-Inquiry-Discovery-LectureProblem Solving-

Background of Students Teachers Community:

Structure of Metric Curriculum: K6-K12-Add On-Integrated-Shot Gun-Construct- 
Plan for Implementation: TRAINERS - TEACHERS

Long-Range Plans: Orientation-Implementation-Middle School-High School-Entire District- 
Examples of Inservice Workshops in Metric

REATON FER WORYSIMP

$\longrightarrow$ OBJECTIVES OP HORKSHOP

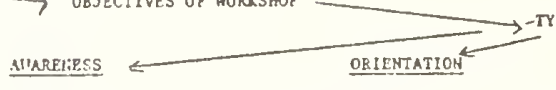

Adminietrator

Mutber of Participants? length of lodkshop?

Inoentive for Portcimants?

Tine of lorkshop?

Tequest Initiated by?

ibrksitop Stnucture?

Content DThasis?

Location and Facilities?

Status of the Participants?

25

1t hours

Inscrulce Day

Hon, Peb 8

9:00am-10:30am

Teacher6

Kinds-on Activittes, Films and Filmstripa

Status of Nietries, ijationally,

In the Schools and Cotmunity

Adoinistration Bullding, tables cha1rs and projection screen

Little Background in thetrics

Tertbocks or Arrriculur Prograns in School?
Bducational Philosophy? Teaching Strategies?

Badioronud of Students? Teacners? Commuty?

stricture of letric

Curriculum?

Plan for Irplementation Into The Classroom?

lang-Range Plans
Inquiry strategles and problem solving thods used in sciences

Secondary School
Sclence Tescher
40

\section{OP WORKSHOP \\ $Y$ IMPLEMENTATION}

Elementary School

Teachers

65

5, - 6 hour days

2 credit hours state

University

Mon-Ex1, July 13-18

9:00 am-3:00pm

Teachers

Ilostly Hands-on Activitles

Fllostrips and Transparencles

Length, mass, volume, concept of measurement and related SI metric density

Temperature and Forces

Central H1gh School, tables cha1rs and projection screen

Have knowledge of retrics, use in lab and solving conversion problems

Iraditlonal Type Textbooks in all areas except SclenceBSCS, Chem Study ana project physics. Introductory course In calculus is the bighest math course

Hest S1de Elementary School, Classroom desks, 4 flat tables and projection screen

Most participants attended an awareness workshop in metrics last March

Houghton-Mifflin Reading Programs SCIS Science Program and 8 new activity orlented social studies program are used. The elementary programs are mostl, activity orlented.

Discovery strategy most prevalent in the elementary school. Childcentered and process oriented approach.

Students are of average abillty, interested in outdoor activities and sclence. Teachers are cooperative and work in joint projects. Surburban comanity with light industry and local businesses. Very supportive of schools. Parents do volunteer work in schools.

Teechers would like to construct the own curriculum $\mathrm{K}-6$. The metrics must be integrated into all sreas of the elementary school curriculum.

\section{$\underbrace{\text { TRE }}_{\text {TVCS OFERS - TEACHEPS }}$}

Relate the objectives of the workshop Provide the rationale for going metric Compare customary units w1th Metrie units

Identify Preferred units of Length, Mass Volude and Temperature in metrica Show technique for evaluating metric materials

Construct some metric activitics

Integrate metrics into the curriculum

Participate in hands-on activities

Show Evaluation techniques

Write course objectives in metrics Select activities for specific grade level Identify activities that are $r \geqslant$ lated to specific disolplines

List needs, 1nterests and abilities of students

Develop $s$ metric unit that integrates cerrics into all areas of the curriculuo Construct brief daily lesson plans in metric Cite method for evaluating student progreas.

Teans of 5 teawers from each

An orlentation workshop for teachers in 5 proje:t schools has been plarred for the fall term. Tiken an sтlienentatim workshop the following sumer. high school wall be trauned in a one-wein work shop by the teaciers who furticipatci in the orientation sesisin. The 5 ceacicrs will reprosent different disciplunes in the high school. ilext summer a worksion io train the jurlor hish school teachers has been plannd. This will be a one-wevk work shop that will include at loust one teacher in each discipline for each junior high school in the district. 
APPENDIX C

TEACHERS - METRIC WORKSHOP

Rationale for Teaching Metrics

Common Metric Units

Concept of Measurement

Mass, Length, Volume and Temperature

Lesson and Course Objectives

Hands-on Activities

Selection of Metric Materials and Activities

Constructing Metric Lessons

Integrating Metrics into the Curriculum

How to Use Community Resources

Evaluating Student Progress

Metrics in Various Disciplines

Needs, Interests and Abilities of Students

Metric Awareness Activities

Experiences Outside of the Classroom

Mini-metric Lessons in the Home 
APPENDIX D

TRAINERS - METRIC WORKSHOP

How to Conduct a Workshop

State Objectives of Workshop

Provide Rationale for Going Metric

Comparison - Metric vs. Customary

Overview of SI Metrics

Preferred Units

Metric Practices

Concept of Measurement

Techniques of Evaluation

Constructing Metric Activities

Hands-on Activities

Development of the Child

Evaluating Metric Materials

Pacing in Workshop

Structures of Workshop

Integrating Metrics into the Curriculum

Community Resources

Teaching Strategies

Status of Metrics 


\author{
Andre Nadash \\ U.S. Metric Association, Mid-Atlantic Region \\ 6123 63rd Avenue, Box 356 \\ Riverdale, Maryland 20840
}

It was a hundred years ago, on May 20, 1975, that the Metric Treaty was signed by 17 nations. I am fortunate that I belong to two of these nations. I was born and raised in Hungary, which became metric immediately; and now I am an American, and we are the only one left of the co-signers and practically the last in the world to go metric; but I am glad to state that the rest of the metric or metric-going countries accept us as a metric-going country. The only non-metric countries are Brunei, Burma, Liberia and Yemen, with a total population of about 35 million.

It is estimated that there are about 400 million handicapped people on this earth, which is about twice the population of U.S.A. Naturally, this includes every type of handicapped. Here in the States we have about 1.3 million visually handicapped people, including about 140,000 visually limited school children. Of the 1.3 million, about 500,000 are socalled legally blind, of which only 50,000 read Braille. The reason for this is that a majority of the blind people become blind with old age and, therefore, they are not able to learn the Braille. A part of these people can read large print and a larger part 1ive with the so-called talking books, which is actually a record or tape recorder. In the Federal and State governments there are about 3,600 blind people employed as operators of, the vending stands.

We are here today to celebrate the 100th anniversary of the I'letric Treaty but I'd 1ike to bring your attention to another anniversary. 1975 is for millions of people in the world the Braille year. It was 150 years ago that Louis Braille invented the writing for the blind which bears his name. Louis Braille was born in 1809, as the son of a tinsmith and became blind by an accident at the age of three. He was 16 years old when he invented his alphabet, six raised points or dots and various combinations of these. Visualize his willpower at that time to overcome his handicap that as a young man he even played the organ in a Paris church. He died in 1852 at the age of 43, but in his short life he created good for millions of people and his name will never be forgotten.

And what a coincidence! Louis Braille was not only a Frenchman but who lived at the time when the metric system, which was developed by the French, was officially accepted by Napoleon and other European countties: Netherlands, Belgium, Luxembourg, Monaco, and Spain; and also countries from other continents: Algeria, Colombia and Cuba.

After this tribute to Louis Braille, let's see what is metric in Braille. It is natural that seeing people don't know the Braille alphabet; therefore, I'11 start by giving the Braille alphabet. It is not to teach Braille but only for a better understanding. The basic of the Braille is built, as mentioned before, on six dots in different variations called the Braille cell. The size of the Braille Cell is about $7 \times 5 \mathrm{~mm}$. The six dots of the cell are numbered vertically 1, 2, 3 and second column 4, 5, 6 and 1ooks as follows:

$$
\begin{aligned}
& 1 \cdot \cdot 4 \\
& 2 \cdot .5 \\
& 3 \cdot \cdot 6
\end{aligned}
$$




\begin{tabular}{|c|c|c|c|c|c|c|c|c|c|}
\hline $\mathrm{a}$ & b & c & d & e & $f$ & g & h & i & j \\
\hline - . & - - & $\bullet \bullet$ & - $\bullet$ & $\bullet$ & - • & - • & • • & - $\bullet$ & \\
\hline - . & - • & . & - • & $\cdot \bullet$ & $\bullet \cdot$ & - • & - • & • • & - \\
\hline - $\cdot$ & - $\cdot$ & . & - $\cdot$ & $\cdot \cdot$ & • • & - • & $\cdot \cdot$ & $\cdot \cdot$ & - \\
\hline$k$ & 1 & $\mathrm{~m}$ & $\mathrm{n}$ & 0 & $\mathrm{p}$ & $q$ & $r$ & $S$ & $t$ \\
\hline - . & - . & - $\bullet$ & - $\bullet$ & - . & - • & - • & • . &. & - \\
\hline - . & - . & . & - • & $\cdot \bullet$ & • • & - • & - • & - • & - \\
\hline - & - & $\bullet$ & - $\cdot$ & $\bullet \cdot$ & $\bullet \cdot$ & - • & - • & • & $\bullet$ \\
\hline $\mathrm{u}$ & V & W & $x$ & $y$ & $z$ & & & & \\
\hline - . & - . & . $\bullet$ & - • & $\bullet$ & - . & & & & \\
\hline - • & - & $\bullet \bullet$ & . & - $\bullet$ & - $\bullet$ & & & & \\
\hline - • & $\bullet \bullet$ & $\cdot \bullet$ & $\bullet$ & $\bullet \bullet$ & $\bullet \bullet$ & & & & \\
\hline
\end{tabular}

It is interesting to note that some of the dots or combinations are not included in the alphabet but used as abbreviations or special symbols; such as dot $6,3456,256$ or 2 . The reason is simple but it takes the mind of a genius iike Braille to work it out.

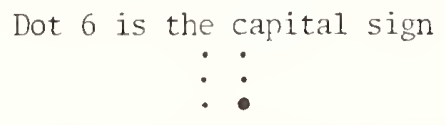

Dots 3456 are the number sign<smiles>C1CCC1</smiles>

Dots 256 are the period $: \dot{0}$

Dot 2 is the comma
Dots 56 are the letter sign

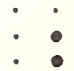

Dots 34 are the slant - it means per

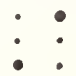

Dots $25+p$ is percent $(\%)$

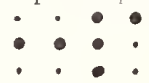

If we come back to the first ten letters of the alphabet, a to $j$, and we apply the number sign before these letters then they become number 1 to 0 :

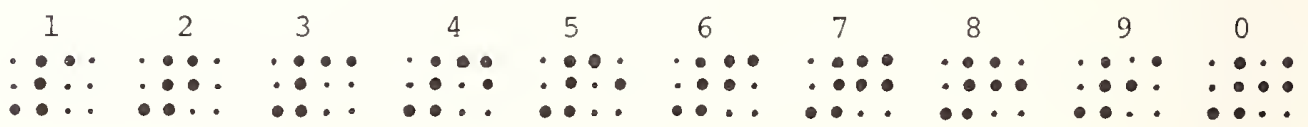

When we use the capital sign, dot 6, before a letter, it becomes capitalized, as you will note later (ampere, volt, watt, etc.)

Naturally, there are many Braille rules and I'will mention only a few. All rules are approved by the so-called Braille authority. The Braille metric symbols must be the same everywhere--but for certain reasons not exactly the same as the SI metric symbols. For instance, in English $m$ cannot be used as such for the symbol of the meter. In fact, in different metric sentences it has to be used in different ways.

For example, "The length of this room is $5 \mathrm{~m} . "$ or "The symbol of the meter is $\mathrm{m} . "$ One of the basic differences in Braille is that the metric symbol precedes the figure--the same as our normal way of pricing by putting the dollar sign before the amount. Therefore, in 
Braille we will not say $5 \mathrm{~m}$ but m 5. If we talk about length or other measurements and we write the symbol and follow it with the figure, then we do not use the letter sign before the $\mathrm{m}$, as it is natural in this case that the $\mathrm{m}$ or $\mathrm{kg}$, etc. stands as a measurement symbol, but we have to use the number sign before the figure. The length of this room is $\mathrm{m}$, number sign 3456 , and the figure 5. But, if we say the symbol of the meter is $m$, then the $m$ has to be preceded with the letter sign of 56 , as no figure appears after the $\mathrm{m}$.

From the above two sentences you see two different usages of the $\mathrm{m}$ as the symbol of the meter. In one case without a letter sign before'it but followed with a number sign and a number. In the other case with a letter sign before the $\mathrm{m}$. You'll ask why don't we form the second sentence the same as the first. The reason is very simple. The m was "sold out" for another purpose much earlier than the Braille metric process began. The m alone stands for "more" and is a world-wide Braille abbreviation which naturally cannot be changed.

Any figure we write in Braille has to be preceded with the sign for which the figure stands, for instance the $\mathrm{m}, 1$, $\mathrm{kg}$, etc. In other words, and this is very important, in Braille the symbol comes first every time.

The length of this room is $5 \mathrm{~m}$.

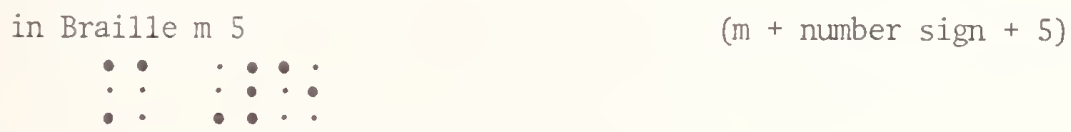

The symbol of the meter is $m$.

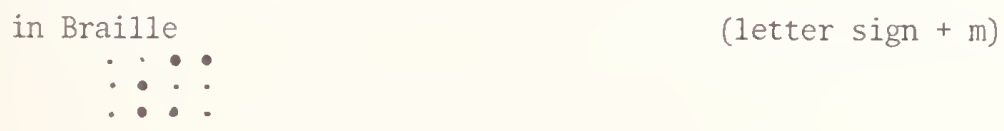

Exponents like in $\mathrm{m}^{2}$ or $\mathrm{m}^{3}$ cannot be written in Braille. Either we write it out or we use sq $\mathrm{m}$ for square meter or cu $\mathrm{m}$ for cubic meter, etc. For temperature we either write out degree Celsius or $\mathrm{dgC}$, which is accepted in Braille.

Braille has the same spacing between each word as regular writing but there is no space between sign and figure.

The following are Braille writings of different metric symbols:
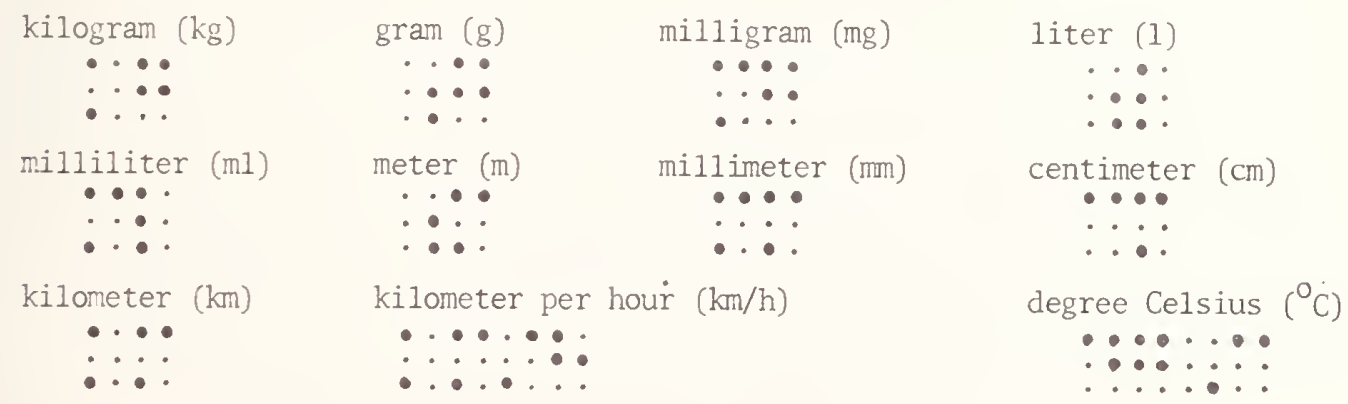
Two or more letters do not get a letter sign (mI, mm, cm) unless they can be confused with a Braille abbreviation.

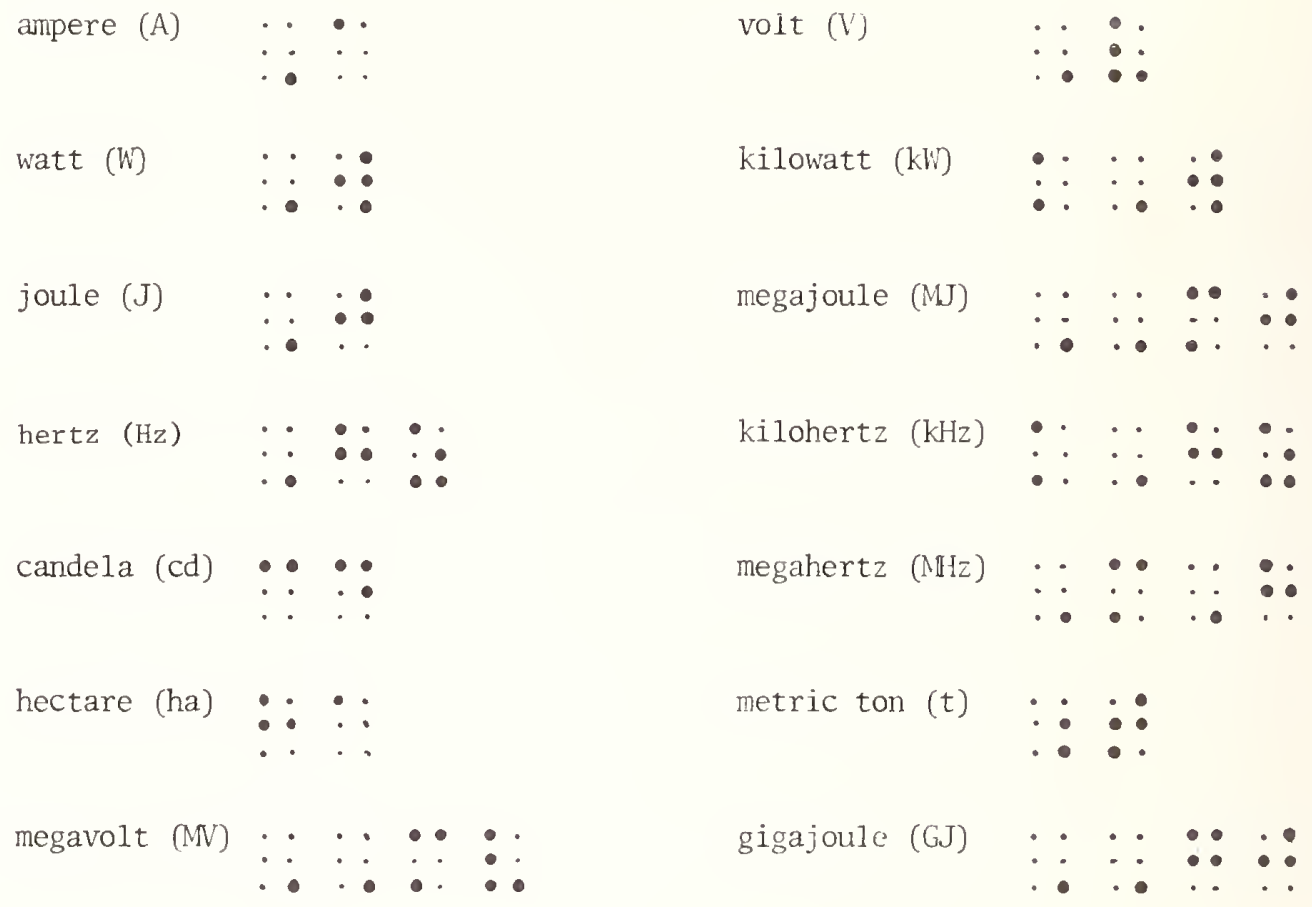




\author{
Fred Burgee \\ Frederick High School \\ Frederick, Maryland 21701
}

As a physical education teacher, I am particularly pleased to be here and to share for a few minutes with you a learning experience that the Physical Education Department of the Frederick High School has conducted earlier this year. More important, though, I hope that we all realize the potential physical education activities have in providing students with an opportunity to experience metric measurements in the areas of recreation, physical education and athletics.

During the spring of 1974, one of the mathematics teachers at Frederick High School, Mr. Clyde Baker, attended a conference on metric. On his return, Mr. Baker made a presentation to the faculty at Frederick High School. He made certain comparisons to the yard and the meter; he explained the status of the metric movement; and, more importantly, he challenged each of us to use metric in our classes. I am probably the only person on the program today that has never attended a metric conference before and I must take a little pride in that, I guess. My previous experiences with metric have been, first, watching the Olympic games on TV, as most of us have done. The olympic games use the metric system exclusively. My second experience was advising some of the members of my wrestling team (I coach wrestling) when they attend post-season wrestling tournaments where metric weight classes are used rather than the customary weight classes used by high schools. My third experience with metric has been that, as a swimming instructor I tell my students that the American Red Cross recommends when you are diving from a one meter board, you should be diving into 12 feet of water. And it is recommended that when you are diving from a three meter board, you should be diving into 14 feet of water. There are surely some cross references here.

Following Mr. Baker's presentation, the Physical Education Department of Frederick High decided in the fall of 1974 to conduct a little experiment in metric to try to get the reactions of the students to listening to the results of athletics contests in terms of metric, and to familiarize them some with metric measures. We chose two groups to participate in this little experiment. One--a group of girls; one--a group of boys. Both groups were in grades 10 through 12. The girls participated in two parts of the national physical fitness test. This was a soft ball throw and the standing broad jump. These tests were conducted by Ms. RaeAnn Rippeon who is a female physical education teacher at our school. For my area, I selected the punt, pass and kick competition which, of course, is footba11.

Our intentions in this experience were not to get the students involved in trying to convert metric measures we were going to give them to feet and inches. The only conversions that were done in this experiment were done by myself--in an attempt to change the existing feet and inches measurements for the soft ball throw, the standing broad jump, punt, pass and kick into the metric system so the students would have something by which to compare. I must give some recognition to Mr. John Maurey, who is an employee of the National Bureau of Standards. He helped me in my conversions and made my job doing this much easier. The only instrument for measure was a 300 foot measuring tape that had metric readings on the bottom side of it. Maybe for this metric conference, I should say the metric readings were on the top side of it and the feet and inches were on the bottom side.

Prior to conducting the events I met with my group of men. I pointed out to them that the olympics games were all conducted in metric. I told them that metric was a thing of the future and now was the time for us to get the jump on it--a head start on it. Most of the response and discussion that followed were negative. They weren't really sure why we wanted to do this; how this would benefit them, etc., but all the students did agree to the project and were very willing to help me.

Usually we conduct the punt, pass and kick competition on a football field. But this would somewhat defeat my purposes because football fields are marked off in yards. I moved the tournament to an open field that had no markings on it. It took me awhile to explain 
this to my students also. I schooled my student aides briefly on reading the metric system or reading the meters. They had a little diffeulty at first in their readings. When I would throw the football, I was getting things like 58.5 yards and it took awhile for them to get the right idea with my corrections, but eventually it came. As we say in physical education, the human mind and body will quickly adapt to new situations and I found this true with my student aides. Not only this but the other students became fascinated with my being able to read using the new system and they all wanted to become involved, and I let them do it as they wished.

If we must measure the results of our many experiments, I would say that what we did was successful. I found that small groups of students during the competition were gathering in the locker room waiting for the dismissal bell to ring and they were discussing the results of their throws and kicks in terms of metric. I approached the groups whenever I heard them doing this. I complimented them on their rapid adjustment to the new terminology and with one exception I was very pleased with the way they had picked it up. One young man, who had thrown the football exceptionally well on a particular day, was standing and I approached him and said, "Gee, that was a great throw you made today!" Today it went 58.7 meters, and he said, "Coach, (he sort of put his head down) 58.7 meters isn't too good when you consider that last year I threw it 60 yards." So it is obvious that from this statement we in physical education are a long way off.

We have some work to do but I do feel that the Physical Education Department of Frederick High School has surely gotten our feet wet. There is much more to be done and next year the Physical Education Department will use metric measures for our physical fitness testing, for our cross country unit, for our punt, pass and kick competition, and especially our track and field. Our physical education team has picked as its special project to mark our 440 yard track so that we can have starting points to run such, events as the 1500 meters, the 400 meters, 100 meters, 60 meters, etc. I say that we are going to put these markings on our track temporarily because the varsity people have yet to accept metric as we physical educators have. I am sure though that in the very near future the varsity sports, particularly track; will be accepting the metric system and that tracks will be built and will be measured using the metric measurements. I feel that the metric experience in physical education will definitely complement the teaching that is done in the other areas. I thank you very much. 


\author{
Audrey V. Buffington \\ State Department of Education \\ P.O. Box 8717, BWI Airport \\ Baltimore, Maryland 21240
}

It's time to "Go Metric," especially in education. This view is obviously shared by the educational agencies of all 50 states since some commitment, formal or informal, has been made by each of them. Through the cooperation of many persons and organizations the conversion to the metric system can be smooth and painless.

In Maryland, the State Board of Education exhibited leadership and foresight by passing a Resolution in August 1973 resolving that we must be metric "in all phases of public education not later than 1980." A State Metric Committee with representation from many sectors of society formulated a comprehensive plan which was accepted by the State Board of Education in Cctober 1974. The State Committee felt very strongly that education should move in concert with public awareness and need. To move too fast could cause confusion and resistance; to move too slowly could cause anxiety and delay. Therefore, an annul review of the State Metric Plan will be made to evaluate progress and to recommend changes necessitated by national plans for and rate of metrication.

Consideration ir a state plan for metrication of public education must be given to (1) timing, (2) education, and (3) support. Even then, there will be problems that have no easy and immediate solution.

Timing

The time allowed in your state for conversion to The International System of Units (SI) as interpreted for the United States by the National Bureau of Standards, previously and hereafter referred to as the metric system, must be divided into three periods. One period must provide for awareness, one for general training, and one for specific training.

During the awareness period, programs using a soft, low-key approach must be provided to overcome fears, reluctance to change, and negative attitudes expressed by professionals in the school system and others in the community. The fears and reluctance may result from inadequate and/or false information and no doubt are closely tied to the reported costs of conversion. The lack of knowledge of SI, its advantages to education and the economy, its present and future applications, and the misunderstanding of our one main reason for going metric are additional causes. Often, the negative attitudes are a result of school-day memories where instruction in the metric system was dull and tedious as a result of emphasis on conversion activities between the customary system and the metric system. The assignments were difficult and boring due to the involved calculations and the need for memorization of many facts--units of the customary system, unrelated and arbitrarily selected; units of the metric system, interrelated and consistent; factors, numerous and "multidigited," that are needed to convert from units in one system to comparable units in the other.

The concerns can be overcome as their causes are challenged and explained in programs provided to meet the needs of the many specific audiences being addressed.

The general training would provide the information needed in everyday life. It would involve instruction in metric units of length, area, volume, mass, and temperature that every person should know. It could also provide instruction in units of time, our monetary system, and our numeration system, none of which will change. Present and future applications of the metric units will play an important part in developing understanding.

Specific training will be provided to persons who need it at the time when it is needed. Business and industry fully support this idea and are focusing on it in their metrication activities. In education the specific training needed by persons in the vocation and technical fields will vary greatly from that needed by those in the scientific field, ... To require al1 in education to take the same comprehensive course would be cost $1 \mathrm{y}$ in terms of money, time, and energy and few benefits would be derived. 
Metrication activities in education are widely accepted when support and encouragement are given by the State and Local Boards of Education, by school administrators at the local and school level, by institutions of higher education, by educational organizations, by parents and by mass media.

In Maryland, we are very fortunate in respect to support. The State Board of Education, as previously mentioned, initiated metrication through the passage of a resolution. Local boards of education, at least all but one, have given full support to the provision of inservice activities for employees at all levels, usually with concentration on the training of teachers.

Administrators have cooperated by attending and/or making provisions for others on their staff to attend workshops for curriculum development and revision and workshops in content and teaching techniques. Many have cooperated in and/or conducted extensive awareness programs. "Metric weeks" have been occurring in many individual schools through the efforts of teachers and the encouragement of the administration.

Some programs have already been provided for parent groups at their request. The support of many parents will be solicited and, hopefully, received through communications with them via meetings, newsletters, programs, school visitations, ... It is imperative that they be involved from the beginning to avoid the "backlash" which resulted from the introduction of "new math" into the curriculum without their knowledge or understanding.

In Maryland, we have also been fortunate in that many state and local activities have received television and/or newspaper coverage. Much more use of mass media needs to be made, however.

There is no doubt that institutions of higher education will lend their support in the provision of preservice and inservice programs for teachers. Close cooperation, however, needs to be maintained to assure that these programs provide the information and techniques that are being required of Maryland public school teachers.

\section{Education}

There are three components in education that must be included in metrication plans-personnel, curriculum, and materials.

Persons involved in education at all levels and in all capacities must receive information related to the awareness phase at the earliest possible moment. General training must then begin according to a comprehensive plan to assure thoroughness, timeliness, and completeness.

Those persons involved in teaching the metric system at the primary and intermediate levels and those involved in mathematics and science instruction at the secondary level may need specific training first, with those in measurement-related fields, such as home economics, machine shop, drafting, following a close second.

Whether such instruction is provided by local education agencies or institutions of higher education, there must be several objectives that are accepted. Teachers must be taught as they are expected to teach; they must be taught using the same totally-metric, activity-oriented approach that they are expected to use with students.

Videotapes of the workshop I conducted repeatedly for many educators in Maryland have been given to each local education agency. These can be used for inservice by local education agencies and/or individual schools. Similar programs may be provided in other states via videotape of ITV.

In Maryland, the development and revision of curricula is the responsibility of each of the 24 local education agencies. This needs to be done at the earliest possible time, however, to insure a sequential development of the measurement strand $\mathrm{K}-12$ and to assure that skilis in decimal and fractional notation and computation have been so sequenced as to provide for the best possible programs. The teaching of measurement cannot be a one-shot deal but must be a continuous program beginning with the primary grades where many activities 
are provided which will teach the concept of measurement with emphasis on vocabulary development (long, short, longer, shortest, full, ...) and on the use of non-standard units. As the need for standard units is realized, formal instruction in the metric system can begin. This instruction will be extended in the intermediate grades. Presently in the secondary schools, fundamental activities need to be planned for the many students who have little or no knowledge of the metric system. The activities will be extended and/or revised as the students enter the secondary school with a better and better understanding of measurement.

Students in colleges and universities, persons in adult education programs, in continuing education programs, and others will also need planned courses in the metric system. These must be developed by interested and competent persons in charge of instruction in each of these programs.

The selection of measurement materials to supplement those presently in use and/or those available from science kits must be wisely made. Many materials now on the market either are not consistent with already established objectives or are in error due to a lack of research and/or expertise. Such materials could do more harm than good if used.

The Maryland State Department of Education is anxious and most willing to provide assistance and advice related to any or all of the areas of concern--personnel, curriculum, and materials.

As mentioned before, even with careful and prompt attention given to all of the above, proulems may still arise. One will undoubtedly be related to research, or lack of it, in developing a revised scope and sequence based on required changes in the teaching of fractions and decimals necessitated by the introduction of a base-10 measurement system. Commercial textbook companies are urged to be involved in such research and to use the results to produce materials that are appropriate and accurate.

Another problem may be the caliber of classroom instruction. Presently, motivation and interest are high on the part of teachers and many are teaching the metric system; some, unfortunately, without the benefit of recent training and carefully selected materials. It is impossible to monitor every teaching situation to see that paper-pencil conversions are not being taught, to see that only approved units and symbols are being used, to see that interesting activities are being provided, ... This problem, I hope, will be short-lived.

I was asked to share with you my ideas on introducing the metric system into state departments of education and into mathematics. This I have done. Hopefully, it was sufficiently specific to be of value.

I was also asked to share experiences of recent conversion activities with you. To date, I have provided workshops and/or sessions in the metric system for more than 1600 persons in Maryland and for more than 1850 persons in 17 other states, including Alaska where I taught a one-semester hour course for the Anchorage School District through the University of Alaska.

Many, many persons come to the workshop with fear and trembling but, fortunately, with a desire to learn. I asked only that each participant keep an open mind and be as actively involved as time and space allowed. This approach has been successful with 99 percent of the participants. I observed that the fears and anxieties were primarily related to questions like "Why should the United States convert to the metric system?", "What are the advantages of going metric?", "How will I learn the system so I can teach it?" Such questions can be answered and the persons with whom I have worked seemed to be content with the answers I gave.

I have noted, too, that the teachers are really very task-oriented. They want something more than fun and games; they want an honest, straight-forward approach to the teaching of the metric system which includes content and techniques.

State departments of education have a valuable and important leadership role, lending support and assistance to any school system that needs and/or requests it. This leadership role should reflect the dedication, interest, and desire that exists to make metrication in the field of public education efficient, effective, and enjoyable. 
Thomas E. Rowan, Mathematics Supervisor

Montgomery County Public Schools

850 Hungerford Drive, Room 236

INTRODUCTION

Rockville, Maryland 20850

Montgomery County is a large suburban school system serving approximately 120,000 students in grades kindergarten through 12. There are approximately 145 elenentary and 55 secondary schools in the county. Approximately 2200 elementary and 450 secondary teachers teach mathematics in those schools. Administrative and supervisory services are provided through a semi-decentralizes organization which includes a central office and six area offices.

This picture of our county school system is provided only for the purpose of setting the scene for the comments which are to follow. Many of the decisions we have made have obviously been influenced by the nature of our school system.

As we considered the question of metrication for Montgomery County Schools, we first looked at the question of timing. Should we move ahead without plans, or should we await action by the Congress, or at least await action by national curriculum leaders in mathematics education? We decided that the schools should act now for two basic reasons. First, schools have a responsibility to provide thoughtful leadership. They cannot sit back and ride with the current. Secondly, the schools must educate students for the future, and the future will be metric, whether or not Congress fulfills its responsibility for leadership.

We began our planning for metrication by first recognizing the need for consideration of at least four main categories: community relations, curriculum, methods of teaching, inservice, and instructional materials. We placed community relations at the top of our list because we felt the metric impact upon the community would be an important factor and because we felt community input would be very important in the development of curriculum, especially at the secondary school level.

\section{Community Relations}

One of the first actions taken was the formation of a citizens' advisory committee. This committee was proposed to, and approved by, our county board of education, which is made up of elected citizens. The discussion of the need for the committee, and the eventual report of the committee to the board, served as vehicles to educate board members on the need for metrication in the schools. The citizens' advisory committee included parents, teachers, representatives of local businesses and industries, a representative of the State roads department, a representative from higher education, and curriculum specialists from the school system. An unfortunate oversight was the failure to include elementary or secondary school principals. Principals are the school-level instructional leaders in Montgomery County, and should have been included.

The citizens' advisory comittee met approximately monthly for a full year and then reported to the Board of Education. A calendar for school metrication was proposed, along with five recommendations regarding aspects of the change.

Suggested Calendar of Change - Montgomery County Metric

$\begin{array}{lll}\text { 10-12 } & \text { Minimal Metric Training } & 1974-75 \\ \text { K-3 } & \text { Metrication of Instruction } & 1975-76 \\ 4-6 & \text { Metrication of Instruction } & 1977-78 \\ 7-9 & \text { Metrication of Instruction } & 1979-80\end{array}$

The proposed calendar attempted to take into account the need for immediate action with respect to students who would be graduating within the ensuing few years, and the desirability of phasing into a continuous program which would move through the grades with the younger children. We now know that, for a variety of reasons, we will not meet the recommendation for metrication of K-3 instruction by 1975-76. We are now planning to meet that 
recommendation as a county by 1976-77, althoug many schools within the county will make the original deadline. One of the problems which necessitated postponement was related to inservice training of teachers. The other committee recommendations dealt with adult education (correlate with-federal legislation - or perhaps school changes), cooperation with county government agencies, consulting with non-county agencies, coordination with the State Department of Education, and planning in the area of career education.

\section{Summary of Recommendations - Citizens' Advisory Committee}

1. Offer adult education programs - correlate these with federal legislation - work through PTA groups when possible.

2. Assist county government agencies to train other county employees as needed.

3. Consult with public and private agencies in a consultative capacity as need arises and time permits.

4. Coordinate with the Maryland State Department of Education and meet 1980 deadline.

5. Make career-related instruction metric as appropriate to the particular career.

\section{Curriculum}

The category in which we have probably made our best progress is that of curriculum development. One reason that I feel so good about our progress in this category is the fact that we were (and are) in the final stages of revision of our program objectives. This means that our metric changes will be fully incorporated into a curriculum document which will be printed and made available to schools in the fall of 1975. Thus the official school mathematics program for grades K-8 will be fully metric beginning next school year. Some of the main features of the objectives (see Table I) we have, established include:

1. Many early experiences with comparisons and non-standard units.

2. First expectancy of performance with standard metric units in grade two.

3. Introduction of decimal fractions early in grade four and use of them in renaming metric units.

4. Postponement of adding and subtracting common fractions with unlike denominators (until junior high).

5. Earlier introduction of computation with decimal fractions.

6. Treatment of customary units as a second measurement system.

Particular interest has been generated by our decision to begin decimal fraction computation in grade four and to postpone addition and subtraction of fractions with unlike denominators until the junior high school level. We feel this is a logical sequence for a metric curriculum. We could find no practical or mathematical reason to do the complicated fractional algorithms as early as has been traditional. Our junior high school teachers have generally reacted favorably, since they have always felt a need to do a great deal of reteaching of this part of the program anyway. It may now be possible to approach the task with techniques which are more akin to algebra for those students for whom this would be appropriate. Some people point out that we are now out of phase with texts. While this is true, we are hopeful that text authors will move in the same direction soon. It seems quite logical that they would. We are also forced to consider the fact that we in Maryland have a state-wide accountability program which uses the Iowa Test of Basic Skills. After a careful review of the test, we feel that our fraction and decimal shifts will not 


\begin{tabular}{|c|c|c|c|c|}
\hline GRADE & $\begin{array}{l}\text { COMMON } \\
\text { FRACTIONS }\end{array}$ & $\begin{array}{l}\text { CECIMAL } \\
\text { FRACTIONS }\end{array}$ & $\begin{array}{r}\text { METF } \\
M E A S U R\end{array}$ & MENT \\
\hline$K$ & & & $\begin{array}{l}\text { Cornpares } \\
\text { Equalizes } \\
\text { Da:cribes }\end{array}$ & $\begin{array}{l}\text { length } \\
\text { weight } \\
\text { capacity } \\
\text { temperature }\end{array}$ \\
\hline
\end{tabular}

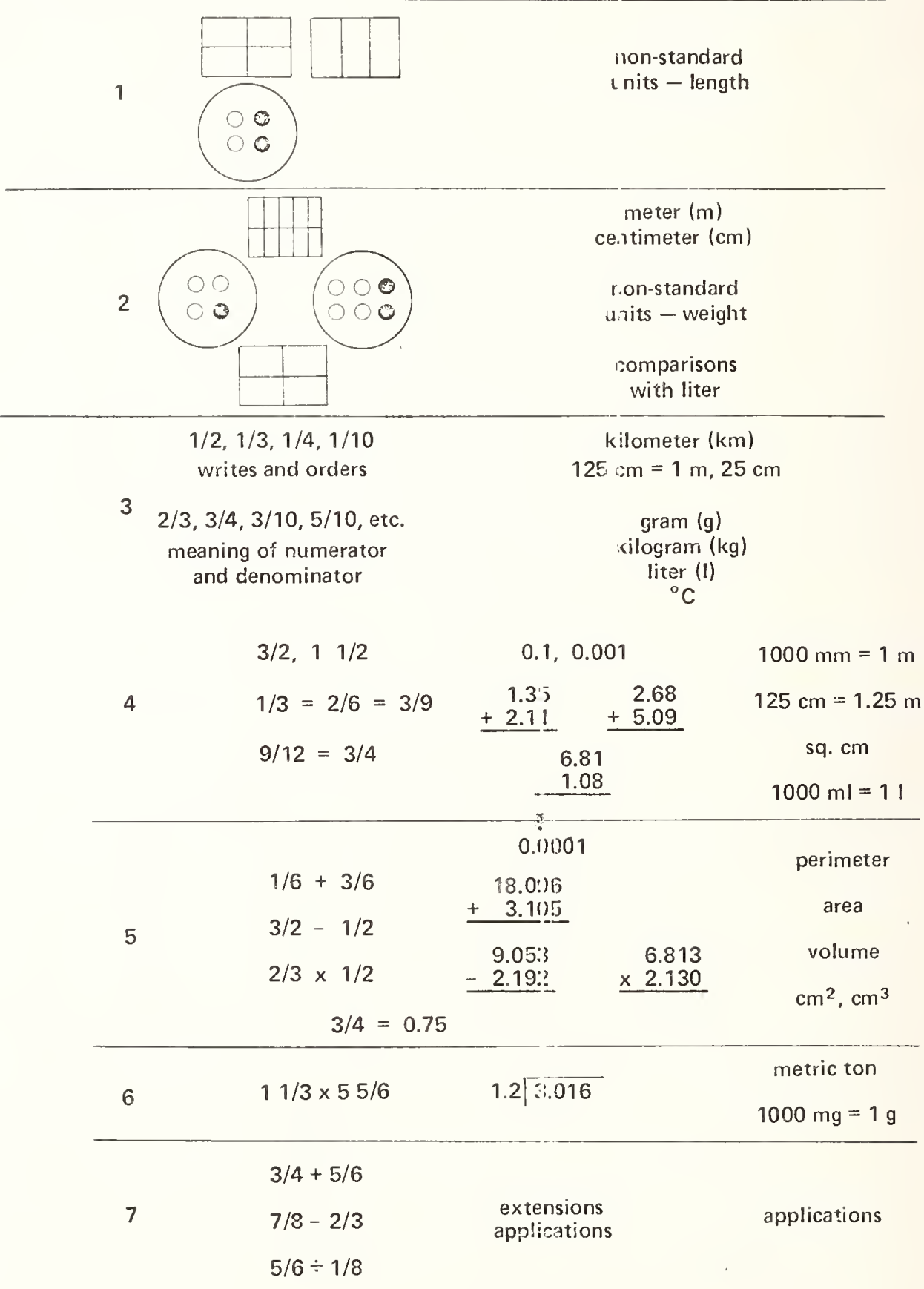


affect our ITBS scores. What may have a more severe impact on the scores is the reduction in emphasis on customary units of measurement. Customary measurement units are used.in a large number of problems at fifth grade level and above. When will a metric version of ITBS be available?

\section{Teaching Methods, Inservice Education}

Our emphasis with respect to teaching methods has consistently been upon active involvement. We have twelve elementary mathematics teacher specialists who teach inservice courses using activities which teachers can, in turn, use with students. At the secondary school level we have a mathematics resource teacher in each junior and senior high school. All of these resource teachers are employed on a 12-month basis and are responsible for providing inservice programs to teachers on their staffs. It was therefore relatively easy to have all resource teachers participate in a summer metric workshop which they were responsible to reproduce in their own schools. Materials for these workshops were provided by purchasing six kits which could be circulated from school to school. These kits supplied the workshops and gave teachers an opportunity to see materials they might want to purchase.

The problem of inservicing elementary school teachers is much larger. In Montgomery County we regularly offer inservice courses with credit which can be applied toward certificate renewal. We began our metric inservice efforts by developing a 15-hour course which carried one credit. During the past two years approximately 400 elementary teachers have taken this course. Others have participated in non-credit courses offered in their schools. Earlier I mentioned that we have 2200 elementary teachers. We still have quite a large number who have tot been inserviced. It is this fact which has caused us to postpone full implementation of our metric program for one year. We are hopeful that we will be able to provide minimal metric training to every elementary school teacher before the end of the 1975-76 school year. This will enable us to get on schedule with the calendar which was proposed by the Citizens' Advisory Committee by 1976-77.

I have already mentioned the fact that building principals are the immediate instructional leaders in our schools. It is therefore important to provide metric inservice for these administrators. During the present (1974-75) school year, arrangements were made for all principals to participate in a metric workshop conducted by the Maryland State Supervisor of Mathematics, Mrs. Audrey Buffington. This was a full day workshop which included content, methods, and implementation procedures. During the course of five separate fullday workshops, 90\% of our 202 elementary and secondary principals were inserviced.

Materials of Instruction

The final category which I mentioned earlier was that of materials. In Montgomery County we have a process through which all texts and instructional materials must be approved centrally before they can be purchased by schools. Although there is a lot of work involved in keeping such a system operating, the benefits are well worth it. There have been many metric materials reviewed and rejected because of their poor quality or lack of relationship to instructional goals. We now have a policy of rejecting any text which does not include adequate and appropriate treatment of the metric system. Our schools receive funds for the purchase of instructional materials. These funds are very inadequate for the needs, but they do offer the opportunity for gradually building a collection of materials to meet a need such as that created by the metric system. In an effort to get every school started with metric materials, \$55 per school was appropriated during 1974-75. This money was used to buy a.standard set of materials for each school. Unless budgetary problems prevent it, we will give each school an opportunity to purchase an additional $\$ 55$ worth of metric materials during 1975-76. Although these are certainly minimal expenditures, they are in addition to regular instructional materials funds which may also be used for metric materials.

\section{Conclusion}

As you can see, we are making some progress in each of the categories mentioned earlier. We are also involved in activities which span several categories and which have not yet been mentioned. The curriculum discussion earlier in this paper was restricted to the mathematics curriculum. We have also begun to move in other curricular areas. Our 
career education staff is watching developments in the various careers very closely. Our physical education staff has done some local school projects using metric measurements and plan to move with curriculum changes in the near future. Our driver education staff has asked the mathematics division to review its materials so that initial changes may be made in curriculum development sessions which are to be held this summer. Resource teachers and department heads in industrial and home arts have participated in inservice workshops conducted by the mathematics staff this year.

We have one elementary school which requested, and received, permission to become totally metric in grades K-3 during the 1974-75 school year. This was done to evaluate methods, materials, and student and community impact. The principal of that school, Mrs. Kelly Guido, is also on the program of this conference.

Finally, we are in the process of developing a set of nine television lessons on the metric system. These lessons are being produced mainly for use with juniors and seniors in high school who are not enrolled in mathematics classes. They are designed to provide a minimal metric background to those students. The nine lessons are generally $8-10 \mathrm{minutes}$ in length and will be used ty the schools on an independent basis.

All in all, Montgomery County Public Schools are moving toward metrication in a reasonably organized and progressive manner. There are some areas in which we need to do more planning and coordination. We are very anxious to have federal legislation so that we will know with more certainty how and when metrication will proceed in the community. We know this could save us money and improve our community relations, but we are not waiting on it. We are moving ahead with the program we feel is appropriate under existing circumstances. 


\section{REMARKS BY SENATOR CLAIBURNE PELI \\ at the \\ METRIC EDUCATION CONFERENCE}

I am delighted at this opportunity to participate in this conference on metric education.

As an advocate in the Senate of metric conversion for the past 14 years, I find this conference more than encouraging. When I came to the Senate in 1961 and introduced my first metric conversion legislation, a conference of educators, businessmen, and government officials interested in conversion to metric measurements could have been amply housed in a telephone booth about one meter square.

Today, the attitude toward metric conversion has changed dramatically in American business, in education, and in government. Just two months ago I spoke at the First Annual Conference of the American National Metric Council in Washington. That meeting was attended by several hundred businessmen, including representatives of some of the largest corporations in our country.

General Motors, Ford, Rockwell International, Sears Roebuck--these are among the corporations that have already committed themselves to a program of conversion to metric measurements.

And here today, we have a similar gathering of the education community.

The fact that these meetings are being held and are being attended by leaders in the fields of business and education conveys a message: The message is that we are past the point of debating whether we should convert in this nation to metric measurements.

Conversion to metric measurements, I believe, is well underway in the United States. The discussion now centers on how we can best manage the conversion to metric measurements in business, in education, and in the everyday life of Americans.

The extent of metric conversion activity--in business, in education, and in state and local governments--is, I think, really remarkable in light of the fact that it is taking place in the absence of a definitive national policy.

It is a tribute to the initiative, the foresight, and the energy of the private sector and of state and local governments, including educators, that so much is being done to prepare for and to implement metric conversion.

At the same time, I believe there is almost universal agreement that metric conversion would be more effective, and better managed, if the Federal government fulfilled its responsibility to establish a clear national policy for our system of weights and measures.

There is a limit to what can be accomplished by the commendable conversion efforts of individual groups and corporations rithout a framework of national conversion policy and national conversion planning. We are rapidly approaching that limit, and for that reason I think it increasingly important that national metric conversion legislation be enacted during this Congress.

It is because of my conviction that the Federal government has an essential role to play in helping to plan, coordinate, and facilitate conversion to metric measurements, that I have introduced again in this Congress S. 100--a bill with a nice round decimal number for a metric conversion bill.

This bill is, I believe, the most comprehensive metric conversion legislation introduced in the Congress. It calls for a mandatory, 10-year conversion, under a comprehensive plan to be developed by a Metric Conversion Board, subject to Congressional approval.

The bill also provides for some measure of government conversion assistance in the form of an increased investment tax credit, SBA loans to small businesses, and SBA grants to individual craftsmen and workers to defray retooling expenses. 
In all frankness, I must say that I do not expect that the Congress will approve this legislation in the form in which it was introduced. I was well aware, when I introduced the bill, that modifications and compromise would be required to gain approval of the Congress. But I believed it important, at the outset, to place on the record the legislation I believed to be optimum.

The real question that confronts us in making a prognosis on metric conversion legislation is not whether this Congress will approve metric conversion legislation, but what kind of metric legislation this Congress will approve.

As I have stated, I believe compromises will have to be made to secure passage in this Congress of metric conversion legislation. At the same time, however, I do not believe we should retreat one centimeter from the long-term objective--legislation that will assist in the conversion of our system of measurements to a predominantly metric system within a reasonable period of time.

It is an understatement to say that the road to metric conversion in the United States has not been a smooth one. It was on March 3, 1817, that the United States Senate directed Secretary of State John Quincy Adams to undertake a study of weights and measures. It was nearly five years later, on February 22, 1822, that Secretary Adams submitted his detailed report to Congress. John Quincy Adams, on the basis of his detailed personal study, was an enthusiastic supporter of the metric system.

But even Adams recognized the need for compromise and for a gradual approach to adoption of the metric system. Accordingly, although his report brimmed with admiration oc the metric system, he recommended adoption of the existing English system in the United States while the government proceeded with consultation with other nations toward establishment of a uniform, international system based on the metric system.

As he said in his report to the Congress; speaking of the adoption of the metric system in France:

"That it is worthy of their acceptance is believed to be beyond question. But opinion is the queen of the world; and the final prevalence of the system beyond the boundaries of France's power must await the time when the example of its benefits, long and practically enjoyed, shall acquire that ascendancy over the opinion of other nations."

John Adams, of course, was correct in his vision. The metric system now has acquired an ascendancy over the opinion of other nations to the point where the United States is the only major non-metric nation of the world.

And, here in the United States, we are now ready, I believe, to make the national policy commitment to convert to a predominantly metric system.

We have reached this point gradually, step by step.

I recall that when I first came to the Senate 14 years ago, my objective in regard to the metric system, was passage of conversion legislation. I was persuaded that conversion legislation was not immediately possible. As a first step, therefore, working with former Representative George P. Miller of California, I introduced legislation providing for a comprehensive study of the advantages and disadvantages of conversion to metric. In 1968 , that legislation was adopted.

Under the authority of that act, the National Bureau of Standards produced an excellent and thorough report entitled "A Metric America." That report has had a profound impact in accelerating the movement toward metric conversion. The study had the effect of persuading the Executive Branch to advocate metric conversion as Administration policy, and the report gave everyone confidence that metric conversion in the United States is a matter of serious, practical policy consideration.

In the last Congress, we took another step forward--and a very important step. As part of the Education Amendments of 1974, I proposed a metric education program to be administered through the Office of Education in the Department of Health, Education, and Welfare. 
That program was adopted by the Congress, and it includes this significant statement of findings by the Congress:

"that the metric system will become the dominant system of weights and measures in the United States."

The bill also included this statement of policy, which I think is equally significant:

"It is the policy of the United States to encourage educational agencies and institutions to prepare students to use the metric system of measurement with ease and facility as a part of the regular educational program."

We authorized a modest sum--\$10 million a year for three years--for grants to educational institutions for metric education programs. The sudget for fiscal year 1976, now working its way through the Congress, includes $\$ 2$ million for the first year of the program.

The Congress, as you can see, has already established as national policy one vitally important element in conversion to the metric system of measurements. It is a formal objective of the United States to train students to use the metric system.

I think this is vitally important, because metric education is the bedrock upon which any successful and effective conversion to metric measurements must be built.

It is inevitable, I believe, that the children who today live in a nation of inches, yards, and quarts will be living and working as adults in a nation and a world of centimeters, meters, and liters.

One purpose of education is to prepare the children of today for the world of tomorrow. If that purpose is to be fulfilled, metric education is essential.

Another vital phase of metric conversion is adult and public education. Metric conversion in the United States will be accomplished over a period of years, probably ten years or less, judging from the experience of other nations that have undertaken national conversion programs. Obviously, in such a conversion, programs to inform the public generally and to retrain workers will be important.

You educators have an important role to play in conversion to metric measurements. To a great extent it will be your job to teach to the American people a whole new language of measurements.

The interest and enthusiasm you have shown by participating in this conference is an indication that this is an educational challenge you are willing and able to meet.

To be fully successful, however, metric education must take place within the framework of a comprehensive national program of metric conversion. For that reason I think it is important that effective metric legislation be enacted by the Congress.

Such legislation, I believe, should include the following provisions:

(1) A recognition of the reality of metric conversion that is already taking place in this nation.

(2) Establishment of a formal government policy of conversion to a predominantly metric system of measurements within a reasonable but specified time period.

(3) Government leadership and participation in assisting industry, education, state and local governments, and labor in planning and coordinating metric conversion.

I am optimistic that this 94 th Congress will be the Congress that will formally adopt such a policy. 
John Quincy Adams, in his 1822 report to the Congress, envisioned the day of a single, worldwide system of measurements in which: "one language of weights and measures will be spoken from the equator to the poles, and which will furnish the links of sympathy between the inhabitanta of the most distant regions..."

When the United States finally begins its conversion to the metric system, that vision will be on the way to fulfillment. 


\author{
Clinita A. Ford \\ Florida A\&M University \\ Tallahassee, Florida 32307
}

\title{
1. Philosophy
}

Education is not static. It is constantly on the move. One of the joys of teaching is that you are always learning new things or modifying that which you already know or going back to the way it was before you changed to the way it is--or you're taking the new and making old applications--or even taking the old and making new applications. The latter is about where we are today in the teaching of metrics in home economics. Metrics is an old thing that has been around for years. It didn't just happen! We just had not bothered to notice it in home economics except where we had to; for example in dietetics the measurements are commonly in metric units.

Now we can see it just over the hill and coincidentally "on the hill," too, where it's been stuck for a while. Even though metrics was legalized in the U.S.A. with the Metric Act of 1866, it has never been mandatory. Unfortunately, now that new life is being breathed into the olds, it has a frightening and terrorizing effect particularly on those who have not routinely used metrics. Recognizing this as generally true for home economists, I planned an inservice training workshop for home economics teachers in the state of Florida. The workshop, conducted the summer of 1974, was conceived with the idea of dispelling fear and developing receptiveness to metrics.

Since that beginning point with the intention of offering a two-week teacher training workshop, we have found ourselves offering metrics every quarter as a regular university course, open to all students. The positive spin offs, side effects, and multiplier effects have far exceeded any expectation I had at the time of planning the initial workshop.

\section{Objectives}

It was expected, as a result of the workshop experience that the participants would:

1. Acquire general knowledge of basic metrics.

2. Gain fundamental skills in the use of metrics.

3. Relate basic metrics to the teaching of home economics.

4. Acquire familiarity with authentic resources in metrics.

5. Recognize multi-approaches to metrics through utilization of interdisciplinary/ interdepartmental personnel.

6. Experience an involvement in translating metric fundamentals to the development of instructional materials for the teaching of home economics.

\section{Faculty}

The workshop residential faculty consisted of university personnel in home economics and mathematics. Those in home economics represented several specialization areas, as home economics education, home and family, consumer education, food and nutrition, dietetics and clothing.

The consultant staff included (1) academic personnel in mathematics, science education, metric education, home economics education, psychology, and metric research; (2) administrative personnel from agencies such as the Food' and Drug Administration and U.S. Department of Commerce (National Bureau of Standards); and (3) national officers from the U.S. Metric Association, Inc., the American Home Economics Association, and the American Metric Journal. 
The residential staff began its full time work two weeks prior to the workshop. The first week was intensive metric training and review of resource materials. The second week was used for planning daily activities and preparing instructional materials.

Together the residential and consultant staffs effectively provided a broad coverage of topics and activities in basic metrics. All presentations and class sessions related metric applications to aspects of teaching home economics.

\section{Participants}

The participants included personnel from the state vocational education department, inservice home economics teachers, graduate students, student teachers, and a youth group of senior high school students. The workshop group, inclusive of participating university faculty, provided a complete circuit of representation of personnel involved in teaching home economics in secondary schools.

This provided direct involvement of state department personnel with a teacher training activity for program implementation in the high schools. Through this process, the state personnel remains actively in touch with what the university is doing in teacher training. This is more meaningful than just a written report of a teacher training workshop.

The inservice teachers were from schools in various parts of the state. A broad geographical coverage is beneficial for broad coverage in the implementation of programs. In this way each teacher can serve as a germinator for the implementation of metrics in home economics. Additionally, the teachers are assets to the programs as a result of their updating, acquiring ideas for a new program thrust and improving their effectiveness as teachers.

The youth group was involved as full time participants in all activities of the workshop. The group served a special purpose as the youth monitors or special sensors of the workshop. The purpose of this group was to give feed-back as to the effectiveness of our work for use with high school students.

We have learned from other experiences that planning processes should involve the consumers of services along with the providers of services. In this regard, it was considered that since the general purpose of the workshop was inservice training for teaching metrics in secondary schools, it was appropriate to have an identifiable group from those to be served actively involved in all processes and secure directly from them reactions as to effectiveness.

The graduate student participants were all in home economics education. Some had teaching experience and/or home economics extension experience. A few had no professional experience. All were in a graduate program preparing for high school teaching. In addition to participating as students, they served also as assistants to the workshop faculty and consultants.

Student teachers, who are preservice teachers, through participation in the teacher training workshop prior to graduation gained breadth and depth in their preparation for the teaching profession. It was an opportunity, too, for the student teachers to work directly with inservice teachers and high school students on a peer basis in class. This was a unique feature which worked well.

\section{Organization and Procedures}

The workshop was designed to include basic instruction in metrics, audio-visual reviews, consultant presentations and individual and group activities.

Consultant presentations were presented in the mornings followed by interaction between the consultant and participants. During the two week period the consultant presentations included: 
"Visual approaches to metric education."

"Humanizing metrics: The psychology of change."

"An educational challenge: Metrics in home economics."

"Metrics for the.home economist."

"Status and outlook of metric education with implications for home economics."

"Consumer metrics and its application in home economics programs."

"Metrics and life styles."

"Legislation and implementation of metrics: Impact on the consumer."

"Metrics in the marketplace."

"A perspective of metric concepts, standards, and practices."

"Metrics: New meanings in clothing and textiles."

Audio visual reviews involved the use of slides, films, filmstrips, transparencies, and cassette tapes; covering numerous topics on metrics. Sometimes these were part of the consultant's presentation or the instructor's presentation or independent activity of the participants.

Basic instruction in metrics was scheduled for early afternoon followed by individual and group activities related to the basic metric instruction for the day. Primary attention was given to linear, volume, mass, and temperature measurements as most applicable to home economics activities. However, some coverage was given to cubic, force, and square measurements.

\section{Activities}

The workshop activities were developed to be relevant to all aspects of home economics. Emphasis was on those measurements basic to the daily routine activities of the consumer. They were planned to stimulate creativity in the expression of metric concepts in home economics classes. The participants were encouraged to "think" metrics not to "convert" to metrics.

Group activities were structured for participants to experience several techniques and approaches to interpreting metrics to high school students. These inçluded role playing, writing radio and television scripts, preparing instructicnal aids and demonstrating their use, designing puzzles and games, and creating numerous other metric materials.

A metric treasure hunt was a popular group activity. This was conducted in a home wherein various household objects were given metric descriptions from which participants had to recognize the object described and locate it in the house. The descriptions were challenging and the problems could be solved only through active involvement.

In a curriculum project, for each of the seven (7) metric measurements listed above, Færticipants prepared a list of suggested metric activities for specific areas of home economics. These were on the high school level. This activity provided practical experience in applying metric principles to home economics teaching activities.

A metric resource review activity, conducted for a half day, gave the participants the opportunity to become familiar with numerous metric materials and equipment available on the market. Through handling, examining, and using the resource items they could evaluate the usefulness of the items. Also, accuracy of information was noted. The collection of resources included audio-visual materials, print materials, instructional kits, games, and household metric measurement devices.

The culmination activity was a developmental project designed and made by individual participants. It was an opportunity for each to give creation expression to methods of including metrics in teaching high school home economics. The projects included charts, posters, transparencies, songs, games, mini-bulletin boards, mock-ups, and learning activity packages (LAPs). Each project displayed was described on a 5 " $x 8^{\prime \prime}$ index card as to name, description, and suggested use. 
The evaluation processes involved as assessment of the effectiveness of the workshop and the progress of the participants. These were handled through daily inventories, total workshop evaluation, and follow-up.

The daily inventories were short quizzes covering basic metric principles covered the previous class day. However, the quizzes on the first and last days were the same, covering a broad scope, used to measure participant growth during the workshop. Those enrolled for college credit were evaluated, too, on participation, productivity, and performance.

An instrument for the general evaluation of the workshop was distributed on the first, not the last, day of the workshop. The distribution was handled in this manner so that participants could do an itemized daily evaluation of all aspects of the workshop. The categories of items included were: (1) consultant presentations, (2) instructional activities, (3) instructional content, and (4) support services. Each of these categories was detailed item by item. The criteria of assessment were: (1) contribution to professional growth, (2) expansion of professional knowledge, (3) value to improving effectiveness as a teacher, (4) acquisition of new/useful ideas, and (5) interest appeal. Subjective items asked for identification of strengths and weaknesses and suggestions for future workshops.

The. youth group, described earlier, was given a special evaluative instrument designed to assess the relevance of workshop activities for high school youth. The first three categories of items listed above were used but with criteria different from the general instrument.

A follow-up instrument was recently distributed to all home economics teachers who attended the workshop. The responses will provide data on the carry over value of the workshop and basis for evaluation of the implementation of metrics in teaching home economics. Particularly we shall note unique approaches and techniques, new resources, adaptations to grade levels, and applications to various areas of home economics.

\section{Related Activities}

One of the greatest benefits derived from the workshop has been the continuation of metric instruction through regular course offerings at the university. A consumer metrics course has been offered each quarter since the workshop. One quarter, by popular demand, the course was offered for graduate students. The credit course is opened to all university students, irrespective of major. However, it has been incorporated into the home economics curriculum as one of the required core courses for all majors.

Currently, several graduate students engaged in Directed Individual Studies (DIS) are preparing the following projects or studies:

(1) Sound on slide: The 1974 Consumer Metrics Workshop at Florida A \& M University.

(2) Annotated metric resource guide; charts, posters, and kits.

(3) Metric motivation for high school home economics.

(4) Metric involvement of consumer related companies.

(5) Metric cookbook for children.

(6) Metric resource bibliography.

All of the metrics courses are taught jointly by home economics and mathematics personnel.

The Florida A and M University program has been one of the pioneers in the state of Florida for training home economics teachers in metric education. We intend to continue and expand this effort. We are planning as a sequel to last summer's workshop one for this summer which will deal exclusively with curriculum and program development in metrics. Our goal is to keep the home economics teacher equipped to be the greatest service to the students in preparing them for today and tomorrow. 
Eugene M. Schanbacher

Industry and Technology

Murray State University

Murray, Kentucky 42071

\title{
INTRODUCTION
}

To reflect some of my experiences in teaching metrics, I think it may be helpful to indicate some circumstantial factors to better understand why I teach what I teach. Therefore, I should like to present for your consideration the following subtopics, which will also set a course for this discussion.

\author{
Industrial Arts \\ Philosophical Foundaticns for Teaching Metrics \\ Content and Concepts in a Basic Course or Unit \\ Implementation Activities of the Classroom \\ Some observations
}

In the course of this presentation, I shall refer to industrial arts at the elementary and secondary levels as well as the university level. When reference is made to metrics, I mean SI metrics. My major objective today is to present several ideas for teaching metrics in Industrial Arts and other subjects which reflect unlimited possibilities for instruction.

\section{INDUSTRIAL ARTS}

Since I am representing the curricular area of Industrial Arts, perhaps one of the first things I should do for those of you not in this field is define that field of study in order that we may develop a general understanding and a base upon which we may relate and focus our metric attention.

Industrial Arts is generally considered to be a study of the tools, equipment, materials, processes, problems, and occupational and technical information of industry for purposes of general education. It has inherent value for both boys and girls from kindergarten to grade twelve and beyond. It is not thought to be "specialized vocational" education; however, it can and does serve as pre-vocational education for many students. It can serve as a function of exploration of the individual as well as the practical world about him, development, and career guidance for virtually all students regardless of their ultimate vocation.

Industrial Arts includes some of the traditional subjects--drafting, metals, graphic arts, wood, electricity, crafts, plastics, and so on--as well as more contemporary innovations involving cluster type activity such as World of Manufacturing, World of Construction, Study of Industry, Experimentation and Research, and many others. We all live, inescapably, in an industrial society.

\section{PHILOSOPHICAL FOUNDATIONS FOR TEACHING HETRICS}

There are several premises upon which my metric instruction is based. They are not necessarily the ultimate; but they serve as a guide for me, and perhaps some of you may profit from them.

1. Development of metric concepts rather than conversion concept. Certainly there is an occasional need to know how to convert, particularly for those of us who have learned the customary system and who relate to it with our tendencies. For the major emphasis, we should focus our attention on instruction of the proverbial "think metric" and gain basic skill therein.

2. Metric education should be taught in a manner as simple and uncluttered as possible and in those areas in which there is the greatest need and practical application. Herein lies not only a great opportunity for industrial arts, but a rather monumental responsibility. The industrial arts laboratory is a place where young people can learn to measure and visibly see their results along with direct correlations to practical applications and needs. It is one of the really natural and meaningful avenues for teaching metric. 
3. Metric is a system of measurement which should generally permeate all application facets of our educational activities. Metrics is not a mathematics subject. Calculation is the same whether the item be oranges, dollàrs, feet, or meters. It is not a social science or a natural science or even an industrial arts subject, as such. But it does have implications for these and nearly all of the other subjects and activities of the educational community. Therefore, metrics should be implemented where feasible--be it in education or in other sectors.

4. One of the best ways to learn metric is to use metric. The more a persons uses metric, the more that person will gain skill and confidence in its use. With these attributes, understanding will follow.

5. Metric education should be implemented as rapidly as feasible lest we continue to handicap our consumer and our industrial society. Of particu?ar concern are our present young workers, our preservice people, and those youngsters who are just now learning measurement. It is these youngsters who can benefit over the longest period of time. And incidentally, this last group may have to learn and then unlearn a greater part of a somewhat outmoded measurement system if implementation is delayed.

Too long we have debated the metric issues in the past. Currently, the issue is not IF or WHEN, but NOW! and HOW?

Certainly, there are other guides which have merit and can be added to this list. I do not profess to have them all.

\section{CONTENT AND CONCEPTS IN A BASIC COURSE OR UNIT}

At this point, I should like to digress to discuss some of the conditions in which I operate so that you may understand the nature of our students, and the needs we are attempting to serve. In the past year at Murray State University, we have offered a three-semester hour workshop for teachers. They represented elementary through post-secondary levels: social science, mathematics, physics, home economics, business, vocational-industrial subjects, industrial arts, and others. We offered a three-semester hour course primarily for undergraduates but open to graduates. Those students represented industrial arts, home economics, journalism, mining, maintenance, chemical technology, and other industrial workers. In addition, we have held some institutes off campus along with other parallel functions.

I know of no single best structure of a metrics course or unit other than that of following a guide to serve individual needs. Here are some of the various areas or units which I teach at the University level, not necessarily in sequential order.

Status of conversion. Students should develop a positive attitude about metrication. They should know where the United States presently stands in the world relative to metrication and be aware of the ill results of a delayed, uncoordinated conversion effort. They should be aware of the fact that industry is going metric, now, ar an increasing rate and that they should keep informed of the progress in legislation, policies, and guides as reflectミd by various states, organizations, manufacturing companies, and the marketplace. Those students who have particular interests in a given field can profit from becoming informed of the conversion status, standards developed, and so on, of those fields.

When we think of the United States converting to metric, we frequently get our concept out of perspective by considering that we are changing from 100 percent customary to 100 percent metric. This is not the case. The United States is now metric, perhaps 20 to 40 percent, and has been metric for years in many fields--photographic equipment, pharmacy, medical, time, electrical, spark plugs, etc. Furthermore we probably never will be 100 percent metric--we will probably not change all the mile sections in Oklahoma, or the feet measure of property deeds in Kentucky. There are numerous other measurements to which we have grown accustomed and will no doubt hold over to the next civilization. After an eight or ten year conversion program, we will then be perhaps 90 to 95 percent converted. So when we think about this task, we should keep in mind the amount of conversion to take place within the eight to ten year period. Would you estimate 50 percent? 60 percent? 65 percent? As such, this task is not so great. 
Metric principles. This is the core content of the course. This includes:
1) base ten with decimal mechanics
2) prefixes and their values
3) base unit
4) supplemental and derived units
5) symbols
6) advantages of the metric system

I will hasten to point out that I attempt to keep this area as simple and basic as possible. The system can become very complex and the typical student need not get that involved. Let me illustrate. Major emphasis in my classes is placed on the units with which students have general need, namely, length (including area and volume), 1iquid capacity, mass, and possibly temperature. It has been estimated that 75 percent of the world's measurements is confined to these first three units. When dealing with prefixes, little time is spent on the use of those other than milli, kilo, and possibly micro. One exception may be the centimeter (centi) since it is a handy unit of metric length. When dealing with the advantages of the system, the coherence and simplicity is stressed, such as, one unit times one unit equals one other unit ( $1 \mathrm{~m} \times 1 \mathrm{~m}-1 \mathrm{~m}^{2}$ ). Perhaps these items will suffice to give you an idea of coverage of metric principles.

Brief history of customary and metric systems. Many times history has a way of turning some people "on" and others "off." Therefore, the nature and degree of teaching this aspect must be tempered to the needs of the group being taught. Although the historical aspect is not the primary content, it does have potential to promote interest, provide humor, develop affirmative attitude, and relate to scientific principles or the lack thereof.

Pactices for written form of metrics. When learning the metric system, emphasis should be placed on the proper form of expression, particularly the written form. While there are instances in which an improper usage may cause no significant difficulty, there are other instances in which one improper usage could result in a monumental problem. An extreme example might be the difference between "megameter" and "millimeter" caused by the capitaiization of an " $m$ " rather than the lower case form. We should do well that which we do.

Correct usage is important to most industrial arts students when learning metric, especially if those students are industrial arts teachers. This person is frequently preparing lessons, making drawings, and evaluating textbook material. One of the problems we face now and will continue to face is the proliferation of incorrect use, examples and applications of metrics.

The primary topics upon which I focus attention relative to written form are: spelling of units, symbols, and terms; (2) capitalization and punctuation; (3) numerals and decimal markers; (4) spacing for numerals, words, and symbols; (5) singular and plural forms; (6) preferred multiples; (7) specifications and their sequences; and (8) importance of correct usage.

Metric standards for various fields. Some of our standards are available, while many more are yet to be established. It is desirable for a course to reflect those standards to a degree commensurate with the needs of the students. A basic industrial arts class may adhere to common standards while a more technical class would be concerned with more detail. As an example of the latter, a metals class may require standard for threaded fasteners, gauges of wire, thickness of metal stock, and so on in considerable detail.

Practical utilization. Here, I try to involve students in the utilization of metrics as much as possible and in a manner of practical, everyday life and occupational activity.

\section{IMPLEMENTATION ACTIVITIES OF THE CLASSROOM}

Frame of reference. My students are encouraged to develop a practical and personal frame of reference for common units. These references serve a better purpose if they are personal, that is to mean, that the learners feel that they are individually theirs. And it only follows that they serve a better purpose if they are as practical as possible. 
As an example, let us take temperature. All students would probably learn for their frame of reference the boiling point, freezing point, normal body temperature, room comfort, a hot day, a cold day, and a few others. Each student can add to his list the temperatures which relate to his interest or field, for example:

Fisherman--water temperature for good'fishing or spawning of different species of fish. Metallurgist--melting point of selected metals or temperature for quenching a given tool. Chef--cooking and baking temperatures of various dishes.

As an example of linear measurements, here is my frame of reference.

$\begin{array}{cl}1 & \mathrm{~mm} \\ 10 & \mathrm{~mm} \\ 100 & \mathrm{~mm} \\ 150 & \mathrm{~mm} \\ 300 & \mathrm{~mm} \\ 0.5 & \mathrm{~m} \\ 1 & \mathrm{~m} \\ 1 & \mathrm{~km}\end{array}$

\author{
thickness of a dime \\ width of smallest fingernail \\ width of hand \\ hand to tip of thumb \\ wrist to elbow \\ bottom of foot to knee joint \\ right shoulder to base of left thumb \\ home to parking lot
}

Persons can arrive at their own individual references. Reference measurements of the anatomy are good because they are usually with a person when he needs to refer to them. However, it should be kept in mind that for growing youngsters, they may need to be reminded that references will have to be adjusted as their anatomy changes.

Other references for the typical student may include such items as the following:

The mass of common items around the office, shop, home, or marketplace.

Usual speeds of automobiles.

Quantities and sizes of items with which they frequently come in contact.

I recommend that a frame of reference for a given unit have some diversity and not be packed at one or two points, unless of course those are the most practical ones. These references should be consistent and serve as a guide or an approximation. If more accuráte measurement is needed, a device should be utilized.

Technique of Estimation. In order for a person to think in metric terms, he should not only have some understanding of the system but have some degree of competency in its use and develop some confidence therein. To accomplish this task, I frequently have activities which require students to overtly make estimations, particularly in the early sessions of the class. The primary purpose of this activity is not to make good estimators, although that is not necessarily all bad. It is recognized that some people cannot estimate well even in customary units, but with only a small amount of practice, they can gain some skill. With success comes confidence, a positive attitude, and other desirable attributes. This technique of estimation interfaces very well with the frame of reference which has been established. Examples of estimation activities are: linear dimensions of wood; thickness of metal; length and diameter of wire and rod; mass of bolts, books, area of paper; capacity of containers; and nearly any common object available.

Utilization of metric measurement. Industrial Arts, being somewhat unique with the tools, equipment, and materials found in its laboratories, is a natural for learning and utilizing metric measurements such as:

Layout size of lumber with a meter stick

Drawing a detail to a metric scale

Set up a saw to cut $25 \mathrm{~mm}$ width

Tapping an M6 metric thread

Milling $8.75 \mathrm{~mm}$ cut and checking with micrometer

Layout printing on metric-sized paper and envelope

Combining quantities of material

Researching products of metric nature

The possibilities for teaching metric in this atmosphere is virtually unlimited. I encourage students in my classes to take every opportunity to utilize metric, and I encourage 
prospective industrial arts teachers to design metric projects and other activities for use in teaching elementary and secondary students.

Here on transparencies are samples of some of the instructional items designed in or for my metric classes.

Metric scales for drafting

Metal turning dimensioned for metric micrometer use

Drawing of metric design

Chart for metric welding rod

Sheetmetal scoop with metric sizes and area

Kilometer map of the Murray area

$100 \mathrm{~mm}$ cube of $1 \mathrm{~kg}$ mass

Scrapbook of articles about conversion and standards

SOME OBSERVATIONS

For the majority of younger students, I have generally "oversold" the metric system, possibly because most of them had no "customary" hangup.

No matter what amount of evidence you produce in an adult class, you will probably have at least one "doubting Thomas" who feels the metric system will never get off the ground.

Young students have a tendency to pick up metric measurement very quickly. 
A BASIS FOR SUCCESSFUL TEACHING OF

VOCATIONAL METRIC EDUCATION

Richard A. Dieffenderfer

The Center for Vocational Education

The Ohio State University

Columbus, Ohio 43210

\section{Introduction}

In presenting what might be described as a basis for successful teaching of vocational metric education, there is a need to establish a perspective of the problems that are different from teaching metrics in other elementary and secondary classes. In setting this perspective as an objective of this paper:

1. The scope of vocational education training in the United States will be described;

2. Teaching success based on performance of job related skills will be discussed;

3. The considerations involved in determining vocational metric content will be presented;

4. A series of factors affecting the demand for vocational metric education will be reviewed; and,

5. Suggested activities for stimulating vocational metric education will be proposed.

Within the limitation of reasonable time and length this presentation will attempt to set some realistic expectations and goals for implementing SI metric training content in vocational education programs. Due to the complexity of the broad field of vocational education, this presentation will attempt to describe metric education problems and concerns that occupational training programs have in common.

\section{The Field of Vocational Education}

Publicly sponsored vocational education programs in the United States provide services to some 12,000,000 students in secondary, post-secondary, and adult level training programs. In support of this effort there are involved approximately 245,000 professional personnel responsible for the teaching, administration, coordination, and development of vocational education programs in the States. The focus of this occupational related training covers over 200 different vocational education instructional programs divided among seven vocational program service areas. These broad program areas include:

1. Agricultural related occupations;

2. Distributive occupations;

3. Health occupations;

4. Consumer and home economics related occupations;

5. Business and office occupations;

6. Technical education; and,

7. Trades and industry occupations.

At the secondary level these programs emphasize training for entry level employment. In the post-secondary and adult level programs emphasis is placed on training for upgrading 
of worker skills, advanced technical training, and some entry level training.

The total scope of all occupational training going on in the country is greatly increased when we take into consideration other training efforts involving:

I. Military related occupational training;

2. Private trade schools and technical institutes;

3. Federal, state, and local government training efforts for --

a. Upgrading agency personnel;

b. Training and information programs involving the public; and, rehabilitation and training programs in special schools.

4. Correspondence courses in technical areas;

5. Community volunteer service agencies; and,

6. Apprenticeship training programs.

By their nature, vocational education programs present a situation in which the manipulative skill training and related trade knowledge required to perform occupational related tasks on the job form the basis for program training objectives that are:

1. Easily identifiable in setting the direction of the course for the instructor; and,

2. Present learning goals that are recognized and understood by the students.

\section{Judging Success of Vocational Metric Education Efforts}

The success of a vocational education program is based on its ability to meet training program objectives in helping the student to:

1. Develop the appropriate level of manipulative skills required;

2. Learn trade related information and knowledge; and,

3. Acquire good work habits and develop personal relations with other workers on the job.

The major concerns for metric education in vocational education programs focus on:

1. Acquiring SI metric measurement skills needed to perform occupational related tasks; and,

2. Developing a knowledge of SI metric needed to "think metric" and make judgments, estimates, and comparisons of measurement values in work related problems.

Successful teaching of SI metric content in vocational education programs is to be judged on how well the training program has prepared the students to succeed on the job.

The suggestions and techniques described in other conference papers for teaching SI metric measurement skills to secondary school and adult learners are highly appropriate to students in vocational education programs. A point to be emphasized in vocational education is the need for the teaching of SI metrics through a series of practical application exercises. 
Successful teaching will also require the application of a certain amount of common sense to avoid making the learning of SI metrics more difficult than it needs to be for both the teachers and students. To avoid such pitfalls emphasis should be placed on:

1. Activities teaching accurate usage of SI metric terminology, prefixes, and symbols in applied measurement;

2. Adoption of a "think metric" strategy featuring SI metrics as the primary,reference point for estimating and computing measurement values;

3. Avoid misplaced precision in equating or converting values between the U.S. customary and SI metric systems; and,

4. Avoid the unnecessary learning of the terms and symbols for all metric system prefixes and place values.

The measure of success for the field of vocational education in the United States metrication effort will depend on the ability of vocational educators to:

1. Develop and utilize appropriate SI metric curriculum and instructional materials;

2. Prepare teachers through inservice and preservice programs to teach SI metric related training content; and,

3. Develop and organize SI metric education training programs to meet the needs of students, workers, trainees, and consumers.

\section{Factors Affecting Metric Education Implementation}

The basic problem of vocational education teachers and curriculum developers is more one of determining what SI metric content to teach, rather than what is the best way to teach SI metrics. This series of concerns focuses on:

1. Identifying the appropriate SI metric content for each occupational training area;

2. Determining the emphasis to be given to SI metrics in each training program at this point in time;

3. Analyzing what changes will actually take place in the teaching content of an occupational area regarding --

a. Measurement related content changes,

b. Changes in trade related product and engineering standards used, and

c. Revision of trade related practices and work procedures.

4. Defining the timing of metric implementation scheduled for each occupational field and related areas;

5. Maintaining the pace of training to mateh the metric implementation needs of industry; and,

6. Determining to what extent vocational metric education efforts can lead the metrication efforts in each occupational area.

\section{Impact on Vocational Education}

It should be recognized that the impact of metrication on business and industry will 
not be the same across all occupations. This is also true for vocational education instructional programs in which students will be required to be familiar with only selected aspects of the SF metric system, and develop measurement skills appropriate to the occupation for which they are being trained. It may be necessary for vocational education teachers and curriculum developers to maintain a perspective of general occupational needs in order to accurately assess the impact of metrication on the content of their teaching area. To illustrate this point it is important to remember that:

1. The range of semi-skilled to technical occupations represented in the variety of vocational education programs means that there will also be great variance in the impact of metrication on specific vocational education subject areas;

2. The impact of metrication on a specific occupational training program will depend on how much of the present trade content is considered measurement sensitive;

3. The impact of metrication on a speciflc occupational training program will depend on how much of the SI metric content is considered new occupational trade content;

4. The impact of metrication on a specific occupational training program will depend on how much of the content related to industry product and engineering standards, and trade practice is subject to change;

5. The impact of metrication on a specific occupational training program will depend on the time frame or schedule established to guide the metric transition in that industry;

6. The impact of metrication on a specific occupational training program will depend on the extent to which adopted metric standards practice is considered to be a "hard" or "soft" metric conversion; and,

7. The availability of SI metric sized and designed materials and equipment based on accepted SI metric standards and changes in industrial practice may be a problem in implementing vocational metric education programs.

Determining Metric Technical Content

Vocational educators are well aware of the importance of using the real world of business and industry as the reference point for determining curriculum content and establishing training program requirements. This same concern holds true in the development of vocational metric education programs. The analysis of metrication efforts in business and industry will provide the vocational teacher and curriculum developer with specific content suggestions based on a:

1. Determination of the impact of metrication on each occupational area;

2. Establishment of a time frame within which metrication plans will be implemented;

3. Definition and development of occupational related SI metric product and engineering standards, and changes in trade practice;

4. Identification of occupational areas requiring SI metric instruction;

5. Development of the specifications for SI metric instructional materials required; and, 
6. Implementation of SI metric education efforts in appropriate amounts to various levels of business and industry personnel.

Vocationa1 Teacher Metric Orientation

The success of vocational metric education efforts will be keyed to vocational teachers who are well versed in SI metrics and current industry metric developments. Much to their credit, there are individual teachers who have developed this technical competence on their own. Many teachers are also participating in the ever increasing number of preservice courses and inservice workshops that are available to them.

The participation of teachers in these experiences will provide them with an:

1. Orientation to what the process of metrication will really involve;

2. Understanding of the basic SI metric system and its use;

3. Awareness of SI metric as it will affect them as consumers; and,

4. Perspective of current metrication efforts in industry.

These types of metrication efforts have made a great contribution in stimulating teacher interest in SI metrics. But, due to the slow progress being made in the United States metrication effort, there is not sufficient information to prepare the vocational education teacher to take the next step and develop fully occupational related metric content needed for their students. There are at this time only limited guideposts available to help vocational education teachers implement a series of specific SI metric content changes in their training programs.

\section{National Metrication Program}

Granted the problems of wrestling with the unknowns concerning metrication in the United States are not just unique to vocational education teachers. We share the frustration of waiting for the establishment of a commitment to metrication in this country through federal legislation.

The present state of limbo that metrication is in places severe constraints on the teaching of SI metrics and specific trade related metric content. In this confusion, vocational educators who must draw their teaching content from trade practice are waiting for more progress to be made in business and industry sectors. Business and industry appear to be holding up their metric decisions waiting for a formal national commitment to metrication. The Congress is waiting for something also, but no one is really sure what that is.

With the passage of federal metric legislation a defined schedule and pace for metrication can be implemented. When it is established where and when we are going in metrication activities, thé specific business and industry related trade practice decisions will be made. This information will form the basis for defining vocational education SI metric teaching content.

At the present time there are three options open concerning the establishment of a national policy on metrication, these include:

1. Passage of metric legislation which provides planning, coordination, and a fixed period of time for the transition to SI metrics;

2. Passage of metric legislation which provides planning, coordination, but no fixed time period in which to complete the metric transition; and,

3. No metric legislation approved and metrication efforts continue in an unstructured manner over an indefinite time span. 
The technology assessment project, NSF/RANN Metric Conversion Study, being completed at the University of Minnesota will present a comprehensive analysis of the problems and conditions evident in these three options. The problems related to the timing of the metric transition will vary for vocational educators according to the pace of industrial metrication. The establishment of a national schedule will set the time span in which preservice and inservice teacher training is to take place, appropriate instructional materials developed, and initial vocational metric education programs taught.

In attempting to establish the need for vocational metric education programs, design programs, train teachers, and develop instructional materials there are important advantages to having detailed metrication plans covering specific time periods. The absence of structured metric planning for government, and business and industrial metrication efforts places the vocational teacher and curriculum developer at a disadvantage in designing and implementing metric education programs.

\section{Getting Started in Metric Activities}

Experiences with the current metrication effort in the United States can be summarized in terms of some of the primary concerns of vocational education teachers and curriculum developers. General recommendations indicate the need for vocational educators to:

1. Develop a working knowledge of the SI metric system;

2. Adopt accepted math/science education techniques for teaching measurement related content;

3. Determine the appropriate technical levels and amount of metric related instruction required in their teaching area;

4. Analyze the actual industrial SI metric content that is relevant to their vocational program objectives;

5. Update vocational program teaching content based on adopted metric product and engineering standards, and revised industry trade practice; and,

6. Determine the pace of industrial metric implementation programs and the timing required to provide vocational metric education programs to meet the needs of students and industry.

There are some procedures that would be helpful to vocational education teachers in meeting their metrication objectives. Some of these suggested activities include:

1. Establishment of a metric practice advisory committee for their vocational program. In this effort charge existing program committees with this responsibility, or create special groups to study what needs to be done;

2. Identification of industry and trade association, and metric information publications that will give teachers an accurate picture of current metric developments related to their trade area;

3. Determination of industrial metric information which is the adopted practice of individual local companies and that which is considered general metric practice for the industry;

4. Creation of criteria to guide the selection of commercial instructional materials, or the development of teacher design or metric teaching aids and applied measurement activities; and,

5. Preparation of questions on annual follow-up surveys of vocational program graduates to determine the extent to which they are 
currently involved in using SI metrics on the job.

Development of quality metric education programs will provide a substantial challenge for vocational educators over the coming years. As in industry, the metric transition will also provide an opportunity to examine other practices in the field that should be revised in order to improve the efficiency and quality of the training programs. Such improvements might involve instructor training practices, upgrading course technical content, updating job training requirements, student placement and follow-up procedures, and the skill training activities provided to students. To insure the continued success of vocational program graduates on the job, vocational educators will need to meet their obligation to provide appropriate levels of metric education now, and also prepare to develop complete metrication programs as they are required by job demands. 


\author{
Albert B. Chalupsky \\ American Institutes for Research \\ P.O. Box 1113 \\ Palo Alto, California 94302
}

As you well know, the United States is last in the line of major nations converting to the modernized metric system--SI. While this is a source of concern to many, and rightfully so, there is at least one advantage to being at the tail end of a queue. We can, if we are wise, profit greatly from the experiences of other countries, particularly those that have begun the process of metrication during recent years. It was with this rationale uppermost that the Metric Studies Center was established at the American Institutes for Research in Palo Alto, California. For the past several years, we have maintained extensive communication regarding metric conversion with a variety of sources in England, Australia, New Zealand, South Africa, and Canada--all of which are now heavily committed to going metric.

Our work has been aided greatly by the National Institute of Education which has sponsored two A.I.R. studies concerned with capitalizing on the metric education experiences of other countries. The first study consisted of a general review and analysis of metric conversion in education in the five countries mentioned previously. It involved an intensive literature search and a survey of some seventy overseas organizations concerned with metric conversion in general or with metric education specifically. The second study focused on the inservice teacher training experiences in England and Australia and their implications for educators in the United States. The primary sources of information for this study were interviews with representatives of teachers' centers and other educational agencies in England and with cognizant staff of selected State Departments of Education in Australia.

My remarks today are based largely on the results of these two projects. 1 In keeping with the purpose of this conference and the limited time available, I would 11ke to focus on the experiences of English and Australian educators that are especially relevant to classroom teachers in this country, in their efforts both to cope with metrication themselves and to introduce SI into their teaching activities.

First, a brief note on the background of metric education in Britain and Australia. In Britain, the decision to convert to the metric system was announced in 1965; however, it was not until 1969 that a Metrication Board was established. A general overall target date of 1975 was set for becoming substantially a metric country--a goal now officially recognized as unattainable. No firm schedule was set by the Board for educational conversion, however. Rather, schools were merely exhorted to keep fully informed of developments throughout the country and to keep pace with or exceed the industrial conversion schedules. It appears that both the teachers and the educational system in England have kept well ahead of the general metric progress of the country.

Australia made its decision to convert in 1970 and in that same year its metric conversion board began operation. In general, the schedule called for the years $1973-1975$ as the time of major implementation, with a target of 70 percent completion by 1976 . In education it was planned that the curricula in primary schools should become fully metric early in 1973 and that a start in metric conversion should be made in secondary schools as soon as possible, with the aim that secondary schools be solely metric by the start of the 1974 school year. At the post-secondary level, the schedules were not so optimistic, particularly in the technical areas. Nevertheless, it was assumed that the institutions beyond the secondary level would be primarily metric by 1976. It appears that the Australian metric conversion program in general, and education in particular, has been on schedule or perhaps slightly ahead of schedule. The smoothness of the metric conversion program in

${ }^{1}$ For a complete discussion of the findings from both projects, see Chalupsky, A.B., Crawford, J.J., \& Carr, E.M. Going Metric: An Analysis of Experiences in Five Nations and Their Implications for U.S. Educational Planning. Palo Alto, Calif.: American Institutes for Research, 1974; and Chalupsky, A.B., Crawford, J.J., Carr, E.M., \& McDonne1, P. Metric Inservice Teacher Training: Learning from the English and Australian Experience. Palo Alto, Calif.: American Institutes for Research, 1975. 
Australia is due in no small part to the lessons they have learned from closely observing the British metrication experiences and taking steps to avoid repeating some of the mistakes the British have done.

The highlights of our overseas experience which I would like to share with you today can be grouped into six major areas:

(1) Overcoming resistance to change.

(2) Importance of parent and community involvement.

(3) Emphasis on effective communication.

(4) General teaching strategies.

(5) Problems to avoid.

(6) New challenges for teachers.

Overcoming Resistance to Change

Many teachers, particularly the older, more experienced ones, will have unnecessary fears and doubts about learning SI and will require reassurance and support. If not dealt with promptly, these fears can seriously reduce the effectiveness of teacher training. A necessary component of staff training must be an initial awareness unit outlining the need for going metric; identifying the major effects on the country in general and on teachers in particular; discussing each source of anxiety and how to cope with it; and above all, demonstrating the basic simplicity of direct measurement in the metric system.

Importance of Parent and Community Involvement

The need for metric awareness and the understanding of why the U.S. is going metric extends far beyond the teaching profession. Community awareness, and parental awareness in particular, will have a major impact on school operations. Because schools will without doubt be in the vanguard of the metrication movement, teachers can expect occasional backlash reactions from parents. Early public awareness campaigns will be helpful. Nevertheléss, teachers can expect more frequent parent conferences. School district will need to prepare parents and demonstrate the ease and benefits of SI. As in the early days of modern math, many parents will be frustrated if they are unable to help their children with class assignments. On the other hand, students themselves present potentially effective agents for educating parents in the metric system. Australia made an obvious attempt to enlist school children in the campaign to educate parents. Educators may well need to develop a combination of approaches to assist in parent education.

One example of an ongoing metric program with special attention to community awareness is "Project Metric" of the Wayne-Westland (Michigan) School District. Under the direction of a community involvement agent, meetings and workshops have been held with local clubs, organizations, and church groups. Businesses, stores, and banks are being encouraged to participate by arranging metric exhibits, displaying posters provided by the project, and distributing metric handouts. Culminating the first year's activities was a "Metric Week" at a major shopping center consisting of exhibits, contests, bake-off, and even a metric fashion show. "Metric Weeks," by the way, have occurred in several areas of the U.S. and we will no doubt see more of them in the months to come. They are an intriguing vehicle for gaining community awareness and for strengthening the linkage between education and business in the conversion process.

\section{Emphasis on Effective Communication}

As our metrication program moves along, teachers will need to be kept informed of news at the Federal, state, and local levels. Lack of information can be very disruptive to teachers, expecially in the early stages when the rumors thrive. Judging from overseas experience in metric education, as well as experiences gained in similar situations in the U.S., it will be a mistake to assume that the metric memoranda and other publications distributed to state departments of education, school districts, or even to individual schools, will automatically and expeditiously be delivered to the teachers most concerned. Some method of communicating directly with teachers on a regular basis merits early consideration. 
One way to communicate to teachers as well as to parents is by a periodic newsletter. Such a vehicle can serve both to inform and to educate at relatively little cost. Attractive newsletters are an important part of the Wayne-Westland project I mentioned previously, as well as the metric projects being conducted by the school district in Winston-Salem, North Carolina and in Bismarck, North Dakota. Based on our own experience, it is clear that

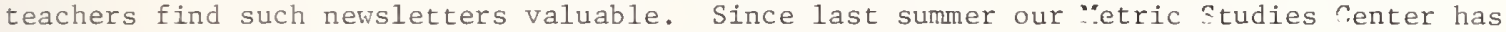
been publishing a bimonthly metric newsletter for educators, the Metri-Gram. The enthusiastic reception on tie part of teachers and administrators is an obvious expression of this need to be kept informed.

Another area which could easily be overlooked in metric education is the need for wide dissemination = $\bar{i}$ effectiv trafning prog-ams and materials. The Euli benefits of expensive developmental efforts can be frustrated by false economy in the dissemination area. All teachers concerned need to be provided ample copies of appropriate metric materials for their own education as well as for use in the classrooil. In order to io this, however, we will need to conduct adequate evaluations of programs and materials. I will mention more about evaluation later.

\section{General Teaching Strategies}

At the risk of overlapping some of the previous speakers, I would like to touch briefly on three general strategies which merit consideration for teacher training: short activity sessions, teacher development of metric materials, and teacher training using student exercises.

Short Activity Sessions. Strong support was voiced by our overseas interviewees for scheduling a series of relatively brief training sessions wilich would allow teachers to practice their newly acquired metric skills, trying them out with students, and then returning for additional training. Follow-up sessions should emphasize evaluation, discussion, and refinement of techniques. Of particular importance is active learning encompassing direct estimates of the length, mass, volume, etc., of common objects. A good deal of practice should be provided for making these estimates and then checking them by actual measurement in order for the teacher to gradually "think metric." Teachers should be encouraged to measure themselves, their rooms, and familiar objects. Small-group discussions of problems will be much more effective than large-group lectures.

Teacher Development of Metric Materials. One of the problems confronted by overseas educators which is also occurring in this country is the early flood of metric materials including many items of poor quality from the standpoint of technical accuracy, construction, or learning effectiveness. Unfortunately, technical assistance in identifying high quality materials may not be readily available to all teachers in the early stages of metrication.

Overseas training programs have taken advantage of this problem and have stressed teacher development of materials as an important training strategy. During the course of inservice training, the learning of SI can be deeply ingrained by designing and constructing simple teaching aids to SI specifications, with considerable savings in expenditures for truly relevant, instructionally useful materials. The same strategy can be used, of course, in teaching children to think metric and the results of these efforts can then be taken home to help the parents learn SI. We have included several examples of construction plans for metric materials in the report on metric inservice teacher training which we recently published.

Teacher Training Using Student Exercises. The construction of metric materials isn't the only exercise that can be of use to both teacher and student education. Since teachers often teach the way they themselves are taught, there is a widespread feeling that teachers, especially those at the primary level, should gain experience with metric units through the same learning activities used by children.

\section{Problems to Avoid}

Conversion to SI without doubt will raise a number of problems--not unsurmountable ones, but problems nevertheless. Hopefully, by anticipating their occurrence we can take steps to eliminate them or at least minimize their adverse effects. Three general problems come to 
mind as particularly deserving of teacher attention in planning for metric education: cechnical inaccuracies, exact conversion, and unnecessary precision.

Technical Inacciracies. As mentioned previously metric instructional materials produced under pressure to meet the rapidly expanding demand are likely to contain a variety of errors. This has been the experience overseas and a similar situation is already occurring in this country. Such a statement is not intended as a wholesale condemnation of commercially developed metric materials. On the contrary, there are many examples of high quality commercial materials. What I am suggesting is for school systems and teachers to take special care in the screening of materials purchased. Ideally, large-scnle evaluations, broadly communicated to schools, could provide a useful guide to educators and a positive influence on materials production. Hopefully, school systems accross the country can work together on such an effort.

I am convinced that school districts and teachers are rea.1y for large-scale joint efforts in the evaluation area. Since last year we have been making available to schools in the area surrounding our Palo Alto facility a collection of metric instructional materials, supplied through the courtesy of a number of producers. In return we ask teachers to apply our preliminary evaluation forms in assessing the materials. We are using the results of these appraisals as a basis for improving our evaluation procedures. In addition, they will serve as a reservoir of information on the strengths and weaknesses of various metric aids. We have also been in touch with a sizeable number of teachers across the country who have indicated their interest in working together to share their experiences in using metric instructional materials as well as in collaborating on other communication efforts.

The proneness for error in metric materials should be a signal for teachers tlemselves to take special precautions in their own teaching and materials development. No matter how expert we may feel in the metric system, most of us as yet have not fully internalized si. We have yet to develop the degree of "Ieel" that we have gained for customary units after living with them all these years. Educators would be well advised to keep handy an authoritative metric practice guide such as the U.S. Department of Commerce publication NBS 330 .

Exact Conversion. The teaching of exact conversions between customary units and SI should be minimized, or better yet, avoided altogether. Familiarity with approsimate equivalents will normally suffice, but where absolutely essential, the use of conversion tables or devices should fill most needs. Our overseas contacts repeatedly stressed that conversion exercises confuse the student, create a false complexity with respect to SI, and on the whole tend to maintain the customary system as the primary system.

Unnecessary Precision. The striving for unnecessary precision is also an error to which we can easily fall prey. How often have students been appalled by the fact that one pound equals 453.592 grams or that one mile equals 1.609 kilometers? The ability of decimals to indicate apparently greater precision simply by adding another figure is an attractive trap even for those who should know better.

\section{New Challenges for Teachers}

During the course of metric conversion in the countries studied, the teachers have been presented with the opportunity to expand their role in the community and assume greater responsibilities for adult education. Metric conversion in the U.S. will no doubt offer similar challenges. Schools will very likely be called upon to provide additional courses for adults. Here, teachers of all specialties can contribute, not just math and science experts. The talents of home economics and industrial education instructors will be of special help in community education. Teachers skilled in SI will be needed to serve as trainers and consultants, particularly for small businesses. On a more subtle level, parent-teacher association meetings and other school functions can be instrumental in setting the neighborhood tone toward SI. Even morei important but likely to be overlooked is the role that students can and will play in educating their parents. The attitudes and practices of teachers, as reflected through their students, will do much to convince parents to support or resist metric conversion. 


\section{SUCCESSFUL EXPERIENCES IN TEACHING METRIC}

\section{Red Auditorium - National Bureau of Standards May 20-21, 1975}

Tuesday, May 20, 1975

$\begin{aligned} \text { OPENING SESSION - Moderator: } & \text { Jeffrey V. Odom, Chief } \\ & \text { Metric Information Office } \\ & \text { National Bureau of Standards }\end{aligned}$

Welcoming Comments:

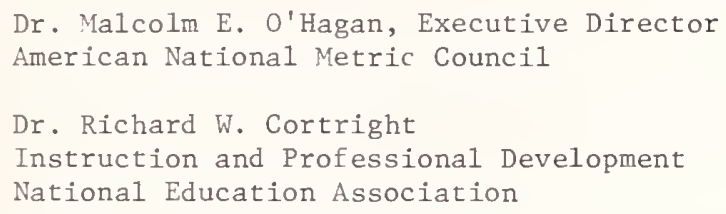

Keynote:

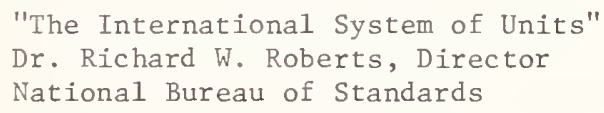


Mathematics

Dr. Stuart Choate

Open Schools

Pontiac, Michigan

Science

Ms. Barbara Logan, Field Agent

University of Delaware

Games in 'Teaching Metric

Dr. Cecil R. Trueblood

Associate Professor of Mathematics Education

Pennsylvania State University

SESSION IV - Moderator: Ms. Mary Marks, Chief

Curriculum Development Branch

Bureau of Adult, Vocational and Technical Education U.S. Office of Education

Inservice, Preservice Teacher Training

Dr. John Lindbeck, Director

Center for Metric Education and Studies

Western Michigan University

Dr. Philip Larson, Associate Professor

Natural Science Division

Western Michigan University

Teaching Metric to the Blind

Mr. Andre Nadash, M.E., Consultant

Vice President, U.S. Metric Association

Sports and Physical Education

Mr. Fred Burgee

Frederick High School, Frederick, Mary and

University Experience

Dr. John M. Flowers, Director

Project for Metric Research

University of Southern Mississippi

Wednesday, May 21, 1975

SESSION V - Moderator: Mr. Louis Sokol, President

U.S. Metric Association, Inc.

State Education Agencies

Mrs. Audrey V. Buffington

Specialist in Mathematics

Maryland State Department of Education

Local Educational Agencies

Dr. Thomas Rowan, Mathematics Supervisor

Montgomery County Public Schools, Maryland

SPECIAL PRESENTATION

Senator Claiborne Pell, Rhode Island

"Metric Conversion and the Congress" 
SESSION VI - Moderator: Mrs. Catherine Leisher, Executive Secretary

Home Economics Education Association

Home Economics

Dr. Clinita A. Ford, Director

Div. of Consumer Science and Home Economics

Florida A\&M University

Industrial Arts

Dr. Eugene M. Schanbacher, Associate Professor

Industrial Education

Murray State University

Vocationa 1

Dr. Richard A.. Dieffenderfer, Research Specialist

Center for Vocational Education

Ohio State University

SESSION VII - Moderator: Mr. Roy E. Clark

Metric Information office

National Bureau of Standards

Learning from the Experiences of Other Countries:

Canada: Mr. Jack Bell, Ministry of Education

Toronto, Canada

"What Can We Learn from the English and Australian Experience in Metric Education"

Dr. Albert B. Chalupsky, Director, Metric Studies Center

American Institutes for Research

Concurrent Activities:

I. Tour of Measurement-related Standards Laboratories

II. Workshop on Proper Metric Practice for Education:

Mr. Louis E. Barbrow

Metric Information office

National Bureau of Standards 
GEORGE W. BRIGHT is Assistant Professor in the Department of Mathematics at Emory University. He has received a B.A. and M.A. from Rice University in mathematics and a Ph.D from the University of Texas in mathematics education. Dr. Bright has authored numerous articles appearing in The Arithmetic Teacher, School Science and Mathematics, Instructor, Today's Education, and Issues in Education. He has made presentations and conducted workshops at national and regional meetings of the National Council of Teachers of Mathematics, School Science Association, and U.S. Metric Association. He is a member of the state-level Georgia Metrication Committee.

FREDERICK P. BURGEE is Physical Education Department Chairman at the Frederick High School in Frederick, Maryland. Mr. Burgee obtained his BS degree from Western Maryland College and has been affiliated with the Masters program at that college. He has pioneered in metric programs in Frederick and has presented a short course in metric measures to his physical education classes.

AUDREY V. BUFFINGTON is State Specialist in Mathematics for the Maryland State Department of Education. She has obtained her A.B. degree from Western Maryland College, her M.Ed. from Penn State University, and is enrolled in a Doctoral program at the University of Maryland. She has had fourteen years of teaching experience in the public schools in Carroll County, Maryland. She spent five years as Supervisor in Mathematics in Carroll County prior to her appointment at the state level. Mrs. Buffington is a member of several educational associations and has conducted metric workshops in 15 states. She also is the author of a six book worktext series on metric.

NILES F. (BUDDY) CALHOUN is Mathematics Coordinator for the Mississippi Authority fo Educational Television. He obtained his B.S. in Mathematics and M.Ed. in Mathematics Education from Mississippi College. Mr. Calhoun is the developer of "The Metric System" instructional television series; co-chairman of the Mississippi Committee of the FiveState Consortium for Metric Education. He has spoken on metric at many national education association meetings, including National Council of Teachers of Mathematics and the National Association of Educational Broadcasters.

DR. ALBERT B. CHALUPSKY is Director, Metric Studies Center, of the American Institutes fnr Research in Palo Alto, California. He received his B.A. from University of Minnesota, an M.S. from Purdue University, and his Ph.D. from Purdue University. Dr. Chalupsky has been director of two AIR projects funded by the National Institute of Education: "Going Metric: An Analysis of Experiences in Five Nations and Their Implications for U.S. Educational Planning" and "Metric Inservice Teacher Training: Learning from the English and Australian Experiences."

DR. STUART A. CHOATE is Project Coordinator, Field Testing for the Mathematical Problem Solving Project of the Oakland Schools in Pontiac, Michigan. He received his B.S. degree from the Eastern Michigan University, Masters degree from the University of Michigan and University of Detroit, and his Ph.D. from the University of Michigan. He is a member of the National Council of Teachers of Mathematics and serves as a NCTM National Director.

LORI S. CLEMENT is a classroom teacher at the Cresthaven School in Silver Spring, Maryland. She received her B.S. in Elementary Education from the University of Maryland. She served as project director for pilot project to teach the metric system as the primary system of measurement at her school.

DR. RICHARD A. DIEFFENDERFER is Research Specialist at the Center for Vocational Education at Ohio State University. He has written articles on metrication in vocational education and conducted research on problems in planning for metrication in vocational education. He was formerly on the staff of the U.S. Office of Education funded metric education project conducted at the Center for Vocational Education at Ohio State University. 
DR. CLINITA A. FORD is Chairman, Division of Consumer Science and Technology, at the Florida A \& M University. She received her B.S. degree in Vocational Home Economics Education from Lincoln University (Missouri), her M.S. in Foods and Nutrition from Columbia University and her Ph.D. in Nutrition and Biochemistry from Kansas State University. She is 1isted in Who's Who in American Education, Who's Who of American Women, and Outstanding Educators of America. She conducted metric workshops at Florida A \& M in 1974 and 1975.

DR. PHILLIP T. LARSEN is Chairman of Math-Science-Education for the Metric Advisory Group of the Center for Metric Education and Studies at Western Michigan University. He received his B.A. degree in Chemistry from Rutgers University, his M. Ed. in Chemistry and Physics from Penn State University, and his D.Ed. in Science Education from Penn State University. Dr. Larsen has served as Western Michigan University Metric Education Coordinator for the Michigan State Department of Education model, Project Metric, Wayne-Westland Community Schools. He is a member of the Metric Education Referent Group Michigan State Department of Education.

PURNELL W. LAWRENCE is Librarian in the Washington, D.C., public school system. She received her education from Cheyney State Teachers College, Howard University, and the University of Maryland. She was a member of the Joint Comittee of the American Association of School Librarians and National Council of Teachers of Mathematics to develop a metric bibliography for school librarians.

DR. JOHN R. LINDBECK is Director, Center for Metric Education and Studies, at the Western Michigan University. He received his B.S., M.A., and Ph. D. degrees in Industrial Education from the University of Minnesota. Dr. Lindbeck is a member of the American National Metric Council Board of Directors and also of its Metric Practice Committee. He was formerly chairman of the ANMC Coordination Committee on Education and Industrial Training. He is the author of a metric book and several articles and has been a speaker at numerous metric seminars.

BARBARA LOGAN is the Science Education Field Agent for the University of Delaware. She received her M.Ed. from the University of Maryland and is presently enrolled in a doctoral program at that school. Ms. Logan is a member of State of Delaware Metrication Board and a member of the writing team for "Introduction to Metric Measurement," a Delaware Department of Public Instruction publication.

ANDRE NADASH is a Vice President of the U.S. Metric Association and Director of its MidAtlantic region. He was educated in Europe as a Mechanical Engineer. Mr. Nadash is a member of the Measurement Technique \& Automatic Scientific Association, a subsidiary of the Hungarian Scientific Academy. He is a member of Prince George's County Public Schools Metric Task Force and is active as metric consultant and lecturer.

CLAIBORNE PELL is a U.S. Senator representing the State of Rhode Island. He received his A.B. degree from Princeton University and his A.M." degree from Columbia University. He has served in the U.S. Senate since 1960. He was a sponsor of the Miller-Pell Metric Study Act of 1968. He has sponsored metric conversion legislation in every Congress since the conclusion of the U.S. Metric Study, including S. 2483 that was passed by the U.S. Senate in 1972. He was sponsor of the metric provision in Public Law 93-380, the Education Act of 1974 .

DR. RICHARD $W$. ROBERTS became the 7 th Director of the National Bureau of Standards in February 1973. At NBS, Dr. Roberts directed one of the largest, most versatile physical science laboratories in existence. The staff totals nearly 3500, over half of whom are professional scientists. Dr. Roberts received his bachelor's degree with distinction (1956) from the University of Rochester and his doctorate in physical chemistry (1959) from Brown University. His professional career began at the NBS where he served as a National Academy of Sciences Postdoctoral Fellow (1959-1960). During his tenure at the General Electric Company's Research and Development Center in Schenectady, New York (1960-1973), Dr. Roberts moved from laboratory research to several successive management positions, culminating in his appointment in 1968 as manager of Materials Science and Engineering. 
DR. THOMAS E. ROWAN is Coordinator, Elementary Mathematics, for the Montgomery County (Maryland) schools. He received his B.S. degree from Frostburg (Maryland) State College, his M.A. and Ph.D. degrees from the University of Maryland. Dr. Rowan was a teacher of mathematics and science for seven years, served as Mathematics Supervisor, Maryland State Department of Education for eight years, and has held his present position since 1972 . He was organizer and Executive Secretary, Citizen's Advisory Committee on the Metric System, for the Montgomery County schools.

DR. EUGENE M. SCHANBACHER is Professor of Industry and Technology at Murray State University in Murray, Kentucky. He received his B.S. degree from Northwestern Oklahoma University, his M.A. from Northern Colorado University, and his Ed.D, from the University of Missouri. Dr. Schanbacher has directed metric workshops and taught metric classes at Murray State University. He has been a consultant on many metric workshops and programs and is a frequent speaker at metric conferences and civic clubs.

DR. CECIL R. TRUEBLOOB is Associate Professor of Mathematics Education at the Pennsylvania State University. He received his B.S. degree from Shippensburg (Pennsylvania) State College, his M.Ed degree in School Administration, and D.Ed. in Elementary Education from Penn State University. Dr. Trueblood has published workbooks and journal articles in the metric activity area. 


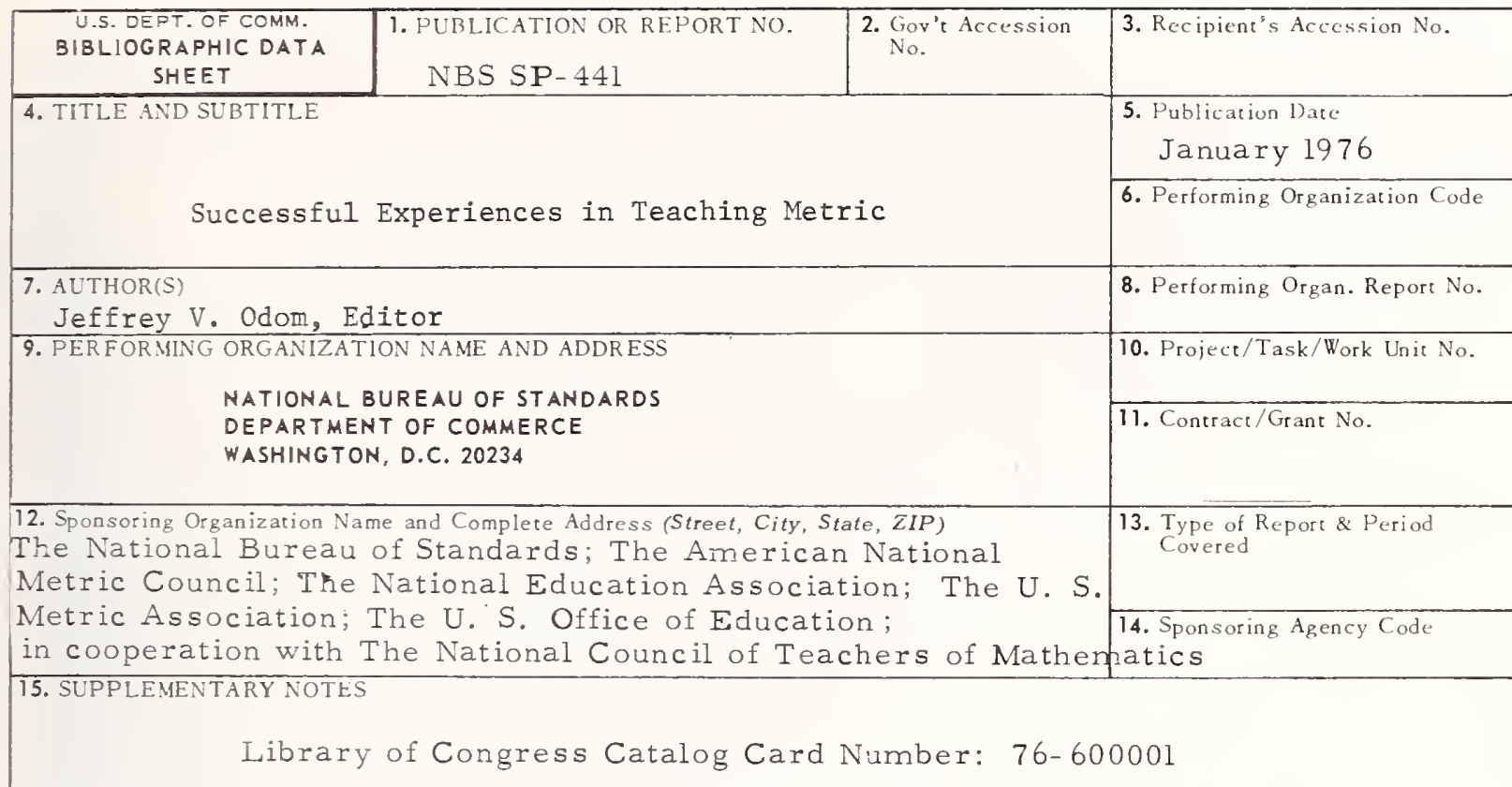

16. ABSTRACT (A 200-word or less factual summary of most significant information. If document includes a significant bibliography or literature survey, mention it here.)

These proceedings contain the texts of the presentations made at a recent conference on Successful Experiences in Teaching Metric. Specific experiences in introducing the metric system in all areas of educational interest were presented. These ideas will be especially useful to educators just beginning to prepare for their change to the metric system.

17. KEY WORDS (six to twelve entries; alphabetical order, capitalize only the first letter of the first key word unless a proper name; separated by semicolons)

Key words: Education, International System of Units, metrication, metric education, metric system, training, Treaty of the Meter

18. AVAILABILITY $\sqrt{\mathrm{x}}$ Unlimited

For Official Distribution. Do Nor Release to NTIS

X Order From Sup. of Doc., U.S. Government Printing Office Washington, D.C. 20402, SD Cat. No.C13.10:441

Order From Nacional Technical Information Service (NTIS) Springfield, Virginia 22151

\begin{tabular}{|l|c|}
\hline $\begin{array}{l}\text { 19. SECURITY CLASS } \\
\text { (THIS REPURT) } \\
\text { UNCL ASSIFIED }\end{array}$ & 115 \\
\hline $\begin{array}{l}\text { 20. SECURITY CLASS } \\
\text { (THIS PAGE) }\end{array}$ & 22. Price \\
UNCLASSIFIED & $\$ 2.30$ \\
\hline
\end{tabular}





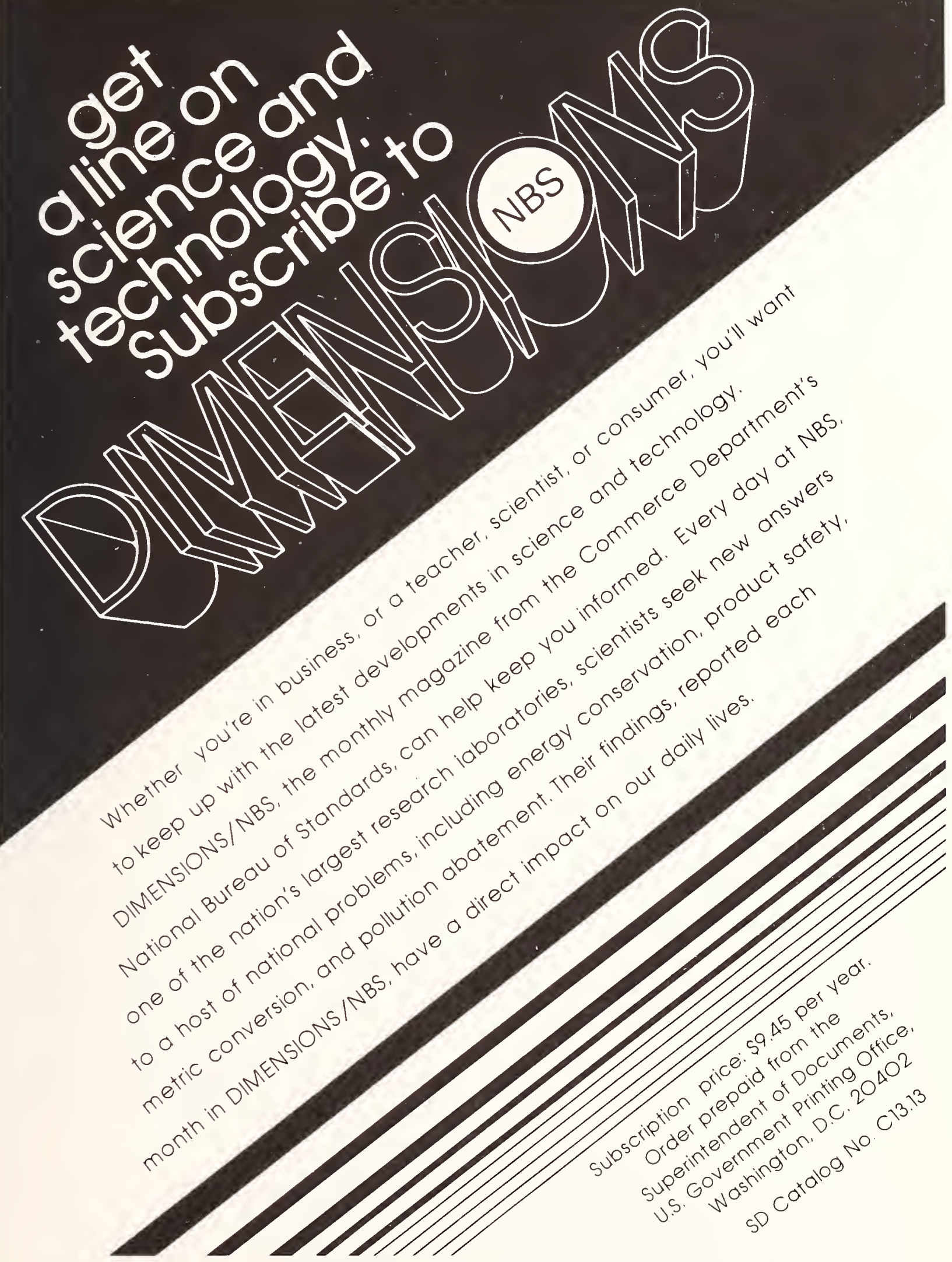





\section{PERIODICALS}

JOURNAL OF RESEARCH reports National Bureau of Standards research and development in physics, mathematics, and chemistry. It is published in two sections, available separately:

\section{- Physics and Chemistry (Section A)}

Papers of interest primarily to scientists working in these fields. This section covers a broad range of physical and chemical research, with major emphasis on standards of physical measurement, fundamental constants, and properties of matter. Issued six times a year. Annual subscription: Domestic, \$17.00; Foreign, $\$ 21.25$.

\section{- Mathematical Sciences (Section B)}

Studies and compilations designed mainly for the mathematician and theoretical physicist. Topics in mathematical statistics, theory of experiment design, numerical analysis, theoretical physics and chemistry, logical design and programming of computers and computer systems. Short numerical tables. Issued quarterly. Annual subscription: Domestic, $\$ 9.00$; Foreign, $\$ 11.25$

DIMENSIONS/NBS (formerly Technical News Bulletin)-This monthly magazine is published to inform scientists, engineers, businessmen, industry, teachers, students, and consumers of the latest advances in science and technology, with primary emphasis on the work at NBS. The magazine highlights and reviews such issues as energy research, fire protection, building tech. nology, metric conversion, pollution abatement, health and safety, and consumer product performance. In addition, it reports the results of Bureau programs in measurement standards and techniques, properties of matter and materials, engineering standards and services, instrumentation, and automatic data processing.

Annual subscription: Domestic, $\$ 9.45$; Foreign, $\$ 11.85$.

\section{NONPERIODICALS}

Monographs-Major contributions to the technical literature on various subjects related to the Bureau's scientific and technical activities.

Handbooks-Recommended codes of engineering and industrial practice (including safety codes) developed in cooperation with interested industries, professional organizations, and regulatory bodies.

Special Publications-Include proceedings of conferences sponsored by NBS, NBS annual reports, and other special publications appropriate to this grouping such as wall charts, pocket cards, and bibliographies.

Applied Mathematics Series-Mathematical tables, manuals, and studies of special interest to physicists, engineers, chemists, biologists, mathematicians, computer programmers, and others engaged in scientific and technical work.

National Standard Reference Data Series-Provides quantitative data on the physical and chemical properties of materials, compiled from the world's literature and critically evaluated. Developed under a world-wide program coordinated by NBS. Program under authority of National Staiaderd Data Act (Public Law 90-396).

NOTE: At present the principal publication outlet for these data is the Journal of Physical and Chemical Reference Data (JPCRD) published quarterly for NBS by the American Chemical Society (ACS) and the American Institute of Physics (AIP). Subscriptions, reprints, and supplements available from ACS, 1155 Sixteenth St. N. W., Wash. D. C. 20056.

Building Science Series-Disseminates technical information developed at the Bureau on building materials, components, systems, and whole structures. The series presents research results, test methods, and performance criteria related to the structural and environmental functions and the durability and safety characteristics of building elements and systems.

Technical Notes-Studies or reports which are complete in themselves but restrictive in their treatment of a subject. Analogous to monographs but not so comprehensive in scope or definitive in treatment of the subject area. Often serve as a vehicle for final reports of work performed at NBS under the sponsorship of other government agencies.

Voluntary Product Standards-Developed under procedures published by the Department of Commerce in Part 10, Title 15, of the Code of Federal Regulations. The purpose of the standards is to establish nationally recognized requirements for products, and to provide all concerned interests with a basis for common understanding of the characteristics of the products. NBS administers this program as a supplement to the activities of the private sector standardizing organizations.

Federal Information Processing Standards Publications (FIPS PUBS)-Publications in this series collectively constitute the Federal Information Processing Standards Register. Register serves as the official source of information in the Federal Government regarding standards issued by NBS pursuant to the Federal Property and Administrative Services Act of 1949 as amended, Public Law 89-306 (79 Stat. 1127), and as implemented by Executive Order 11717 (38 FR 12315, dated May 11, 1973) and Part 6 of Title 15 CFR (Code of Federal Regulations).

Consumer Information Series-Practical information, based on NBS research and experience, covering areas of interest to the consumer. Easily understandable language and illustrations provide useful background knowledge for shopping in today's technological marketplace.

NBS Interagency Reports (NBSIR)-A special series of interim or final reports on work performed by NBS for outside sponsors (both government and non-government). In general, initial distribution is handled by the sponsor; public distribution is by the National Technical Information Service (Springfield, Va. 22161) in paper copy or microfiche form.

Order NBS publications (except NBSIR's and Bibliographic Subscription Services) from: Superintendent of Documents, Government Printing Office, Washington, D.C. 20402.

\section{BIBLIOGRAPHIC SUBSCRIPTION SERVICES}

The following current-awareness and literature-survey bibliographies are issued periodically by the Bureau: Cryogenic Data Center Current Awareness Service

A literature survey issued biweekly. Annual subscription: Domestic, $\$ 20.00$; foreign, $\$ 25.00$.

Liquefied Natural Gas. A literature survey issued quarterly. Annual subscription: $\$ 20.00$. survey issued quarterly. Annual subscription: $\$ 20.00$. Send subscription orders and remittances for the preceding bibliographic services to National Bureau of Standards, Cryogenic Data Center (275.02) Boulder, Colorado 80302 .

Electromagnetic Metrology Current Awareness Service Issued monthly. Annual subscription: $\$ 24.00$. Send subscription order and remittance to Electromagnetics Division, National Bureau of Standards, Boulder, Colo. 80302 . 


